\title{
A HISTOCHEMICAL ASSESSMENT OF TEETH STAINED IN VITRO BY BLOOD: EVALUATION OF THE EFFICACY OF VARIOUS BLEACHING AGENTS.
}

PAUL D. MARIN, B.D.S., F.R.A.C.D.S.

Thesis submitted in partial fulfilment for the degree of Master of Dental Surgery in The University of Adelaide (Department of Dentistry) 


\section{CONTENTS}

DECLARATION i

DEDICATION ii

ABSTRACT iii

ACKNOWLEDGEMENTS v v

ABBREVIATIONS vi

LIST OF FIGURES vii

LIST OF TABLES $\quad$ xii

$\begin{array}{ll}1.0 \text { GENERAL INTRODUCTION } & 1\end{array}$

2.0 LITERATURE REVIEW 2

2.1 THE CAUSES OF TOOTH DISCOLORATION 2

2.1.1 Decomposition of pulp tissue 3

2.1.2 Intra-canal medicaments 4

2.1.3 Excessive haemorrhage following pulp removal 5

2.1.4 Filling materials 5

2.1.5 "Mummifying" or devitalizing agents 6

2.2 THE PULPAL REACTION IN TRAUMATIZED TEETH 7

$\begin{array}{ll}2.3 \text { HAEMATOLOGY } & 12\end{array}$

2.3.1 The function of erythrocytes 12

2.3.2 The structure of haemoglobin 12

2.3.3 Sites of erythrocyte destruction 13

2.3.4 Extravascular degradation of haemoglobin 15

2.3.5 Iron metabolism in the mononuclear phagocytic system 19

2.4 REVIEW OF AGENTS \& TECHNIQUES USED IN BLEACHING BLOOD-STAINED,ROOT-FILLED TEETH 20 
2.5 COMPLICATIONS OF BLEACHING ROOT-FILLED TEETH

4.0 MATERIALS AND METHODS

4.1 REPRODUCTION OF PULPAL HAEMORRHAGE AND TOOTH DISCOLORATION 25

4.1.1 Storage of teeth 26

4.1.2 Addition of blood products 25

4.1.3 Centrifugation 27

4.2 PREPARATION OF HISTOLOGICAL SECTIONS FOR MICROSCOPIC EXAMINATION 27

4.2.1 Fixation 28

4.2.2 Decalcification 28

4.3 SPECTROPHOTOMETRIC ANALYSIS OF THE DECALCIFYING SOLUTIONS 28

4.4 HISTOCHEMICAL TESTS 29

4.5 PREPARATION OF MACROSCOPIC SECTIONS 29

4.6 EVALUATION OF VARIOUS BLEACHING AGENTS 30

4.7 THE EXAMINATION AND TREATMENT OF A NONINFECTED, NECROTIC PULP FOLLOWING TRAUMA

$\mathbf{5 . 0}$ RESULTS 37

5.1 DETERIORATION OF HUMAN RED BLOOD CELLS 37

5.2 CAUSES OF TOOTH STAINING 37

5.3 SPECTROPHOTOMETRIC ANALYSIS OF THE DECALCIFYING SOLUTIONS $\quad 38$ 
5.4 HISTOCHEMICAL TESTS 40

5.4.1 Benzidine 40

5.4.2 Zinc leuco 41

5.4.3 Perl's 41

5.4.4 Turnbull Blue 42

5.5 MACROSCOPIC EXAMINATION OF STAINED TEETH 42

5.5.1 Benzidine 42

5.5.2 Zinc leuco 43

5.5.3 Perl's 43

5.6 EVALUATION OF VARIOUS AGENTS TO REMOVE THE STAINING PRODUCED USING PACKED RED BLOOD CELLS 44

5.7 RESULTS OF THE HISTOCHEMICAL EXAMINATION OF A NON-INFECTED, NECROTIC PULP FOLLOWING TRAUMA 46

5.8 FIGURES $\quad 47$

5.9 TABLES 94

6.0 DISCUSSION 103

6.1 DISCUSSION OF MATERIALS, METHODS AND TECHNIQUES 103

6.2 DISCUSSION OF RESULTS 109

$\begin{array}{lll}7.0 & \text { CONCLUSIONS } & 116\end{array}$

$\begin{array}{ll}\text { APPENDIX I } & 117\end{array}$

APPENDIX II 118

APPENDIX III 121

APPENDIX IV 122 
This work contains no material which has been accepted for the award of any other degree or diploma in any university or other tertiary institution and, to the best of my knowledge and belief, contains no material previously published or written by another person, except where due reference has been made in the text.

I give consent to this copy of my thesis, when deposited in the University Library, being available for loan and photocopying. 


\section{DEDICATION}

Thomasina,

Rachel, James-Paul, Thomas, Jonathan. 


\section{ABSTRACT}

There is little information in the literature regarding the causes of discoloration of traumatized teeth or the breakdown of blood products in the pulp chamber. The most commonly quoted causes of the various types of tooth discoloration are based on empirical observations made almost fifty years ago. It is generally considered that the main aetiological factor of tooth discoloration is pulpal haemorrhage following trauma or pulp extirpation.

The aims of the study were to determine which component of blood is the primary cause of discoloration in non-infected, traumatized teeth and to determine the degree of catabolism of haemoglobin in the pulp chamber.

Initially, sterile saline, platelet concentrate, whole blood and packed red blood cells were placed in the pulp chambers of each of five teeth and centrifuged twice daily for twenty-five minutes over a period of three consecutive days in order to experimentally induce staining following trauma and haemorrhage into the pulp chamber. When this confirmed that the blood pigment responsible for the staining of the teeth was found in the erythrocytes, a further group of five teeth was stained, as above, using packed red blood cells. These teeth were subjected to benzidine, zinc leuco, Perl's and Turnbull Blue histochemical tests to evaluate the degree of haemoglobin breakdown. A positive response to benzidine and zinc leuco was demonstrated whereas Perl's and Turnbull Blue gave a negative response. It was concluded that, following 
haemolysis of the red blood cells, haemoglobin was found either intact or in the form of one of the haematin molecules with no further breakdown of the haem structure and no evidence of any free ferric ions or haemosiderin.

In view of the above findings, non-traditional bleaching agents and enzymes which may be involved in the removal of blood pigments within the body were evaluated, and compared to hydrogen peroxide and sodium perborate in their efficacy in removing blood stains from teeth. Results obtained to date suggest that there may be an alternative to the traditional bleaching agents and further investigation into the use of biological enzymes to remove blood stains from traumatized teeth in vivo is required. 


\section{ACKNOWLEDGEMENTS}

I wish to express sincere appreciation to Professor Mark Bartold, The University of Queensland, for his continued guidance and supervision throughout this project.

Special thanks are due to my clinical supervisor, Dr. Geoffrey Heithersay, Senior Lecturer in Endodontics, The University of Adelaide, for his valued advice and support.

To Dr. Trevor Bridges, Senior Lecturer in Pharmacology, The University of Adelaide, I am indebted for his valued criticism and encouragement during the difficult times.

I am most grateful to Sandie Powell, Peter Dent and Judy Thompson, for their advice and instruction on histological and photographic techniques.

To Victor Marino I extend special thanks for his support and assistance particularly when using the spectrophotometer.

Special thanks to my wife and children for their understanding, encouragement and support, without which this project could not have been completed. 


\section{ABBREVIATIONS}

$\begin{array}{ll}\text { ANSI } & \text { American National Standards Institute } \\ { }^{\circ} \mathrm{C} & \text { Degree Celsius (Centigrade) } \\ -\mathrm{CH}_{3} & \text { methyl group } \\ \mathrm{C}=\mathrm{CH}_{2} & \text { vinyl group } \\ \mathrm{CH}_{3}-\mathrm{CH}_{2}-\mathrm{COOH} & \text { propionic acid } \\ \mathrm{Cm} & \text { centimetre } \\ -\mathrm{COOH} & \text { carboxyl group } \\ \mathrm{EDTA} & \text { ethylene diamine tetra-acetic acid } \\ \mathrm{Fe}++ & \text { ferrous ion } \\ \mathrm{Fe}+++ & \text { ferric ion } \\ \mathrm{g} & \text { gram } \\ \mathrm{hr} & \text { hour } \\ \mathrm{M} & \text { molar } \\ \mathrm{mg} & \text { milligram } \\ \mathrm{ml} & \text { millilitre } \\ \mathrm{mm} & \text { millimetre } \\ \mathrm{nM} & \text { nanoMolar } \\ \mathrm{nm} & \text { nanometre } \\ \mu \mathrm{m} & \text { micrometre } \\ \mu \mathrm{S} & \text { microSiemens } \\ \mathrm{PBS} & \text { phosphate buffered saline } \\ \mathrm{RCF} & \text { relative centrifugal force } \\ \mathrm{rpm} & \text { ultra-violet } \\ \mathrm{UV} & \end{array}$




\section{LIST OF FIGURES}

Figure No.

Page

1 A flow diagram representing the degradation of haemoglobin. 17

2 Structure of haematin compounds.

3 Intra-oral photograph of a discoloured, traumatized upper incisor tooth.

4 Periapical radiographs of the discoloured, traumatized tooth. 48

5 Periapical radiograph of the completed root canal therapy on the discoloured, traumatized tooth.

6 Intra-oral photograph of the traumatized tooth after bleaching.

7 Photomacrograph of teeth stained with sterile saline, platelet concentrate, whole blood and packed red blood cells.

8 Detailed photomacrograph of teeth comparing the staining ability of sterile saline and concentrated platelets.

9 Detailed photomacrograph of a tooth following the addition of platelet concentrate. 
10 Photomacrograph of sections of teeth after the addition of packed red blood cells.

11 Photomacrograph of sections of teeth after the addition of packed red blood cells and following fixation.

53

12 Detailed photomacrograph of a tooth after the addition of packed red blood cells.

54

13 Visible spectrum of acid-EDTA prior to, and after use, as a decalcifying agent for stained teeth.

55

14 UV spectrum of acid-EDTA prior to, and after use, as a decalcifying agent for stained teeth.

56

15 Visible spectrum of EDTA-cacodylate prior to, and after use, as a decalcifying agent for stained teeth.

57

16 UV spectrum of EDTA-cacodylate prior to, and after use, as a decalcifying agent for stained teeth.

58

17 Acid-EDTA with the addition of 1:10,000 volumes haemolysed packed red blood cells.

59

18 Acid-EDTA with the addition of $1: 100,000$ volumes haemolysed packed red blood cells. 
19 Photomacrograph of teeth stained with packed red blood cells and decalcified with acid-EDTA.

20-25 Photomicrographs of tooth sections stained with packed red blood cells and demonstrating a positive response to the benzidine histochemical test.

62-67

26-32 Photomicrographs of tooth sections stained with packed red blood cells and demonstrating a positive response to the zinc-leuco histochemical test.

68-74

33-36 Photomicrographs of tooth sections stained with packed red blood cells and demonstrating a positive response to the Perl's histochemical test.

37-38 Photomicrographs of tooth sections stained with packed red blood cells and demonstrating a positive response to the Turnbull Blue histochemical test.

$79-80$

39 Photomacrograph of teeth stained with sterile saline, and packed red blood cells and subjected to the benzidine histochemical test.

40 Photomacrograph of a tooth stained with packed red blood cells, decalcified with acid-EDTA and subjected to the benzidine histochemical test.

82 
41 Photomacrograph of a tooth stained with packed red blood cells and subjected to the zinc leuco histochemical test.

42 Photomacrograph of a tooth stained with packed red blood cells, sectioned just beyond the pulp chamber and subjected to the zinc leuco histochemical test.

43 Photomacrograph of a tooth after the addition of sterile saline to the pulp chamber and subjected to the zinc leuco histochemical test.

44 Photomacrograph of a tooth stained with packed red blood cells and subjected to the Perl's histochemical test.

45 Photomacrograph of a tooth after the addition of sterile saline to the pulp chamber and subjected to the Perl's histochemical test.

46 Photomicrograph of the pulp from the discoloured upper central incisor subjected to the benzidine histochemical test.

88

47 Detailed photomicrograph of the pulp from the discoloured upper central incisor subjected to the benzidine histochemical test.

48 Photomicrograph of the pulp from the discoloured upper central incisor subjected to the zinc leuco histochemical test.

90 
49 Detailed photomicrograph of the pulp from the discoloured upper central incisor subjected to the zinc leuco histochemical test.

50 Photomicrograph of the pulp from the discoloured upper central incisor subjected to the Perl's histochemical test.

51 Photomicrograph of the pulp from the discoloured upper central incisor subjected to the Turnbull Blue histochemical test. 


\section{LIST OF TABLES}

Table No.

Page

1 Groups and numbers of teeth prepared.

33

2 Teeth prepared for histological examination.

34

3 Reflectance density changes of stained teeth during bleaching with hydrogen peroxide.

94

4 Reflectance density changes of stained teeth during bleaching with sodium perborate.

5 Reflectance density changes of stained teeth during bleaching with saturated oxalic acid.

6 Reflectance density changes of stained teeth during bleaching with "Enzymatic Cleaner".

7 Reflectance density changes of stained teeth during bleaching with $10 \%$ hydrochloric acid.

96

8 Reflectance density changes of stained teeth during bleaching with $30 \%$ hydrochloric acid.

9 Reflectance density changes of stained teeth during bleaching with $40 \%$ orthophosphoric acid. 
10 Reflectance density changes of stained teeth during bleaching with "HiClean".

11 Reflectance density changes of stained teeth during bleaching with "Desferal".

12 Reflectance density changes of stained teeth during bleaching with $1 \mathrm{M}$ oxalic acid.

13 Reflectance density changes of stained teeth during bleaching with "Liquid Iron Chelator".

14 Reflectance density changes of stained teeth during "Control" immersion in DDW.

100

15 A summary comparison of the various bleaching solutions. 101

16 Maximum percentage change after one week of bleaching. 


\subsection{GENERAL INTRODUCTION}

The incidence of dental injury to permanent teeth by the age of 14 years has been reported to be $22 \%$ (Andreasen, 1981), the type of trauma varying from uncomplicated crown fractures to severe crown root fractures, luxations or avulsion. In those cases of severe trauma, not only is there loss of dental hard tissue but there is alteration of the blood flow to the tooth, which may cause tooth discoloration. Pulp death often follows such trauma due to ischaemia, and endodontic treatment becomes necessary.

There is little information in the literature regarding the causes of discoloration of traumatized teeth or the breakdown of blood products in the pulp chamber. The most commonly quoted causes of tooth discoloration are based on empirical observations made almost fifty years ago. It is generally considered that the main aetiological factors of tooth discoloration are pulpal haemorrhage following trauma or pulp extirpation, necrotic pulp tissue, or bacterial contamination of the pulp chamber. latrogenic causes of staining in internally non-vital teeth are due to failure to remove the sealers from the pulp chamber following root canal therapy or the inappropriate use of some restorative materials.

In light of advances in knowledge concerning the haemolysis of red blood cells and the breakdown of haemoglobin, the long accepted beliefs as to the causes of staining in traumatized teeth will be critically reviewed. 


\subsection{LITERATURE REVIEW}

\subsection{THE CAUSES OF TOOTH DISCOLORATION}

One of the earliest references to the causes of discoloured teeth can be found in a textbook entitled "Root Canal Therapy" by Louis Grossman (1943). In the chapter entitled "Bleaching of discoloured pulpless teeth", Grossman listed the following as the principal reasons for the discoloration of teeth.

1 Decomposition of the pulp tissue

2 Intra-canal medicaments

3 Excessive haemorrhage following pulp removal

4 Filling materials

5 Use of arsenic for devitalization

Grossman (1943) stated that, in the majority of cases, discoloration of teeth was caused by haemolysis of the red blood cells and subsequent release of haemoglobin which later combined with hydrogen sulphide, produced by bacteria, to form iron sulphide, which is black in colour, thus staining the affected tooth. It was considered that the depth of dentinal penetration determined the degree of discoloration. If only the pulp chamber was discoloured, the tooth would appear lustreless and dull grey in colour. However, if the haemoglobin had penetrated deep into the dentinal tubules, the crown would be greyish-black or greyishbrown in colour. Many years later, Grossman (1988) modified his earlier concepts and claimed that as a result of the rupture of the pulp blood vessels, "haemoglobin, an iron containing pigment, is set free and breaks down to form new coloured compounds such as haem, 
haematoidin and haemosiderin, and the degree of tooth discoloration depends upon the degree of breakdown of the haemoglobin". However, this theory did not give any indication as to the rate at which the discoloration occurs or the mechanism involved in the breakdown of haemoglobin which presumably leads to the release of the iron component or indeed, why the cascade of breakdown products should give an ever increasing staining.

A closer examination of the reported causes of tooth discoloration will be considered in order to assess their continued relevance.

\subsubsection{Decomposition of the pulp tissue}

Grossman (1943) considered that pulpal decomposition as well as pulpal haemorrhage contributed equally to the discoloration of teeth. This assertion was well accepted and it has appeared frequently in the literature. Thomas (1959) offered an unsupported explanation as to how a necrotic pulp may produce tooth discoloration of an internally non-vital tooth when he claimed, "as pulp degenerates the resultant necrotic tissue, which contains various protein degradation products, creates the familiar greyish-black discoloration of the crown". Grossman's supposition received further support from Ingle (1974) when he asserted, without any evidence, that "discoloration will also frequently result from the decomposition of necrotic pulp tissue even though frank haemorrhage has not occurred." However, not all researchers have agreed with the contribution played by degenerative pulp tissue in producing staining in internally non-vital teeth. Nutting and Poe (1963) observed that pulpal ischaemia and subsequent pulp death, without bacterial contamination, does not produce a discoloured tooth to the 
same extent as one that has undergone haemorrhage into the pulp chamber.

\subsubsection{Intra-canal medicaments}

Grossman (1943) claimed that often the discoloration occurred many months after the endodontic treatment had been completed. He proposed that this discoloration was a result of the "slow formation of compounds of haemoglobin" within the dentine but did not attempt to explain how this occurred, or what biological processes were involved. It was also possible that the observed discoloration was due to sealer remaining within the pulp chamber following root canal therapy or from by-products of bacterial contamination within the pulp chamber.

It has been shown by van der Burgt (1986) that the use of endodontic materials can lead to internal discoloration of teeth, and that all endodontic sealers produce measurable coronal discoloration. "Diaket" and "Tubli-seal" cause a mild pink discoloration, "AH26" gave a distinct colour shift toward grey and Riebler's paste caused a severe dark red stain. Zinc oxide-eugenol, "Grossman's Cement", "Endomethasone", and "N2" can all produce a yellowish band at the amelodentinal border. The liquid component of these materials consists mainly of eugenol and Hume (1984) demonstrated that zinc oxide-eugenol mixtures release eugenol, even after they have set, which continues to penetrate through a layer of dentine, although at a slower rate. Furthermore, Boksman et al. (1983) have claimed that the majority of post-endodontic discolorations can be traced to failure of the operator to completely remove blood or organic material from the pulp chamber. This can occur because the access cavity into the pulp chamber may be 
inadequate and the pulpal horns have not been debrided of organic material. The initial aim of endodontic treatment is to obtain good access so that complete debridement of the pulp chamber is possible. At the completion of the root canal therapy, the medicaments and sealing pastes must be removed from the coronal portion of the tooth.

\subsubsection{Excessive haemorrhage following pulp removal}

Failure to control haemorrhage after a vital pulpectomy may allow blood to enter the pulp chamber and the dentinal tubules to produce tooth discoloration. When haemorrhage persists, it usually indicates that a vital fragment of pulpal tissue is still present in the root canal and should cease after removal of the pulpal remnant. The pulp chamber and root canal should be thoroughly irrigated removing blood elements from the dentinal tubules and so prevent discoloration.

\subsubsection{Filling materials}

Amalgam used as a coronal sealing agent will result in a grey discoloration largely because of its colour and the thin labial enamel and dentine in the anterior teeth. If amalgam is left in place for a long time, discoloration of a more permanent nature can be observed due to the penetration of metallic ions into dentine as corrosion of the amalgam occurs. The earlier glass ionomer cements such as "Ketac Silver" have been known to produce severe grey-black discoloration when used as a restorative material for access cavities (Smales et al. 1990). These materials contained silver which was the principle cause of the discoloration. Since 1987, the silver component has been chemically 
bound (sintered) to the glass ionomer in order to reduce this type of discoloration.

Other forms of glass ionomer cements, such as "Ketac Fil", and the composite resins or a combination of the two, provide a better seal of the access cavity due to the chemical bond to the dentine and/or enamel (Wilson and McLean 1988). As a result of colour matching, these materials provide superior aesthetics and there is no reported evidence to suggest that they will lead to subsequent discoloration of the tooth. However, marginal staining of composite resin materials, as a result of microleakage and bacterial contamination, may stain the margins and may lead to discoloration of the tooth.

\subsubsection{Use of "mummifying" or devitalizing agents}

Formocresol, silver nitrate and arsenic produced dramatic tooth discoloration and unacceptable aesthetics when used in pulp therapy. The "mummifying" agent formocresol is no longer used because of its potential to produce an immunological response in the underlying tissues (Rolling et al. 1976, Block et al. 1977, Pruhs et al. 1977, Magnusson 1978, Block et al. 1978, and Myers et al. 1983). As a result of their toxic nature, Seltzer et al. (1961) recommended that silver nitrate and arsenic should not been used to devitalize adult teeth.

Grossman (1943) originally proposed that haemolysis and catabolism of haemoglobin occur both sequentially and concurrently in the pulp chamber producing tooth discoloration due to the release of iron from the haemoglobin superstructure. This has been widely accepted and quoted by many authors such as Ingle (1974), Frank (1980), Howell 
(1980), Freccia and Peters (1982), Boksman et al. (1983), and Tronstad (1991). Although the experimental basis upon which this proposal was based was not described, it has not been verified or challenged in the half century since it was proposed. A recent example of Grossman's premise still being repeated almost verbatim is exemplified by Rotstein et al. (1991) when they stated that "erythrocytes undergo haemolysis and liberate haemoglobin which releases its iron content. The iron is combined with hydrogen sulphide to form iron sulphide, a black compound which gives the tooth its dark discoloration."

\subsection{THE PULPAL REACTION IN TRAUMATIZED TEETH}

Even in cases of slight damage to teeth, the immediate result of trauma may be temporary disruption of the vascular supply to the pulp. Arwill et al. (1967) have stated that irrespective of the severity of the trauma, the most likely event to occur is some degree of haemorrhage immediately in the pulp chamber. However, this opinion is not shared by Stanley et al. (1978). They claimed that trauma results either in compression of the blood vessels at the apex or severance of the blood supply and that anoxic conditions within the pulp lead eventually to pulpal death without haemorrhage. When the supply of blood is cut off, the cytoplasm of the parenchymal cells undergo coagulation necrosis as a result of anoxia and from chemical injury caused by accumulated catabolic products and the action of intracellular enzymes. They asserted that if trauma leads to the immediate rupture of the pulpal vessels, then there is extensive haemorrhage into the pulp chamber producing a reddish tooth with severe damage to the pulp and subsequent pulp death. This observation was in agreement with the earlier work of Magnusson and Holm (1969). However, if there is only a disruption of the arterial blood 
flow without a massive haemorrhage, Stanley et al. (1978) claimed that the redness is only observed after the dissolution of erythrocytes present within the pulp releasing haemoglobin particles. Goldstein (1987) stated that blood from a ruptured blood vessel is driven hydraulically into the dentinal tubules where it causes a red-pink discoloration of the tooth presumably by the penetration of the blood products into the dentinal tubules. The larger the dentinal tubules and the greater the haemorrhage into the pulp chamber, the more likely is the intensity of the staining. Arwill et al. (1967) reported that this discoloration is probably due to the haemoglobin component. Although not substantiated, they claimed that as the haem component disintegrates the colour turns bluish and produces a grey-blue hue through the enamel. They also claimed that this shift from pink to grey seemed to be directly related to time from the trauma and it takes approximately 14 days to occur.

These observations were supported by Jacobsen (1980). in her research with traumatized permanent incisors. She reported that a pinkish hue became evident within two days, and a further change to a grey colour was observed from six days to three weeks. Although the cause of the discoloration was not examined in this study, it was proposed that the discoloration was due to internal haemorrhage into the pulp chamber. In view of the short interval before the discoloration became apparent, the possibility of the discoloration being caused by bacterial contamination can be discounted. Bergenholtz (1974) investigated the occurrence of bacteria in traumatically devitalized teeth with an intact pulp chamber and found that several teeth demonstrated no growth of bacteria despite an interval of more than one year. These findings have been confirmed by Sundqvist (1976) 
who demonstrated that in some cases the pulp chamber may remain aseptic for many years and no bacteria were found despite an interval of six years between trauma and sampling. The phenomenon of sterile pulp necrosis following dental luxation is not an unusual occurrence for it has also been observed by Andreasen (1989). However, it has been shown by Bergenholtz (1974) that the existence of necrotic tissue increases the potential risk of later infection and periapical complications.

The pulp chamber is an isolated micro-environment different from any other in the body especially in relation to the haemolysis and catabolism of red blood cells. According to Stanley et al. (1978), the disruption to normal blood flow in the pulp produces pulpal infarction which is different from other areas of the body where, due to abundant anastomoses, a collateral circulation is soon established. In most parts of the body even when a large artery is blocked, fresh blood flows to the vessels of the developing ischaemic area and usually prevents permanent damage. When a major pulpal artery is obstructed, the vessels of the accessory canals have the potential to act as peripheral arterioles, as in other organs, and allow the inflow of some blood. However, following histological assessment, Stanley et al. (1978) concluded that the accessory canals are insufficient to support pulpal vitality because the capillaries in the pulp dilate, congest and degenerate permitting the erythrocytes to diffuse through the pulp. Pulp tissue is surrounded by dentine and cementum which acts as a physical barrier to a collateral circulation from the peri-radicular tissues. As a consequence, pulp necrosis occurs thus precluding an inflammatory response or normal healing. Stanley et al. (1978) observed that the breakdown of capillary walls, with subsequent 
escape of erythrocytes, released haemoglobin which appeared as scarlet-red dusty granules. Most of the pulpal cell nuclei undergo karyolysis but others, for unknown reasons, undergo pyknosis. The dentinal walls of the pulp chamber act as a barrier and the normal hyperaemic inflammatory response cannot act on the pooling erythrocytes. The usual inflammatory exudate and cellular response seen in most tissues is thus restricted or absent in the pulp. Stanley et al. (1978) have stated that, there is a lack of macrophages to digest and degrade the haemoglobin and convert it into other breakdown products and consequently, the haemoglobin merely separates from the disintegrating erythrocytes to form scarlet-red granules. In the absence of an inflammatory response, no reparative process occurs and the infarcted pulp remains for months or years, with no changes unless subjected to bacterial invasion (Möller et al.,1981).

It has been well documented (Van Wyk, 1987) that at post-mortem examinations following violent death by drowning, burning, knifing or strangulation, a "pink teeth" phenomenon may occur. It is believed that this occurs because of increased flow of blood in the pulpal circulation. Spectrophotometric studies (Beeley and Harvey, 1973) of the pulps in these cases suggested that the pigment was haemoglobin.

Apart from permanent discoloration, transient staining following moderate trauma such as extrusion and luxation to teeth has been noted in teeth with completely formed apices (Andreasen, 1986). The observed pulpal damage and tooth discoloration gradually disappeared with the revascularization of the pulp and the re-establishment of normal responses to sensibility testing. In addition, she proposed that a transient apical breakdown may facilitate the revascularization of the 
pulpal tissue and thus the repair process in the traumatized pulp. No explanation was offered to account for the observed reversal of colour. One may speculate that there is a (haem) protease/enzyme circulating within the blood plasma which is responsible for the removal of the blood pigment. Further research in this area is needed.

Throughout the literature, a strong case has been presented that the initial discoloration of non-infected internally non-vital teeth is due to haemoglobin granules that have separated and disintegrated from erythrocytes. To date, the scientific evidence indicates that the porphyrin ring of haemoglobin is not broken and that no free iron is liberated. Therefore, it is proposed that the most likely cause of staining in traumatized, non-infected teeth is due to the haemoglobin granules rather than the subsequent degradation products releasing iron. 


\subsection{HAEMATOLOGY}

Basic to understanding the causes of stains in teeth due to blood pigments is a knowledge of the structure and function of haemoglobin as well as the likely biological mechanisms available to degrade haemoglobin following haemorrhage in the pulp chamber.

\subsubsection{The function of erythrocytes}

The mature erythrocyte is an enucleated, bi-concave disc, with an average diameter of about $8 \mu \mathrm{m}$, which is well adapted to its special function of transporting haemoglobin around the body (Erslev and Gabuzda, 1975). In order to carry out this function, the erythrocyte needs to be readily deformable so that it may pass through the narrow capillary channels of the circulation and, at the same time, maintain haemoglobin in a suitable form allowing the exchange of oxygen between the lungs and the tissues and the removal of carbon dioxide in the reverse direction.

\subsubsection{The structure of haemoglobin}

Haemoglobin is a tetrameric protein consisting of two $\alpha$-polypeptide chains of 141 amino acids and two $\beta$-polypeptide chains of 146 amino acids held together by non-covalent interactions (Stryer, 1988). X-ray crystallographic observations by Perutz (1978) have shown that each of the four chains coils into eight helices forming an efficient quaternary structure which allows each haemoglobin molecule to bind four oxygen molecules. The site responsible for the reversible binding of oxygen is the haem group and it consists of a protoporphyrin ring with an iron 
atom at its centre in the ferrous form $\left(\mathrm{Fe}^{++}\right)$. The porphyrin ring has been described by Pippard and Hoffbrand (1989) as consisting of four pyrrole groups united together by methene (=C-) bridges. The hydrogen atoms in the pyrrole groups are replaced by four methyl $\left(-\mathrm{CH}_{3}-\right)$, two vinyl $\left(=\mathrm{C}=\mathrm{CH}_{2}\right)$, and two propionic acid $\left(-\mathrm{CH}_{2}-\mathrm{CH}_{2}-\mathrm{COOH}\right)$ groups. Stryer (1988) attributes the distinctive colour of haemoglobin to the haem group.

The formation of haemoglobin begins at the earliest precursor stage of the developing erythroid cell in the bone marrow and it is completed when the enucleated reticulocyte matures to an erythrocyte. No additional haemoglobin is produced during the 120-day life span of the erythrocytes in the circulation.

\subsubsection{Sites of erythrocyte destruction}

It has been reported by Noyes and Garby (1967) that almost $90 \%$ of normal erythrocyte destruction occurs without the release of haemoglobin into the plasma and that the major part of the destruction process occurs extravascularly within the mononuclear phagocytic system; previously known as the reticulo-endothelial system (Walter and Israel, 1987). The following description of erythrocyte destruction is a condensation of the text by Fairbanks and Beutler (1990). Digestion of phagocytosed erythrocytes proceeds at a rate sufficient to release approximately $20 \%$ of the haemoglobin iron within a few hours. The iron released by this action is absorbed bound to transferrin in the plasma, and ultimately reincorporated into haemoglobin. Approximately $40 \%$ of the haemoglobin iron of non-viable erythrocytes reappears in circulating red cells within twelve days. The remainder of the iron derived from the 
haemoglobin degradation enters the storage pool as ferritin or haemosiderin, and normally turns over very slowly.

Special features characterize those situations in which red blood cells are destroyed within the circulation rather than within the mononuclear phagocytic cell. It has been reported by Hershko (1975) that, following haemoglobin catabolism in healthy individuals, only a very small amount of extracellular haem compounds can be detected in normal plasma. However, in patients with syndromes characterized by excessive haemolysis, such as paroxysmal nocturnal haemoglobinuria, marked elevations of plasma haemoglobin may occur. In such patients, supplementary mechanisms regulate the disposal of haemoglobin which involve binding haemoglobin to the plasma proteins, haptoglobin and haemopexin (Noyes and Garby 1967). Haptoglobin is an $\alpha$-glycoprotein, synthesized in the liver, with a strong affinity for haemoglobin. Haptoglobin has been described by Allison and Rees (1957) as being capable of readily binding to extracorpuscular plasma haemoglobin to prevent loss via the kidneys, thereby conserving iron and protecting the renal tubular cells from damage. In the absence of haptoglobin, some haemoglobin is cleared by the uptake into parenchymal cells in the liver, as well as by renal excretion. In these instances, haemoglobin is oxidized to methaemoglobin, and dissociates to free haemin and globin. Such free plasma haemin is avidly bound by B-globin haemopexin, which is a glycoprotein synthesized in the liver. It binds haemin but not haemoglobin, and the complex is cleared by hepatic parenchymal cells. Pippard and Hoffbrand (1989) have stated that, in the absence of haemopexin, free haemin may complex with albumin to form methaemalbumin. 


\subsubsection{The extravascular degradation of haemoglobin}

Our early understanding of the catabolism of haemoglobin arises from the work of Virchow (1847). He was the first to use the term haematoidin when he observed a yellow crystalline pigment appearing in areas of extravasation of blood. The term haemosiderin was first used by Neumann (1888) for an intracellular iron containing pigment distinct from Virchow's haematoidin. It was shown by Rich (1924) that haematoidin, like haemosiderin, is formed intracellularly in phagocytes which have ingested red blood corpuscles. Following phagocytosis of senescent erythrocytes, macrophages of the mononuclear phagocyte system degrade haemoglobin producing an iron-containing haemosiderin and an iron-free haematoidin. Virchow (1847) also noted that following the extravasation of blood, there is an accumulation of bilirubin which he deduced to be a derivative of haemoglobin.

Virchow's conclusions regarding the final outcome of the extravascular degradation of haemoglobin are still applicable today. However, our knowledge in this field has progressed such that Robinson (1990) has stated that the conversion of haem to bilirubin is found in the phagocytic cells of the mononuclear phagocytic system in the spleen, marrow and liver, and parenchymal cells of the liver and kidney. This occurs following the initial breaking of the $\alpha$-carbon bridge of the tetrapyrrole haem molecule by an enzyme in the microsomal fraction of these cells (Tenhunen et al., 1969). This enzyme system is known as the microsomal haem system and it is responsible for the release of iron from the haem and the conversion of iron to the ferric $\left(\mathrm{Fe}^{+++}\right)$state (Tenhunen et al. 1969). The microsomal haem system appears to be induced by its substrate and activity increases dramatically about three 
hours after erythrophagocytosis. Carbon monoxide, generated during the conversion of haem to biliverdin, is transported as carboxyhaemoglobin to the lungs and excreted in expired air (Coburn et al., 1967). Once the protoporphyrin ring of haem is opened, the tetrapyrrole compound biliverdin is formed and is promptly reduced to bilirubin by a second enzyme, biliverdin reductase. Following conjugation in the liver, bilirubin is excreted into the bile and further reduced by anaerobic bacteria in the colon to urobilinogen (Wintrobe et al., 1981).

Figure 1 outlines the major events accompanying the degradation of haemoglobin within the mononuclear phagocyte system. The structures of the haematin molecules produced after the globin chains of the haemoglobin molecule are hydrolysed are presented in Figure 2. 


\section{A FLOW DIAGRAM REPRESENTING THE DEGRADATION OF HAEMOGLOBIN}

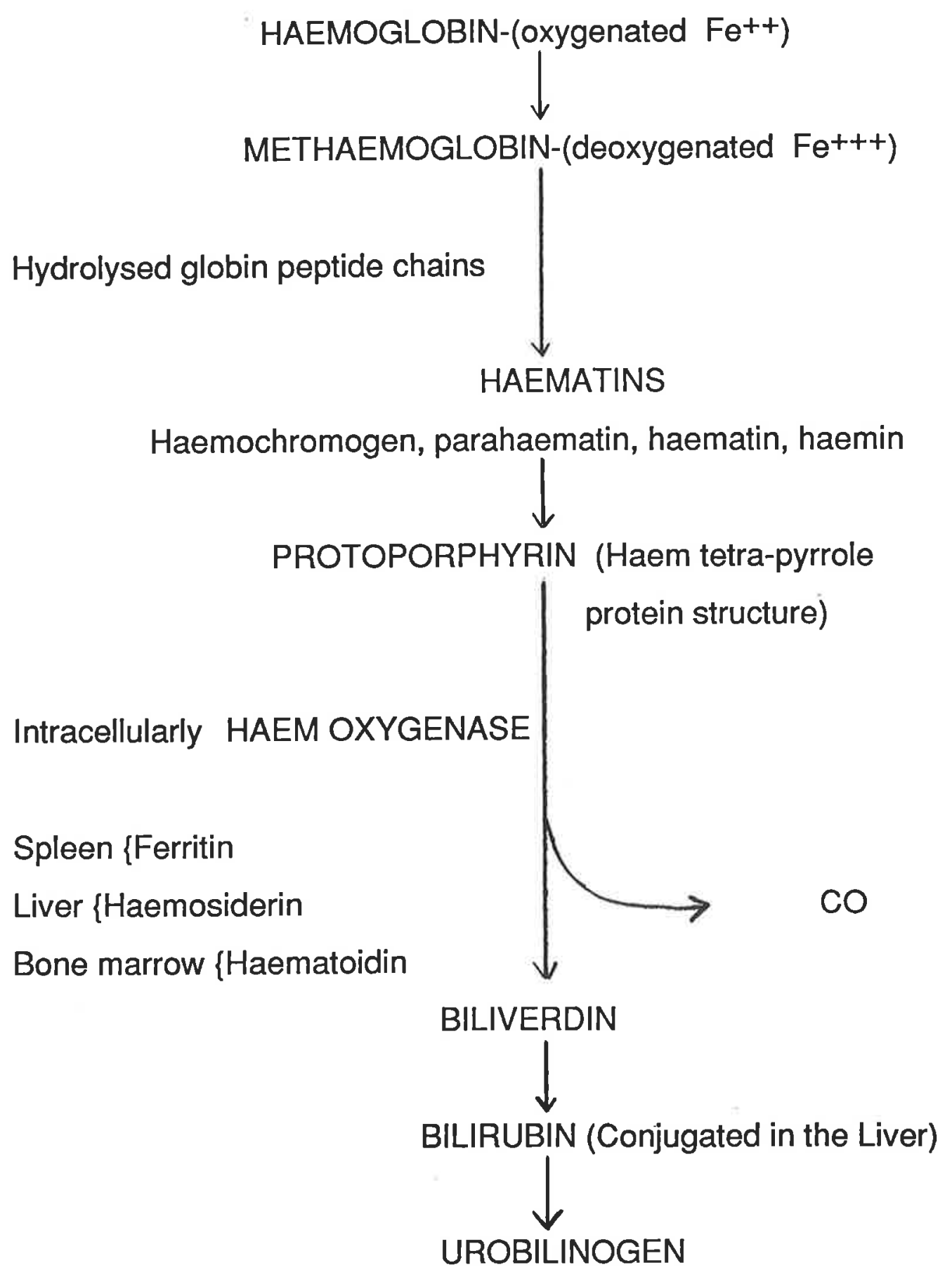

Figure 1. 


\section{STRUCTURE OF HAEMATIN COMPOUNDS}

$N=$ Porphyrin Nitrogens which contribute two negative charges to the complex. $\mathrm{N}^{\prime}=$ Non-porphyrin Nitrogens.

\begin{tabular}{|c|c|c|c|c|}
\hline & \multirow[b]{2}{*}{ Structure } & \multirow[b]{2}{*}{ Charge } & \multicolumn{2}{|c|}{ Iron Alom } \\
\hline & & & Valency & $\begin{array}{c}\text { Ferrous } \\
\text { or } \\
\text { Ferric }\end{array}$ \\
\hline Haem (reduced haematin) & & 0 & 2 & Fertous \\
\hline Haemochromogens & & 0 & 2 & Ferrous \\
\hline Haematin & & 0 & 3 & Ferric \\
\hline Haemin (chloride, elc.) & & +1 & 3 & Ferric \\
\hline Parahaematin (chloride, etc.) & & +1 & 3 & Ferric \\
\hline
\end{tabular}

Figure 2 
2.3.5 Iron metabolism in the mononuclear phagocytic system

Following phagocytosis of the erythrocyte, the cell membrane is broken and haemoglobin iron is oxidized to the trivalent state forming methaemoglobin which readily dissociates non-enzymatically into haem and globin (Bunn and Jandl, 1972). The globin chains are hydrolysed to their constituent amino acids which subsequently re-enter the general metabolic pool (Linman, 1975). Iron from recently destroyed erythrocytes passes quickly through the mononuclear phagocytic system and it is transported to the marrow for reincorporation into newly synthesized haem (Linman, 1975). Excess iron from the degradation of haemoglobin is stored as two iron compounds, ferritin and haemosiderin. The ferritin molecule is roughly spherical in shape with the iron in a trivalent, polymerized form of colloidal ferric oxy-hydroxide and phosphates with a probable subunit structure of $(\mathrm{FeOOH}) \cdot\left(\mathrm{FeO} \cdot \mathrm{PO}_{3} \mathrm{H}_{2}\right)$ (Wintrobe et al., 1981). Haemosiderin has been described by Pippard and Hoffbrand (1989) as appearing as an amorphous structure with a higher iron to protein ratio $(37 \%)$ than ferritin (20\%) and they consider that it is probably formed by lysosomal enzyme action on aggregates of ferritin. In normal subjects, storage iron is about two-thirds ferritin and one-third haemosiderin but in iron overload the proportion of haemosiderin increases considerably. Ferritin is primarily an iron storage protein which may be used for haem synthesis. From a physiological viewpoint, haemosiderin appears to represent a more stable and less readily available form of storage iron than ferritin (Wintrobe et al., 1981; Pippard and Hoffbrand, 1989). 
The major part of the destruction of normal erythrocytes occurs extravascularly, within macrophages of the mononuclear phagocyte system. It has not been shown whether the normal phagocytic cell population of pulpal tissue has the capacity to catabolize haemoglobin following trauma and haemorrhage into the pulp chamber.

\subsection{REVIEW OF AGENTS AND TECHNIQUES USED IN BLEACHING* BLOOD-STAINED, ROOT-FILLED TEETH}

The following review of the accepted bleaching techniques and agents is presented to assist in the understanding of this part of the research.

The first report of bleaching discoloured, root filled teeth was published in 1877 by Chapple. Over the years, many different bleaching agents have been used with varying success. Among the earlier ones were oxalic acid, calcium hypochlorite (Taft, 1878), hydrogen peroxide (Harlan, 1884), perhydrol, (30\% solution of hydrogen peroxide in water), (Abbot, 1918), and chlorine (Garretson, 1895). The first recorded use of a solution of perborate in hydrogen peroxide, which was activated by a light source, was in 1924 by Prinz. Thirty four years later Pearson (1958) used a solution of $25 \%$ hydrogen peroxide and $75 \%$ ether.

\footnotetext{
"Bleaching is defined by the Oxford Dictionary as "to make white or lighten by exposure to sunlight or by chemical means". In the dental literature, bleaching is defined as the use of a chemical agent or agents, sometimes in combination with heat or light ( visible or ultraviolet) to restore normal colour to a tooth.
} 
This solution was activated by a photo flood lamp and it was considered that both heat and light were necessary to activate the solvent qualities of ether. Stewart (1965) took this technique a stage further when he placed a saturated cotton pellet of "Superoxol" ( $30 \%$ hydrogen peroxide) into the pulp chamber and heated it with a hot instrument. The method of bleaching teeth by activating hydrogen peroxide with heat has been referred to as the "thermocatalytically activated bleaching technique". Spasser (1961) reported a new bleaching technique using a mixture of sodium perborate and water to form a thick paste which was sealed in the pulp chamber. This technique has become known as the "walking bleach". A modified version of this technique, proposed by Nutting and Poe (1963) in which "Superoxol" was substituted for the water, has been referred to as the "combination walking bleach" method. This bleaching technique has since proved to be more popular than the thermocatalytically activated technique because it decreases the amount of chairside time.

\subsection{COMPLICATIONS OF BLEACHING ROOT FILLED TEETH}

It has been reported by Ingle and Taintor (1985) that the most commonly used agent to bleach discoloured root filled teeth is $30 \%$ hydrogen peroxide ("Superoxol"). Goldstein \& Feinman (1987) and Grossman et al. (1988) advocated the use of hydrogen peroxide in both the thermocatalytically activated and the combination walking bleach techniques. More recently, in vitro studies by Holmstrup et al. (1988) and Rotstein et al. (1991) have suggested that sodium perborate combined with water is clinically effective in bleaching blood stained teeth. However, it is considered that sodium perborate combined with 
hydrogen peroxide is a more effective bleaching agent than sodium perborate and water (Ho and Goerig, 1989; Warren et al., 1990).

Some concern has been expressed regarding the use of hydrogen peroxide when used as a bleaching agent. Harrington and Natkin (1979) were the first to report seven cases in which external root resorption occurred two to seven years following bleaching with "Superoxol" and a heat source. Montgomery (1984) and Cvek \& Lindvall (1985) have also reported cases of cervical resorption following bleaching and, in all instances, the involved teeth had experienced some type of traumatic injury. It has not been possible to determine the exact cause of the resorption. However, several hypotheses have been discussed. Heat was considered as one possible causative agent. However, Madison and Walton (1990) rejected this hypotheses because they were unable to experimentally induce cervical resorption in adult beagle dogs by heat alone. Casey et al. (1989) proposed that "Superoxol" may have penetrated through the dentinal tubules to the cervical area of the tooth setting up an inflammatory process in the periodontal ligament producing cervical resorption. The involvement of hydrogen peroxide in cervical resorption was further implicated in case reports by Lado et al. (1983) and Latcham (1986). This association between bleaching and cervical resorption has prompted Montgomery (1984) to suggested that there was sufficient evidence to support a cause and effect relationship between "Superoxol" and cervical resorption. Latcham (1986), Goon et al., (1986), Chivian (1987), Friedman et al. (1988) and Madison \& Walton (1990) have all recommended that the use of $30 \%$ hydrogen peroxide solution for bleaching root filled teeth should be avoided as it may initiate cervical root resorption. 


\subsection{INTRODUCTION TO THE PRESENT STUDY}

This research project was stimulated by the reported differences between the post-traumatic degradation of blood products in the pulp chamber, where there is a lack of collateral circulation, and their degradation elsewhere within the body. The aims of this research project were to investigate the causes of discoloration of teeth following traumatic injury and to examine some of the biological events that occur following haemorrhage into the pulp chamber.

A technique devised by Freccia and Peters in 1982 (APPENDIX I) has frequently been used to produce blood stained teeth (Ho and Goerig, 1989; Warren et al., 1990; Costas and Wong, 1991). However, this method was never intended to reproduce the staining pattern caused by trauma and subsequent haemorrhage into the tooth. It was primarily developed to test the efficacy of various bleaching agents and to evaluate bleaching techniques in extracted teeth. This method of staining teeth does not replicate the in vivo situation because the teeth are immersed in sodium hypochlorite for to dissolve the organic tissue remnants, thereby increasing the dentine permeability. In addition, the whole tooth is immersed in blood which may allow staining to occur from an external approach rather than just from the pulp chamber. As a result of these limitations, a modified version of the Freccia and Peters technique was devised to mimic haemorrhage into the pulp chamber and the subsequent tooth discoloration by centrifugation of blood products within the pulp chamber.

A further aim of this research project was to evaluate the efficacy of various agents in removing the staining in teeth induced by the 
introduction of blood pigments. In view of the possible relationship between hydrogen peroxide and cervical resorption, a search for an alternative agent for the bleaching of root filled teeth is desirable. Agents not currently being used to remove the staining in internally nonvital teeth were tested to determine their ability to remove such stains.

In summary, the main aims of this research were to:

1. Replicate the staining in teeth caused by trauma.

2. Prepare blood-stained, decalcified tooth sections for histological examination, and calcified tooth sections for macroscopic examination.

3. Determine which component of blood is the primary cause of discoloration in traumatized teeth.

4. Determine the degree of catabolism of haemoglobin in the pulp chamber.

5. Evaluate the efficacy of various chemical agents in removing the staining in teeth due to blood pigments. 


\subsection{MATERIALS AND METHODS}

A variety of blood products were introduced into the pulp chambers of extracted teeth, which were subsequently fixed, sectioned and histochemically stained for haematin, haemoglobin, ferric ions and haemosiderin. A modified version of the technique devised by Freccia and Peters (1982) (APPENDIX I) was used to mimic haemorrhage into the pulp chamber and the subsequent tooth discoloration. Additional teeth were filled with packed red blood cells and immersed in various bleaching solutions. These teeth were sectioned and examined using a "Speedmaster" R75-CP Reflection Densitometer (APPENDIX II) in order to determine the efficacy of the bleaching solutions. In a further study, a non-infected, necrotic pulp was removed from a patient's tooth which had previously suffered trauma. The tissue was prepared for routine histological examination and sections were subjected to histochemical staining for haematin, haemoglobin, ferric ions and haemosiderin.

\subsection{REPRODUCTION OF PULPAL HAEMORRHAGE AND TOOTH DISCOLORATION}

Singled rooted premolar teeth, extracted for orthodontic reasons, were collected from consenting patients. The extractions were carried out under local anaesthesia using forceps in the Department of Oral Surgery at the Royal Adelaide Hospital, and South Australian Dental Service Clinics in the Adelaide metropolitan area. The sex of the donors was not considered to be relevant and the age of the donors was between $10-18$ years. 


\subsubsection{Storage of teeth}

All teeth were stored in sterile polystyrene containers containing phosphate buffered saline (PBS) and $0.05 \%$ sodium azide (APPENDIX III). The addition of azide excluded the likelihood of bacterial growth. The containers were capped, and stored at $4^{\circ} \mathrm{C}$ until required.

\subsubsection{The addition of blood products}

An aseptic technique was used to eliminate the introduction of bacteria into the pulp chamber and root canal. An access cavity was made through the occlusal surface of the premolar teeth with a cross cut fissure tungsten carbide bur at high speed. The organic matter in the pulp chamber was removed with a round bur at low speed and the root canal filed to a size 35-40 Hedström file. The root canal was irrigated with $1-2 \mathrm{ml}$ sterile $0.9 \%$ saline (1.54 mM sodium ions and $1.54 \mathrm{mM}$ chloride). The same tungsten carbide bur was used to remove $2-3 \mathrm{~mm}$ of length from the root to facilitate sealing at the apex.

Initially, four groups, each comprising five teeth, were prepared and each pulp chamber was filled with $0.4-0.6 \mathrm{ml}$ of the following:

Group A. Whole blood.

Group B. Platelets concentrate.

Group C. Packed red blood cells (erythrocytes).

Group D. Sterile $0.9 \%$ saline. 
After the addition of one of the above blood products into each tooth, the access cavity and the apical foramen were sealed to a depth of $3 \mathrm{~mm}$ with "Cavit" (APPENDIX II).

\subsubsection{Centrifugation}

The prepared teeth were placed crown first in individual centrifuge tubes of a BHG Roto-Uni. bench centrifuge (APPENDIX II), and immersed in sterile saline. They were centrifuged at 3,500 rpm twice daily for twentyfive minutes over three consecutive days. In the interim period between centrifugation, the teeth were stored at $370^{\circ} \mathrm{C}$ and $100 \%$ humidity.

The relative centrifugal force (RCF) exerted on the crowns of the teeth was calculated by the following formula:

$\mathrm{RCF}=11182 \times 10^{-8} \times$ Radius of the centrifuging arm $(\mathrm{cm}) \times(\mathrm{RPM})^{2}$

Where Radius $=13 \mathrm{~cm}$

$$
\mathrm{RPM}=3,500
$$

and therefore $\mathrm{RCF}=17,807 \mathrm{~g}$

\subsection{PREPARATION OF HISTOLOGICAL SECTIONS FOR MICROSCOPIC EXAMINATION}

All the teeth to be examined by histological means were fixed, demineralized, embedded, and cut to an appropriate thickness and prepared by normal histological methods as outlined in APPENDIX V. 


\subsubsection{Fixation}

A solution of $10 \%$ neutral buffered formalin (37\%-40\% formaldehyde, $\mathrm{pH} 7.0$ ), at room temperature was used for 48 hours to fix the blood stained teeth.

\subsubsection{Decalcification}

Two different types of decalcification solutions, acid-EDTA and EDTAcacodylate, were examined to determine which decalcifying solution is least likely to interfere with the experimentally induced discoloration of the teeth. Eight teeth similar to those in group $\mathrm{C}$ and prepared as in section 4.1.2 and 4.1.3 were sectioned longitudinally at $3 \mathrm{~mm}$ thickness using a Van-Moppes diamond cutting disk (APPENDIX II) at 12,000 rpm with water spray. Four teeth stained with packed red blood cells were immersed in acid-EDTA (APPENDIX V), $\mathrm{pH} \mathrm{1.0,} \mathrm{and} \mathrm{the} \mathrm{other} \mathrm{four} \mathrm{teeth}$ were immersed in EDTA-cacodylate (APPENDIX V), $\mathrm{pH}$ 7.3. The end point of decalcification was determined by radiographic examination.

\subsection{SPECTROPHOTOMETRIC ANALYSIS OF THE DECALCIFYING SOLUTIONS}

A Perkin-Elmer Lambda 5 UVNIS Spectrophotometer using matched quartz cuvettes (Appendix II) was used to examine the acid-EDTA and EDTA-cacodylate decalcification solutions before and after use as decalcifiers. Both the ultra-violet $(200-400 \mathrm{~nm})$ and visible wavelength spectra $(400-700 \mathrm{~nm})$ of the decalcifying solutions were examined. 
Solutions of acid-EDTA decalcifying solution "spiked" with a known volume of haemolysed packed red blood cells in the ratio of 1:1,000, $1: 10,000,1: 100,000$, and 1:1,000,000 were examined in order to determine the detection limits of the spectrophotometer for the blood pigments.

\subsection{HISTOCHEMICAL TESTS}

Benzidine, zinc leuco, Perl's and Turnbull Blue histochemical tests, used for the detection of haematin, haemoglobin, ferric ions and haemosiderin respectively (APPENDIX VI), were carried out on three groups immersed in either concentrated platelets (Group B), packed red blood cells (Group E) and sterile saline (Group G) These teeth were prepared as outlined in section 4.1.2 and 4.1.3 except 2-3mm of the root length was removed from those teeth with closed apices and the apical foramina were not sealed during the centrifugation process. All the teeth were demineralized in acid-EDTA for 48 hours and subsequently prepared for histological examination (APPENDIX V).

\subsection{PREPARATION OF MACROSCOPIC SECTIONS}

An additional five teeth, Group F, stained with packed red blood cells, were to chosen for macroscopic examination and subjected to the benzidine, leuco blue and Perl's tests. These teeth were prepared similarly to those in section 4.4 except they were not demineralized but they were sectioned longitudinally at a thickness of $1 \mathrm{~mm}$, using a VanMoppes diamond cutting disk at $12,000 \mathrm{rpm}$ with water spray, and fixed in $10 \%$ solution of neutral buffered formalin (APPENDIX V). 


\subsection{EVALUATION OF VARIOUS BLEACHING AGENTS}

An additional five teeth (Group $H$ ) were stained with packed red blood cells and they were sectioned longitudinally at $1 \mathrm{~mm}$ thickness using a Van Moppes diamond cutting disk at 12,000 rpm with water spray. Representative samples of these teeth were further sectioned until $1 \mathrm{~mm}$ $\times 1 \mathrm{~mm} \times 1 \mathrm{~mm}$ specimens of stained teeth were produced. It was important to ensure all the sections were of the same dimensions and it was assumed that all the different teeth were of the same density with the only variation being the colour. Changes in colour were measured using a "Speedmaster" R75-CP Reflection Densitometer (APPENDIX II). The densitometer measures the reflectance density on a linear scale from 0 to 2.5. It is calibrated so that the ANSI standard white on the calibration plaque registers 0.8 and ANSI standard black registers 1.86. The initial reflection readings were performed on five sections from the pool of five teeth selected at random and recorded (Day 1), prior to the immersion in each of the bleaching agents listed below. Two surfaces of each section were measured and the average of the two readings was registered. The changes in reflection density were recorded over a period of seven days (Day 2, Day 3, Day 4, Day 5, \& Day 7). In the interim period the teeth were stored at $37^{\circ} \mathrm{C}$ and $100 \%$ humidity.

The following agents were evaluated to determine their efficacy in removing the colour from blood stained teeth:

1. Routinely used bleaching agents

Hydrogen peroxide (APPENDIX II) $30 \%$ v/v solution

"Amosan" (APPENDIX II)

Thick paste 
Hydrochloric acid

Hydrochloric acid

Orthophosphoric acid

Oxalic acid

Oxalic acid

2. Non-traditional bleaching agents

"Hi-clean" (APPENDIX II)

"Enzymatic Cleaner" (APPENDIX II)

"Desferal" (APPENDIX II)

"Liquid Iron Chelator" (APPENDIX II)
$10 \% \mathrm{v} / \mathrm{v}$ solution

$30 \% \mathrm{v} / \mathrm{v}$ solution

$40 \%$ v/v solution

Saturated solution at room temperature

$1 \mathrm{M}$
$2 \mathrm{gm} / 5 \mathrm{ml} \mathrm{w} / \mathrm{v}$ of DDW

1 tablet $/ 5 \mathrm{ml}$ of DDW

$1: 5 \mathrm{w} / \mathrm{v}$ in DDW

As supplied

Distilled deionized water (DDW) (APPENDIX II)

At the present time, hydrogen peroxide and sodium perborate monohydrate ("Amosan") are the most commonly used agents to bleach stained root filled teeth. Other bleaching agents such as oxalic acid (Taft 1878 ) and $20 \%$ hydrochloric acid (Croll and Cavanaugh 1986) have also been included to evaluate their ability to remove the experimentally induced blood stains. In addition to the routinely used bleaching agents, the following non-traditional agents were evaluated:

1. "HiClean" a commercially available stain remover which the manufacturer claims removes "even dried blood".

2. "Enzymatic Cleaner" containing enzymes such as amylase, trypsin, and lipase in the total enzyme content of $98.55 \mathrm{mg} / \mathrm{tablet}$.

3. "Liquid Iron Chelator", a commercial iron chelator, used for the regulation of iron. 
4. "Desferal", a commercial iron chelator (desferrioxamine) capable of taking up iron from transferrin, ferritin, and haemosiderin, and forming the iron complex ferrioxamine.

A summary of all the groups of teeth and their preparation is presented in Table 1. The number of teeth and samples from each tooth subjected to histochemical testing is outlined in Table 2. 


\section{A SUMMARY OF THE DIFFERENT GROUPS OF TEETH PREPARED}

GROUP:

A

B

C

D

E

$\mathrm{F}$

G $\quad H$

STAIN:

whole

blood

$\mathrm{RBC}$

saline $\quad \mathrm{RBC}$

RBC saline $\mathrm{RBC}$

No. OF TEETH

PER GROUP:

5

5

5

5

5

5

$5 \quad 5$

SIZE OF

TOOTH

SLICES:

$2 \mathrm{~mm}$

$2 m m$

$2 \mathrm{~mm}$

$2 \mathrm{~mm}$

NA

$1 \mathrm{~mm} \quad \mathrm{NA} \quad 1 \mathrm{~mm}^{3}$

DECALCIFIED:

NO

YES

NO

No

YES

NO

YES NO

HISTO-

CHEMICALLY

No

YES

No

NO

YES

YES YES NO

MACROSCOPIC

EXAMINATION:

NO

No

No

YES

NO

YES NO

NO

BLEACHED

No

NO

No

No

NO NO

NO YES

Table 1 


\section{A SUMMARY OF THE TEETH AND THE NUMBER OF SECTIONS}

\section{PREPARED FOR HISTOLOGICAL EXAMINATION}

\section{HISTOCHEMICAL TESTS}

BENZIDINE ZINC LEUCO PERL'S
TURNBULL
BLUE

GROUP B

(PLATELETS)

TOOTH

2

5

5

5

5

5

5

3

5

5

5

$4 \quad 5$

5

5

5

$5 \quad 5$

$\begin{array}{lll}5 & 5 & 5\end{array}$

5

5

5

GROUP E

(RBC)

TOOTH 1

5

$\begin{array}{lll}5 & 5 & 5\end{array}$

2

5

5

5

3

5

5

5

4

5

5

5

5

5

5

5

GROUP G

(SALINE)

TOOTH

1

5

5

5

5

2

5

5

5

3

5

5

5

4

5

5

5

5

5

5

5

Table 2 


\subsection{THE EXAMINATION AND TREATMENT OF A NON-INFECTED, NECROTIC PULP FOLLOWING TRAUMA.}

The examination of a non-infected, necrotic pulp following trauma is included because the in vitro model established in this research project was devised to replicate such a clinical situation.

A healthy, 30-year old Chinese male presented for examination at the Department of Dentistry, The University of Adelaide. The chief complaint was the discoloration of the upper right central incisor upon the removal of the fixed orthodontic appliances following eighteen months of orthodontic treatment (Figure 3). Examination revealed no extra- or intra-oral soft tissue lesions. The discoloured tooth tested negative to both electrical and thermal $\left(\mathrm{CO}_{2}\right)$ pulp sensibility testing. The tooth was not tender to percussion, and palpation of the anterior labial sulcus was not painful. Two periapical radiographs (Figure 4) were taken at different angulations and these suggested that there was no evidence of any periapical pathology. A diagnosis was made of non-infected necrosis following trauma associated either with the orthodontic treatment or trauma of unknown origin.

Informed consent was obtained to undertake root canal therapy. Protective dam isolation was applied to the discoloured tooth which was then disinfected with alcoholic "Savlon" (APPENDIX II) for three minutes. An access cavity was prepared without local anaesthetic with a $169 \mathrm{~L}$ tungsten carbide bur. An aseptic technique was employed and the pulp was removed intact with a size $40 \mathrm{~S}$-file and immediately placed in a solution of $10 \%$ neutral buffered formalin. 
The pulp was prepared for normal histological preparation as outlined in APPENDIX $V$ and subjected to the same histochemical tests as the in vitro model under review. Five sections of the pulp were subjected to benzidine, zinc leuco, Perl's and Turnbull Blue histochemical tests as outlined in APPENDIX V.

Root canal therapy was completed within two further visits by sealing the root canal with "AH26" (APPENDIX II) and gutta-percha using a lateral condensation technique (Figure 5). The tooth was subsequently bleached using a combination of the thermocatalytic activation of hydrogen peroxide at the chairside and the combination "walking bleach" using hydrogen peroxide and sodium perborate (Figure 6). 


\subsection{RESULTS}

\subsection{DETERIORATION OF HUMAN RED BLOOD CELLS}

In the process of experimentally producing blood stained teeth by centrifugation and during the interim storage period at $37^{\circ} \mathrm{C}$, there had been a rapid increase in red blood cell haemolysis and deterioration. This was evident by the pungent odour originating from the centrifuge tubes and the separation of the packed red blood cells into a gelatinous surface layer and an even more viscous base layer.

\subsection{CAUSES OF TOOTH STAINING}

Representative examples illustrating the effect of adding sterile saline, platelet concentrate, whole blood, and packed red blood cells to the pulp chamber of the teeth can be seen in Figure 7. Staining was present in two of the groups; one containing whole blood, and the other, packed red blood cells (erythrocytes). The degree of staining due to packed red blood cells was noticeably more extensive than that which occurred with whole blood. When platelet concentrate was compared to the sample of sterile saline, there was no observable difference in colour or any evidence of staining (Figure 8). It is evident from Figure 9 that platelet concentrate did not contribute to any tooth discoloration.

Representative samples of teeth from Group F, freshly stained with packed red blood cells, prepared as in section 4.5 and cut longitudinally into $1 \mathrm{~mm}$ thickness, are demonstrated in Figure 10. Initially these teeth appeared to be stained bright red in colour. After fixation in neutral buffered formalin, the bright tooth stain darkened as demonstrated by 
Figure 11. Although there was a change in intensity of the discoloration, the arrangement and distribution of these teeth stained with packed red blood cells remained the same.

Figure 12 represents a tooth similar to those seen in Figure 10 but at higher magnification ( $x$ 7.5). It demonstrates that a colour gradient exists within the stained teeth with the staining greatest in the dentine layer closest to the pulp chamber, but gradually decreasing in intensity as it extends towards the cementum. Although the teeth were immersed in packed red blood cells and both the apex and access cavity were open, the staining occurred from the inside of the tooth and extended through the dentine to the exterior surface of the tooth. The majority of blood staining was confined to the dentine, but there was also some discoloration of the enamel. This enamel staining was not as pronounced as that observed in the coronal and radicular dentine, rather it appeared as a pinkish hue (Figure 12).

\subsection{SPECTROPHOTOMETRIC ANALYSIS OF THE DECALCIFYING SOLUTIONS}

Although there was no visible addition of colour to the decalcifying solutions after the demineralization of the blood stained teeth, more sensitive analysis of these solutions was undertaken using a UV-VIS spectrophotometer. No differences in the visible spectrum (400-700nm) of the acid-EDTA decalcifying solution before and after digestion was noted (Figure 13). A comparison of the same solutions in the UV range $(200-400 \mathrm{~nm})$ indicated the appearance of an absorbance band (a-b $\lambda$, i.e. $200-230 \mathrm{~nm}$ ) with a peak at about $210 \mathrm{~nm}$ (Figure 14). It was 
assumed that this represents digestion products leached from the samples but having no visible colour.

When the visible spectrum of the EDTA-cacodylate, before and after digestion, was compared, no differences were seen (Figure 15). In the UV spectrum (Figure 16), the EDTA-cacodylate solution, post-digestion, showed an absorbance band (a-b $\lambda$, i.e. 230-250nm) with a peak at about 240nm. Intriguingly, this absorbance was in a different wavelength band to that obtained with acid-EDTA decalcification solution. This could only result from the two decalcification solutions leaching different colourless substances from the stained teeth.

With visibly coloured solutions, in the dilution of $1: 10,000$ volumes, a spectral scan over the visible range $(400-700 \mathrm{~nm})$ revealed a broad peak around 420nm (Figure 17). A dilution of haemolysed packed red blood cells of $1: 100,000$ (Figure 18) gave an insignificant absorbance in this region and 1:1,000,000 showed no absorbance peak anywhere in the visible region. This indicated that blood products were detectable by eye at $1: 10^{4}$ and detectable spectrophotometrically down to levels between $10^{5} \& 10^{6}$.

Figure 19 demonstrates three teeth from Group $F$ stained with packed red blood cells and subsequently decalcified with acid-EDTA. The degree and distribution of staining was similar to that seen in nondecalcified, packed red blood cell stained teeth (Figure 11). 


\subsection{RESULTS OF HISTOCHEMICAL TESTS}

\subsubsection{Benzidine test}

Figures 20-25 demonstrate representative specimens of teeth in Group E which were stained with packed red blood, sectioned longitudinally through the pulp chamber, prepared for histological examination and then subjected to the benzidine histochemical test. These teeth, stained with packed red blood cells, demonstrated a positive response to benzidine and indicated the degree and distribution of haematin in the coronal and radicular dentine (Figure 20). All the teeth stained with packed red blood cells displayed more blood pigments in the coronal dentine than in the radicular dentine. This was most likely a result of the alignment of the tooth during the centrifugation process or due to the wider diameter of the dentinal tubules in this area. Within the tooth, the greatest staining occurred closest to the pulp chamber and radiated outwards in diminishing intensity through the dentinal tubules towards the outer tooth surface. The normal S-shaped arrangement of the dentinal tubules visible when teeth are sectioned in a longitudinal direction, was highlighted as a result of the benzidine staining. Figures $21,22, \& 23$ show in increasing detail, the intensity and distribution of the benzidine staining in two areas of coronal dentine adjacent to the pulp chamber. The distribution of haematin staining within dentinal tubules can be seen in Figures $24 \& 25$, and it demonstrates that the haematin material is found within the tubules and not in the intertubular dentine. 


\subsubsection{Zinc leuco test}

Figures 26-32 demonstrate representative specimens from Group E which were stained with packed red blood cells, sectioned longitudinally through the pulp chamber, prepared for histological examination, and subjected to the zinc leuco histochemical test. A positive response to the zinc leuco test, indicating haemoglobin scattered throughout the coronal dentine, was seen in this group (Figures $26 \& 27$ ). The diffuse nature of the staining closest to the pulp chamber is seen in Figures 2830. The structure and arrangement of the outer dentinal tubules are highlighted by the zinc leuco staining in Figure 31. Analysis under higher magnification of the dentinal tubules confirms that the haemoglobin is found within the tubules and not in the intertubular dentine (Figure 32). The haemoglobin molecule is found to concentrate mainly in the coronal dentine closest to the pulp and does not penetrate through the dentinal tubules to the same extent as the benzidine stainable material as illustrated in Figure 20.

\subsubsection{Perl's test}

In the presence of ferric ions Perl's solution turns blue. The specimens from Group E, which were stained with packed red blood cells, sectioned longitudinally through the pulp chamber and prepared for histological examination, were consistently negative on all occasions when subjected to the Perl's test. The presence of packed red blood cells within the pulp chamber and the blood stained radicular dentine failed to produce a positive reaction (Figures $33 \& 34$ ). Analysis at higher magnification demonstrated that the dentinal tubules are packed with blood products yet they remain negative to the Perl's test (Figure 
35-36) indicating the absence of ferric ions or any protein bound forms of ferric ion.

\subsubsection{Turnbull blue test}

Representative examples of teeth from Group E, stained with packed red blood cells, sectioned longitudinally through the pulp chamber and prepared for histological examination, demonstrated a negative response to the Turnbull Blue test (Figures $37 \& 38$ ).

All histological specimens of teeth from Groups B (platelet concentrate) and $\mathrm{G}$ (sterile saline) tested negative to benzidine, zinc leuco, Perl's and Turnbull Blue histochemical tests.

\subsection{MACROSCOPIC EXAMINATION OF STAINED TEETH}

\subsubsection{Benzidine test}

Figure 39 shows two teeth from Group $F$ and a control tooth from group $D$ which were subjected to the benzidine test. The blood stained teeth (Group F) responded positively, while the control tooth (Group D) remained unaltered. Although the distribution of staining following the benzidine solution remained unchanged the degree of discoloration was greater when compared to the pre-benzidine samples of teeth stained with packed red blood cells (Figure 11).

The above procedure was repeated on a decalcified tooth from Group $F$ to establish what effect decalcification might have on the blood stains. Under these conditions benzidine staining on decalcified teeth failed to 
produce a reaction (Figure 40). It was assumed that the precipitation of organic material during the decalcification reacted with the benzidine and produced a non-specific reaction.

\subsubsection{Zinc leuco test}

Figure 41 shows a representative specimen from Group F which was stained with packed red blood cells, sectioned longitudinally and when subjected to the zinc leuco test, demonstrated a positive response. The arrangement and distribution of the staining were similar to the preexisting staining except there had been a shift to a blue-green colour indicating the presence of haemoglobin. Similarly, Figure 42 demonstrates the staining in a section of tooth cut longitudinally just beyond the pulp chamber and it shows a more diffuse response to the zinc leuco stain. Conversely, teeth from group D (sterile saline) did not show any staining of the coronal or radicular dentine. However, a representative specimen from this group did show some slight uptake of the zinc leuco stain on the cementum at the mid-root level and at the apical area of the tooth (Figure 43). The uptake of zinc leuco stain in these areas was most likely a positive response to the presence of residual blood from the periodontium.

\subsubsection{Perl's test}

The application of Perl's solution to specimens from Group F which comprised teeth stained with packed red blood cells and sectioned longitudinally, failed to produce a Prussian blue colour, (Figure 44) Although a representative control specimen from Group D (sterile saline) appeared to stain lightly by a non-specific reaction in the outer 
area of the radicular dentine, this was not considered a positive reaction to the Perl's test, as the characteristic Prussian blue histochemical stain was not evident (Figure 45).

\subsection{EVALUATION OF VARIOUS AGENTS TO REMOVE THE STAINING PRODUCED BY PACKED RED BLOOD CELLS}

The changes in reflectance density over a period of one week of five tooth samples immersed in various solutions, presented in Tables 3-14, were analysed using an unbalanced repeated measures model with structured covariance (5V, BMDP Statistical Software, Inc. Sepulveda Blvd, Los Angeles, CA, USA). As a result of this analysis and selecting the average value $D 1=1.1$ for the initial reading in each treatment group, it was possible to illustrate the efficacy of the various solutions in the resultant model, Table 15. In addition, the percentage change of each bleaching solution was calculated using the formula D1-D7 $\times 100=\%$ and this is presented in Table 16. It was found that the most rapid and efficient remover of the blood products was $30 \%$ hydrogen peroxide in which a $19.8 \%$ reduction was noted. DDW demonstrated the lowest degree of change of $3.1 \%$. It was also observed that the reflectance density of the stained teeth placed in DDW, (Table 14), initally increased and only after Day 5 did the staining commence to "wash out" from the sections.

Macroscopic observation indicated that hydrogen peroxide was very effective in removing all blood stains from the specimens and sodium perborate was effective in removing most of the blood stains from the specimens. In the model under review, both hydrogen peroxide and sodium perborate demonstrated a reflectance density reading (Tables 3 
\& 4) of less than 1.0 after one week (i.e. Reflectance Density at D7 $<1.0$ ). Therefore, it was deduced that the agents under test were successful in bleaching blood pigments from a tooth only if they produced a reflection density $D 7<1.0$. The iron regulator, commercial stain remover, "HiCLEAN", saturated oxalic acid, and 1M oxalic acid solutions were very inefficient in reducing staining caused by the blood products (D7>1.0, Table 15). Not only did the "Desferal" and "Liquid Iron Chelator" treatment fail to demonstrate any ability to remove the staining from the tooth sections, but they appeared to be associated with an increase in staining after one week with an increase of $-5.7 \%$ and $-7.8 \%$ respectively (Table 16).

The "Enzymatic Cleaner" produced some reduction in the reflection density over the observation period in the blood stained samples and, although it was not as effective as hydrogen hydroxide and sodium perborate, it did demonstrate some ability to remove the blood stains. The D7 score of 1.02 for the "Enzymatic Cleaner" was very close to that which was assessed as being significant for a bleaching agent.

The greatest change in reflectance for hydrogen peroxide and sodium perborate solutions occurred after three days and, thereafter, any further changes were minimal (Tables 3 \& 4).

Tables 8 \& 9 indicate that strong concentrations of acid solutions were unsuitable for the bleaching the blood stained tooth samples as they caused demineralization of the sections and led to their eventual loss. 


\subsection{RESULTS OF THE HISTOCHEMICAL EXAMINATION OF A NON INFECTED, NECROTIC PULP FOLLOWING TRAUMA}

The pulp was prepared for normal histological preparation as outlined in APPENDIX $V$ and subjected to the same histochemical tests as the in vitro model under review. Five sections of the pulp were subjected to benzidine, zinc leuco, Perl's and Turnbull Blue histochemical tests as outlined in APPENDIX VI.

There was a positive response to the benzidine (Figure $46 \& 47$ ) and zinc leuco histochemical tests (Figure $48 \& 49$ ). The Perl's and Turnbull Blue histochemical tests (Figure $50 \& 51$ ) produced negative staining. The finding of haemoglobin and haematin molecules, and the failure to demonstrate the presence of ferric ions or haemosiderin was an identical pattern to that from the in vitro model devised in this research project. 


\subsection{FIGURES}

Figure 3:

An intra-oral photograph of a 30 year old male upon presentation to the Department of Dentistry, The University of Adelaide, complaining of a discoloured upper right central incisor at the completion of 18 months of orthodontic treatment. 


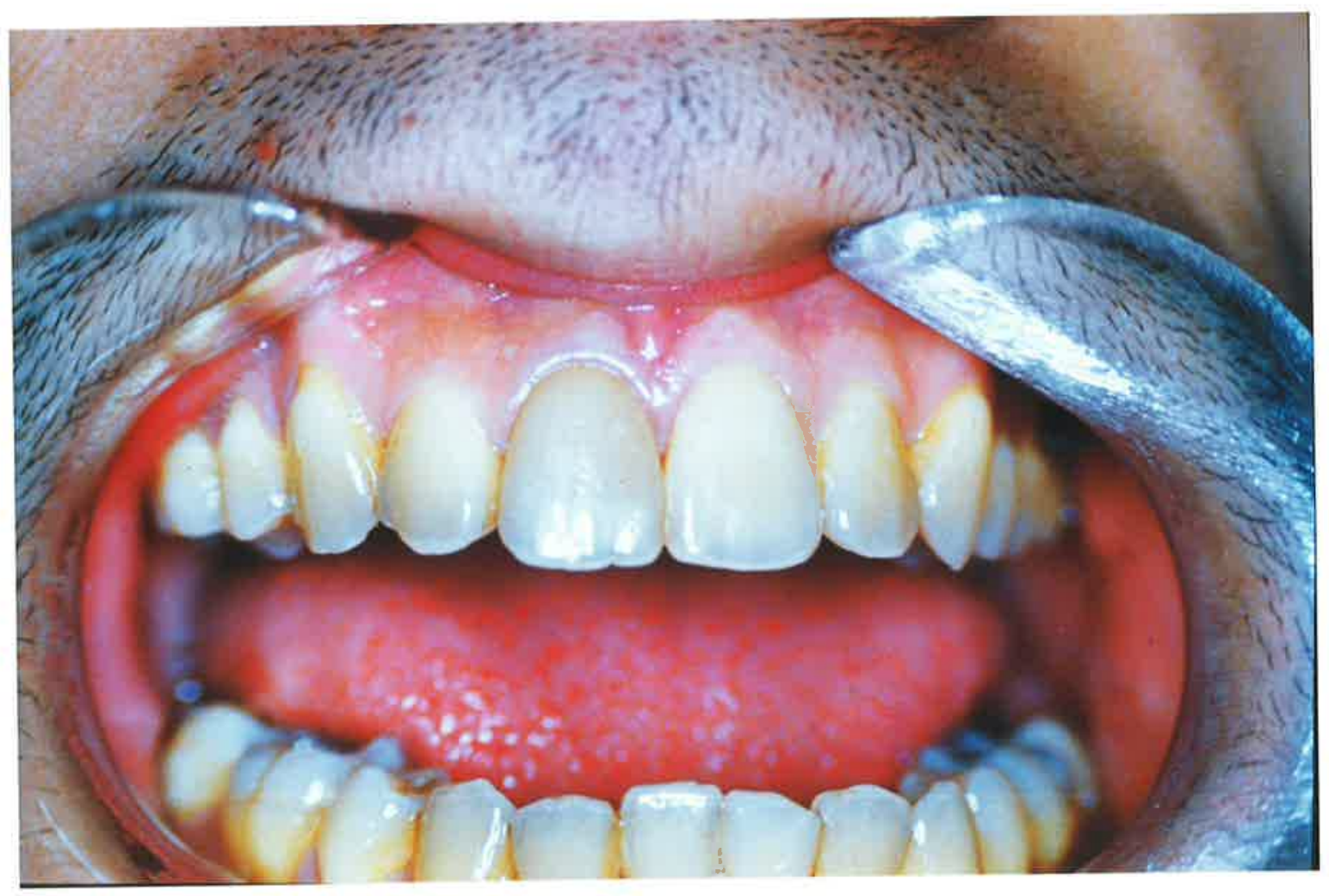


Figure 4:

Photographic presentation of two periapical radiographs, at different angulations, of the upper central incisor shown in Figure 3. This indicates that there is no periapical pathology associated with this tooth. 

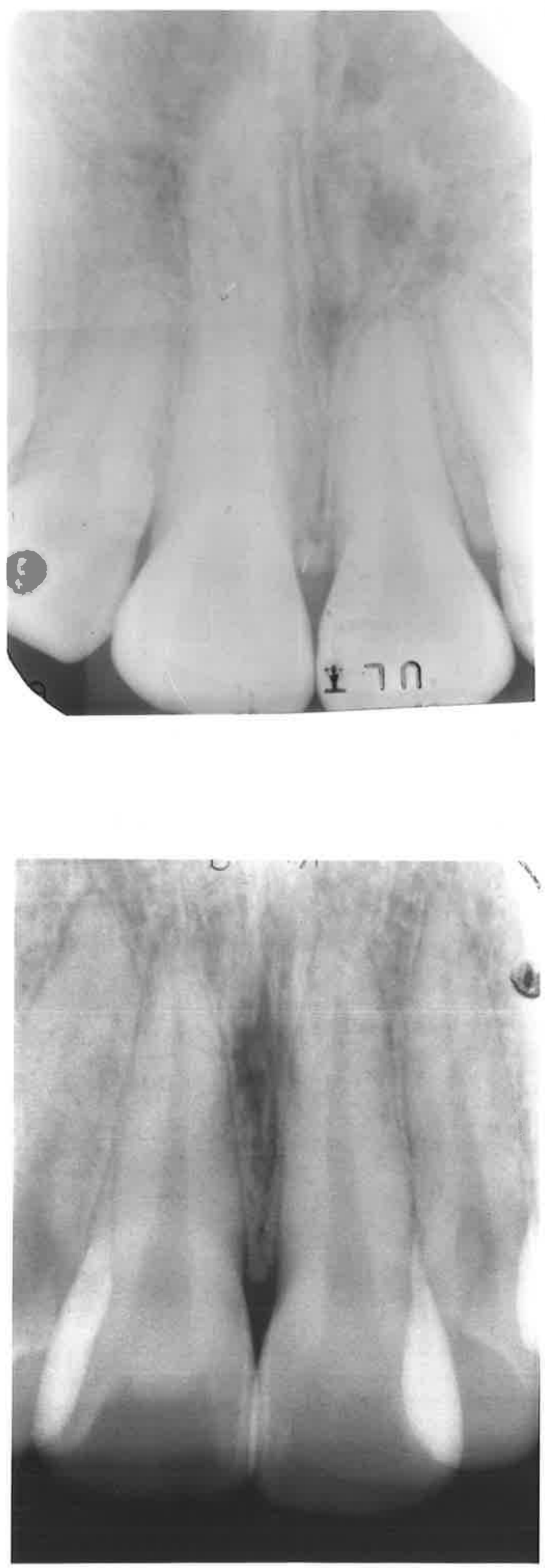
Figure 5:

Photographic presentation of a periapical radiograph of the completed root canal therapy of the upper central incisor in Figure 3 . The tooth was sealed with "AH26" and gutta-percha using a lateral condensation technique. 


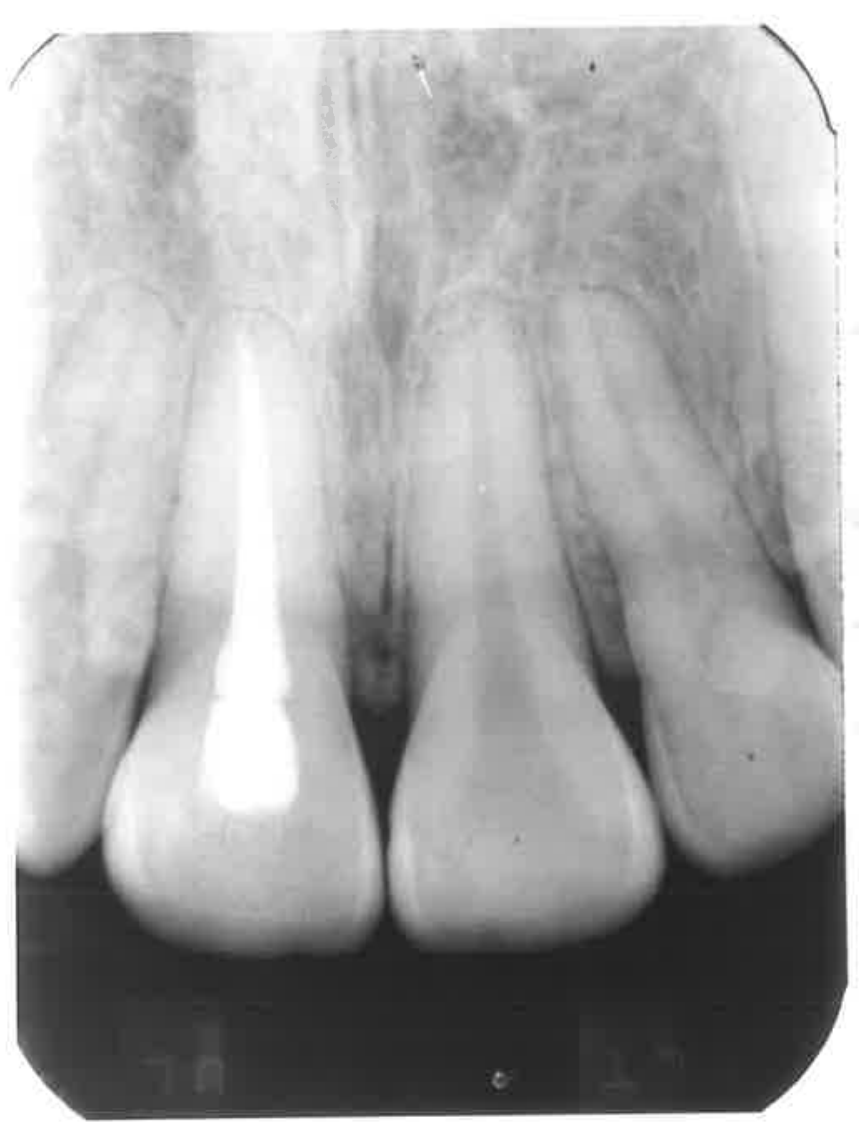


Figure 6:

An intra-oral photograph one week after bleaching the upper central incisor seen in Figure 3. The tooth was bleached using thermocatalytically activated hydrogen peroxide at the chairside and the combination "walking bleach" using hydrogen peroxide and sodium perborate. 


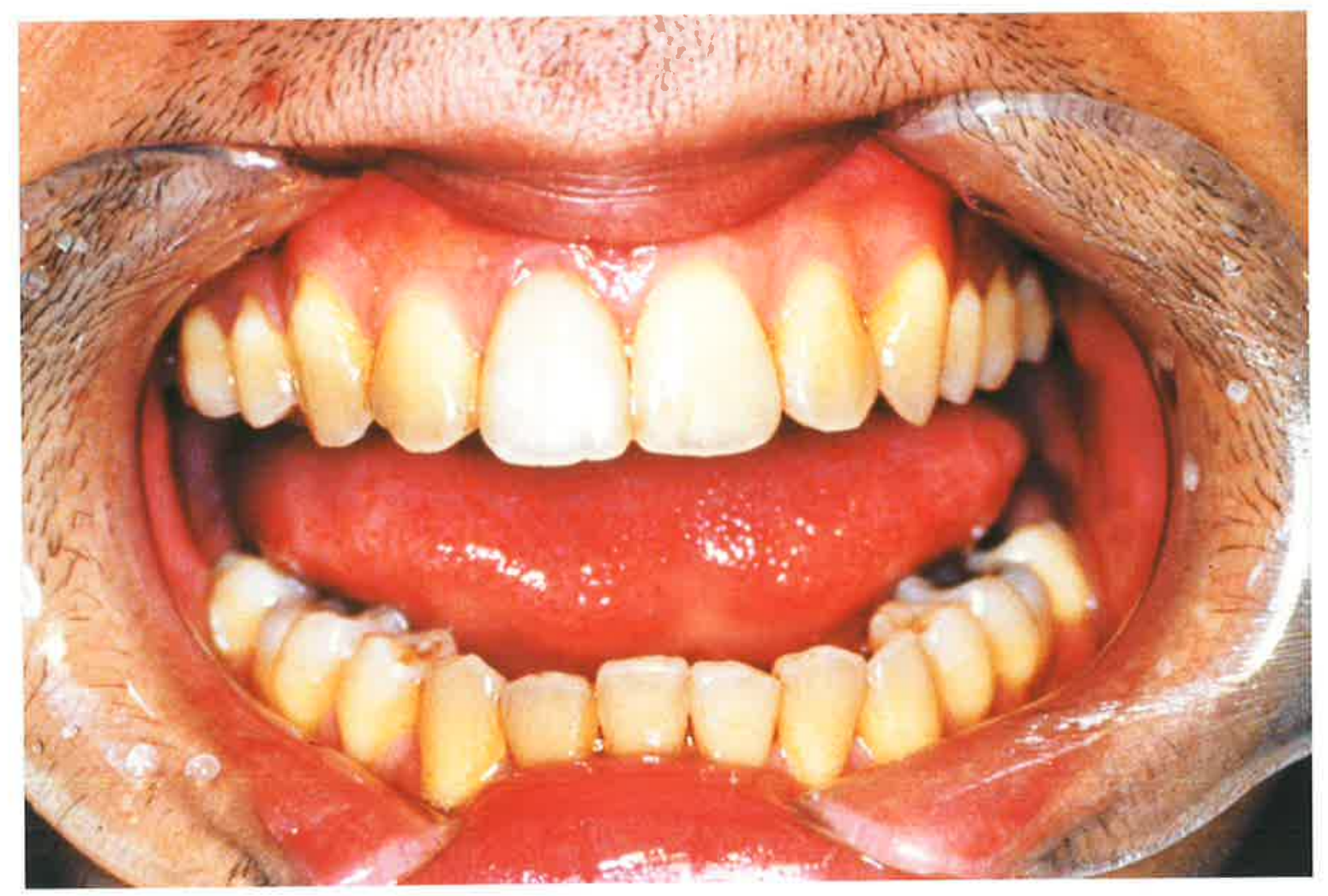


Figure 7:

Photomacrograph of representative examples of teeth demonstrating from left to right, the effect of adding sterile saline (Group D), platelet concentrate (Group B), whole blood (Group A), and packed red blood cells (Group C) to the pulp chambers of extracted premolars. Prepared as outlined in section 4.1.2 \& 4.1.3. Magnification $\times 4.5$.

All magnifications represented in the following photomacrographs refer to photographic magnification.

Figure 8:

A detailed photomacrograph comparing the addition of sterile saline (Group D) vs platelet concentrate platelets (Group B). Magnification x 5 . The platelet concentrate did not contribute to any discoloration of the tooth. 

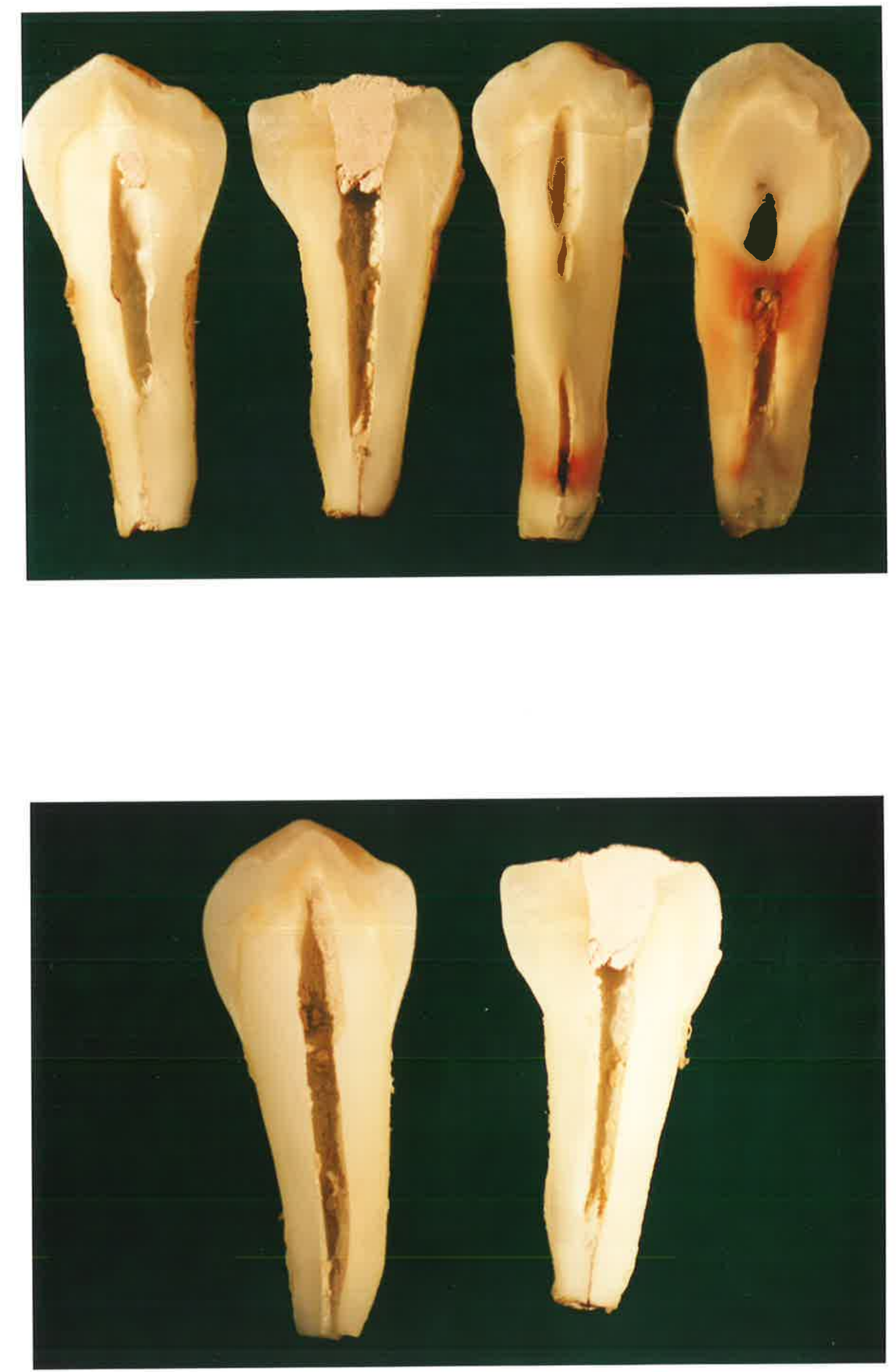
Figure 9:

Photomacrograph of the tooth in Figure 8 showing in detail the negative response after the addition of platelet concentrate and preparation as outlined in section 4.1.2 \& 4.1.3. Magnification x 5.5. 


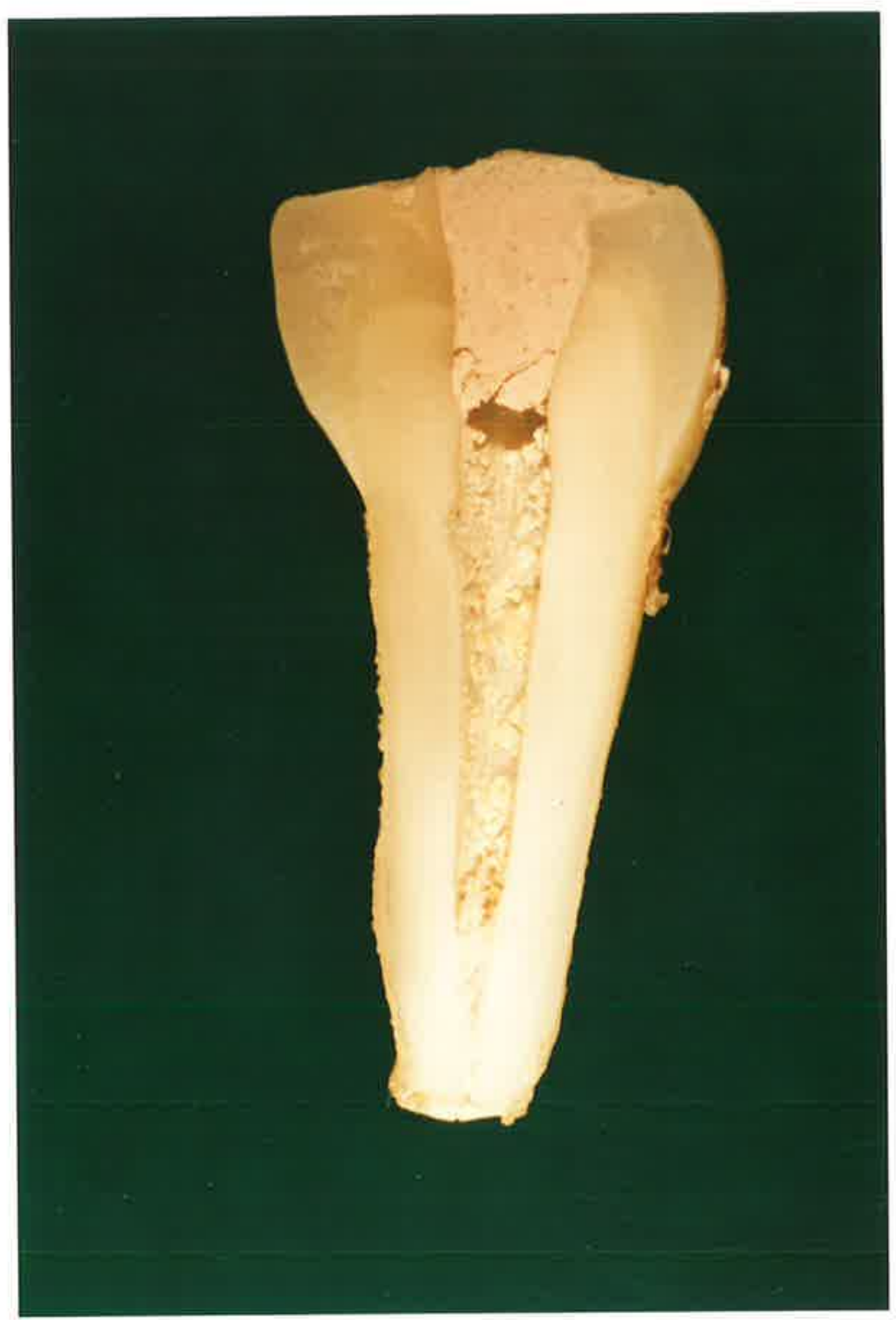


Figure 10:

Photomacrograph demonstrating representative examples of $1 \mathrm{~mm}$ longitudinal sections of three teeth in Group $F$ after the addition of packed red blood cells, and prior to fixation. Prepared as outlined in section 4.5. Magnification x 4.5.

Figure 11:

Photomacrograph demonstrating representative examples of four teeth prepared as in Figure 10, after fixation in a $10 \%$ solution of neutral buffered formalin. The tooth discoloration darkened after fixation. Magnification x 4.5 . 
Figure 12:

Photomacrograph demonstrating a representative specimen of a tooth in detail after the addition of packed red blood cells (Group F), and prior to fixation. Prepared as outlined in section 4.5. Magnification $\times 7.5$. 


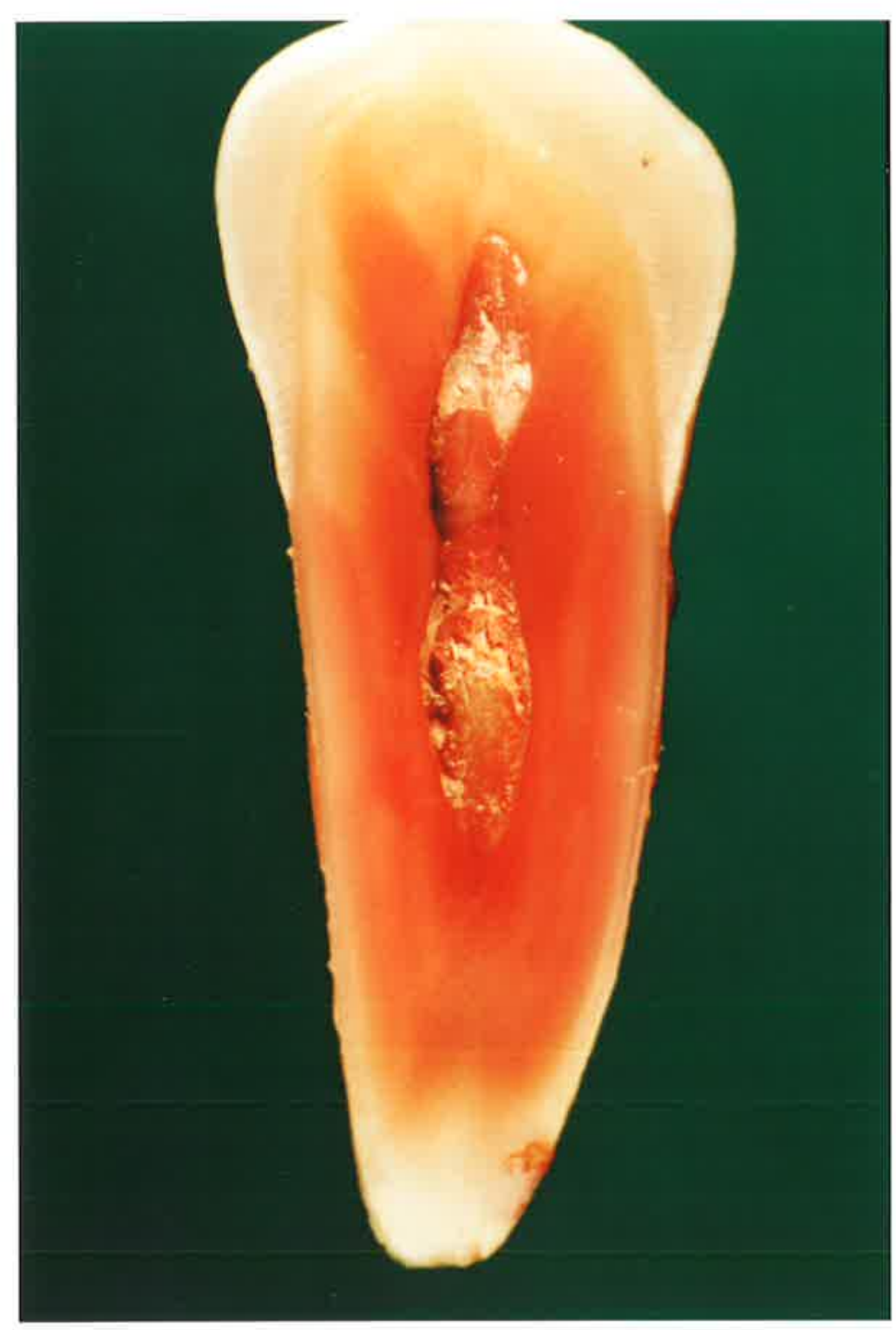


G. EE.

E. E2

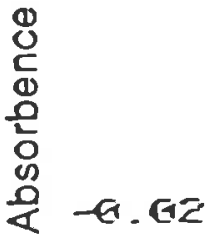

-E. EE.

$4 G G$

sGe

E.GG

TEG

Wavelength $(\mathrm{nm})$

Figure 13: Visible spectrum of acid-EDTA prior to, and after use, as a decalcifying agent for stained teeth. 
$1.4 E$

1. $4 E$.

G. 94

E. 54

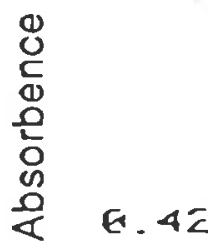

E. 4 Z

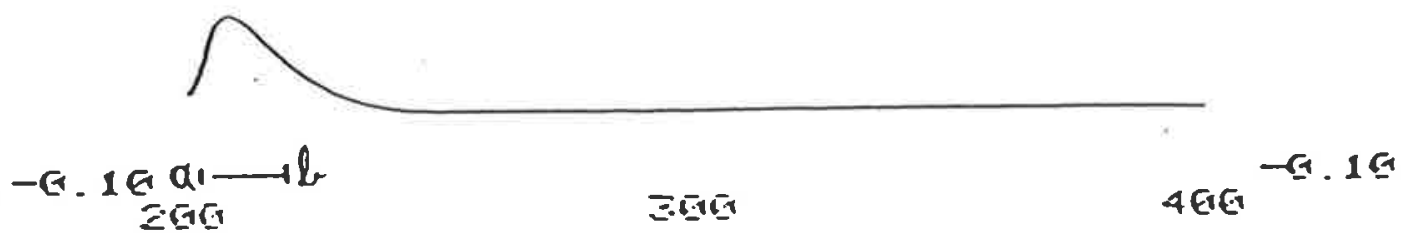

Wavelength $(\mathrm{nm})$

Figure 14: UV spectrum of acid-EDTA prior to, and after use, as a decalcifying agent for stained teeth. 
E. EE

G. GE

$-6.6 \geq$

- E. GE

Wavelength $(\mathrm{nm})$

Figure 15: Visible spectrum of EDTA-cacodylate solution prior to, and after use, as a decalcifying agent for stained teeth. 
1.78

1. $5 E$

1. 14

1.14

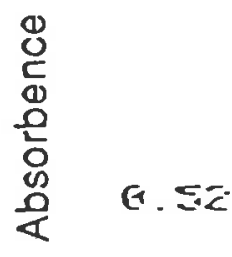

G. $5 \equiv$

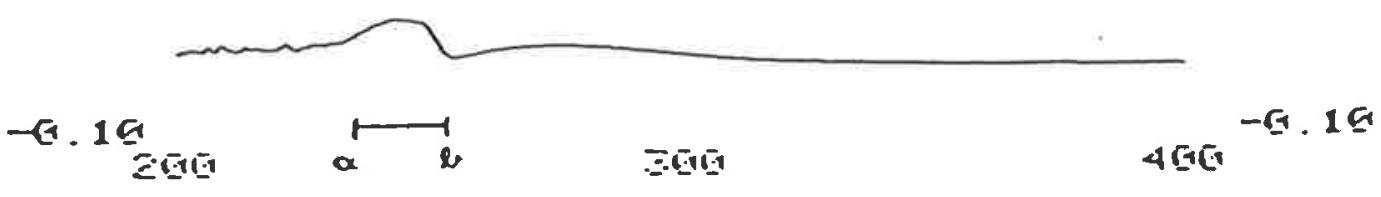

Wavelength $(\mathrm{nm})$

Figure 16: UV spectrum of EDTA-cacodylate solution prior to, and after, use as a decalcifying agent for stained teeth. 
E. 19

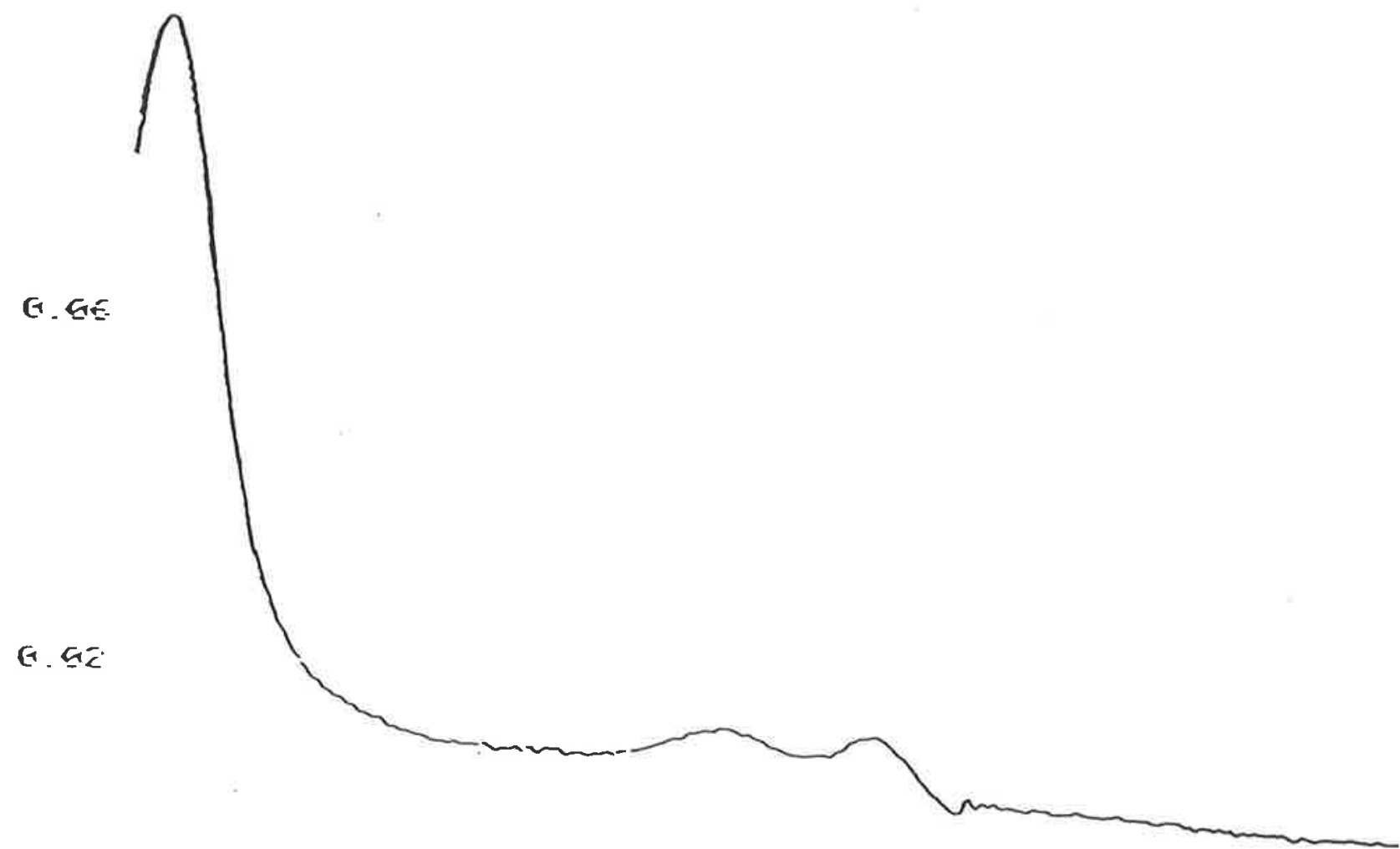

$-G .62$

Wavelength (nm)

Figure17: Acid-EDTA with the addition of 1:10,000 volumes of haemolysed packed red blood cells. 
G. E1Z

E. EG4

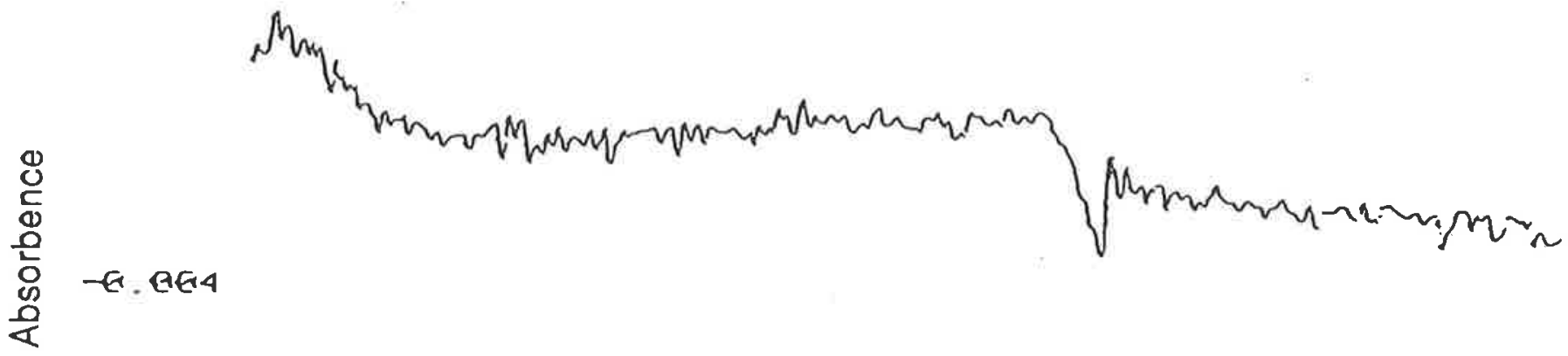

- G. G12

46

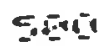

600

-

Wavelength $(\mathrm{nm})$

Figure 18: Acid-EDTA with the addition of 1:100,000 volumes of haemolysed packed red blood cells. 
Figure 19:

Photomacrograph of three teeth from Group F stained with packed red blood cells, prepared as outlined in section 4.5 and then decalcified with acid-EDTA solution. The degree and distribution of staining were similar to the appearance before decalcification. Magnification $\times 4.5$. 


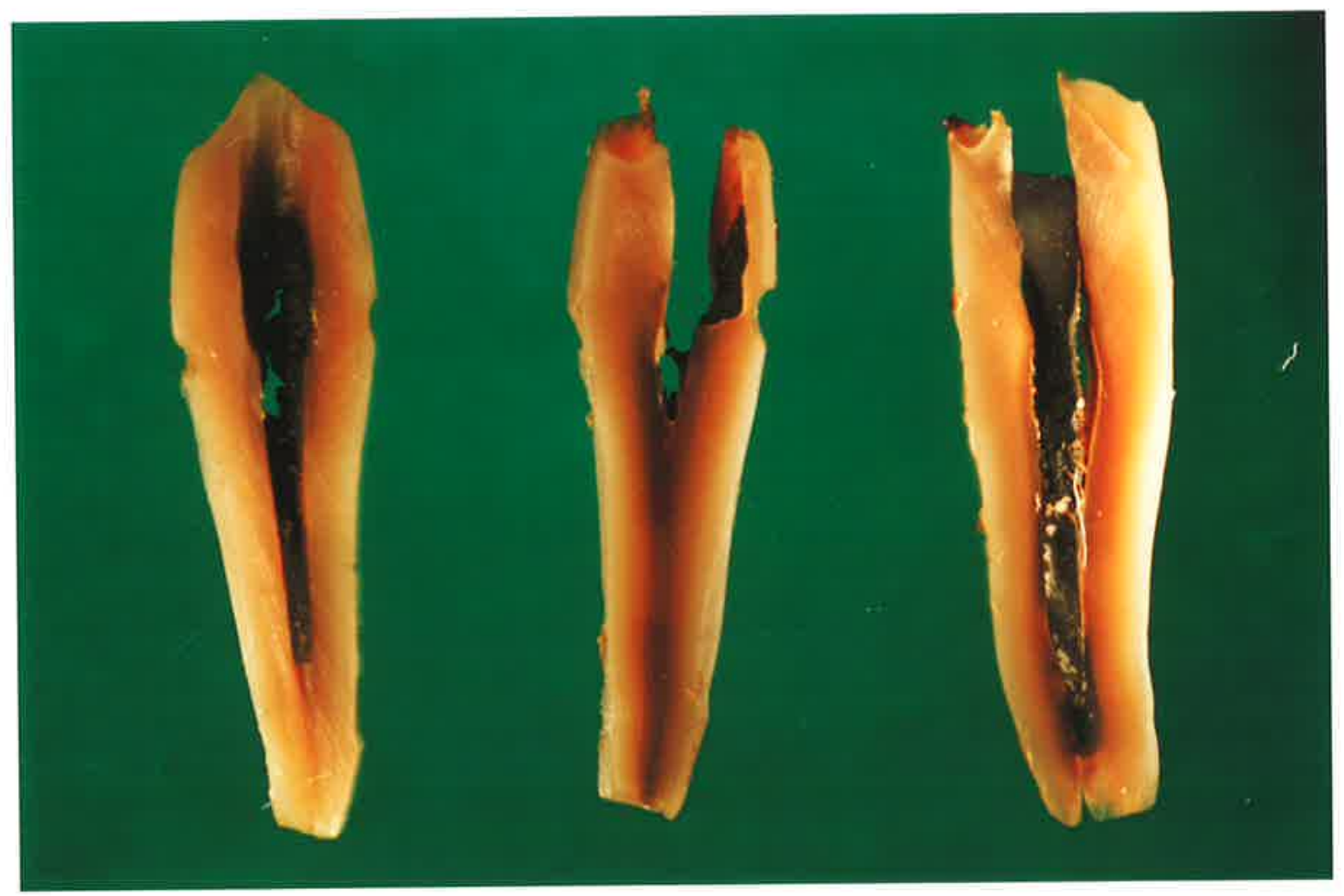


Figure 20:

A representative photomicrograph of a tooth from Group $E$ stained with packed red blood cells and demonstrating a positive response to the benzidine histochemical test. Magnification $\times 20$.

All magnifications represented in the following photomicrographs refer to photographic magnification.

All histological specimens in Figures 20 to 38 were from Group E, prepared as outlined in section 4.4 and counterstained with nuclear fast red. 


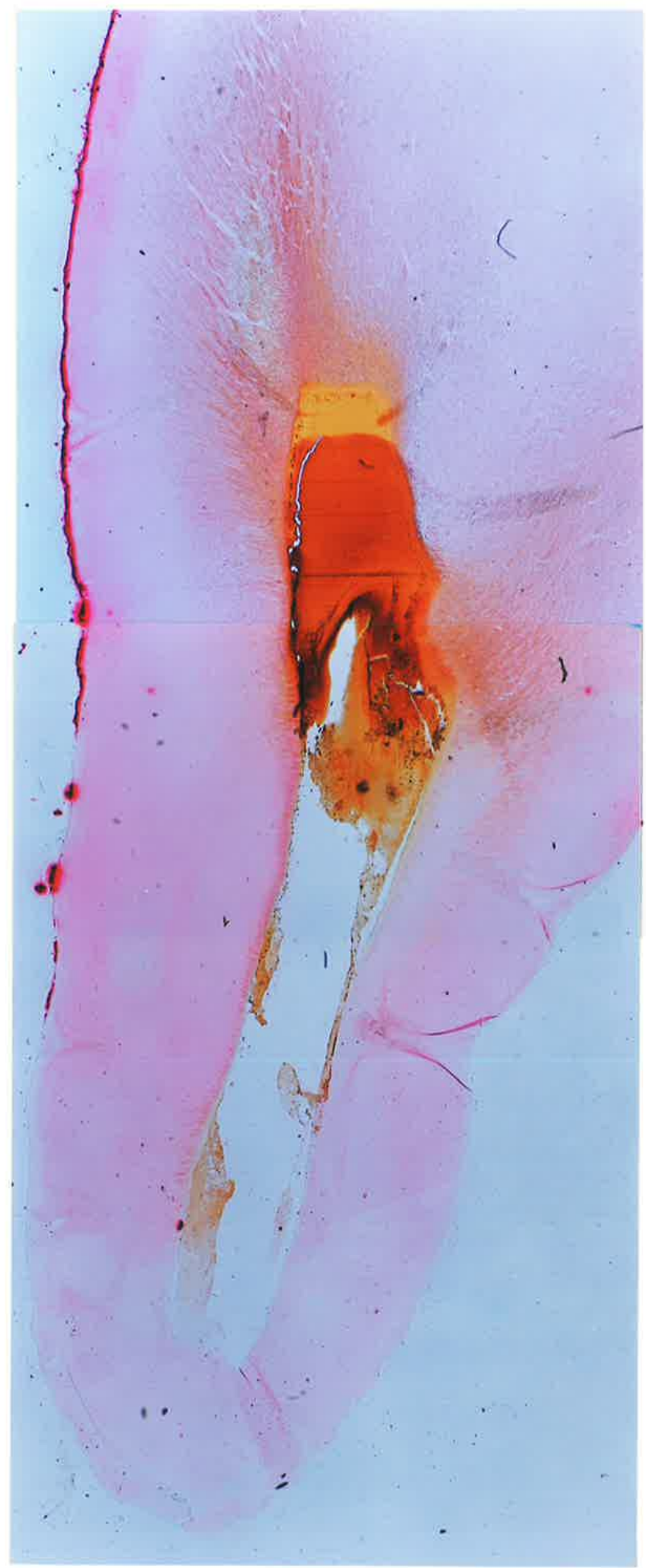


Figures 21:

Photomicrograph showing detail of the coronal dentine in Figure $\mathbf{2 0}$ and displaying the degree and distribution of a positive response to the benzidine histochemical test. Magnification x 93 . 


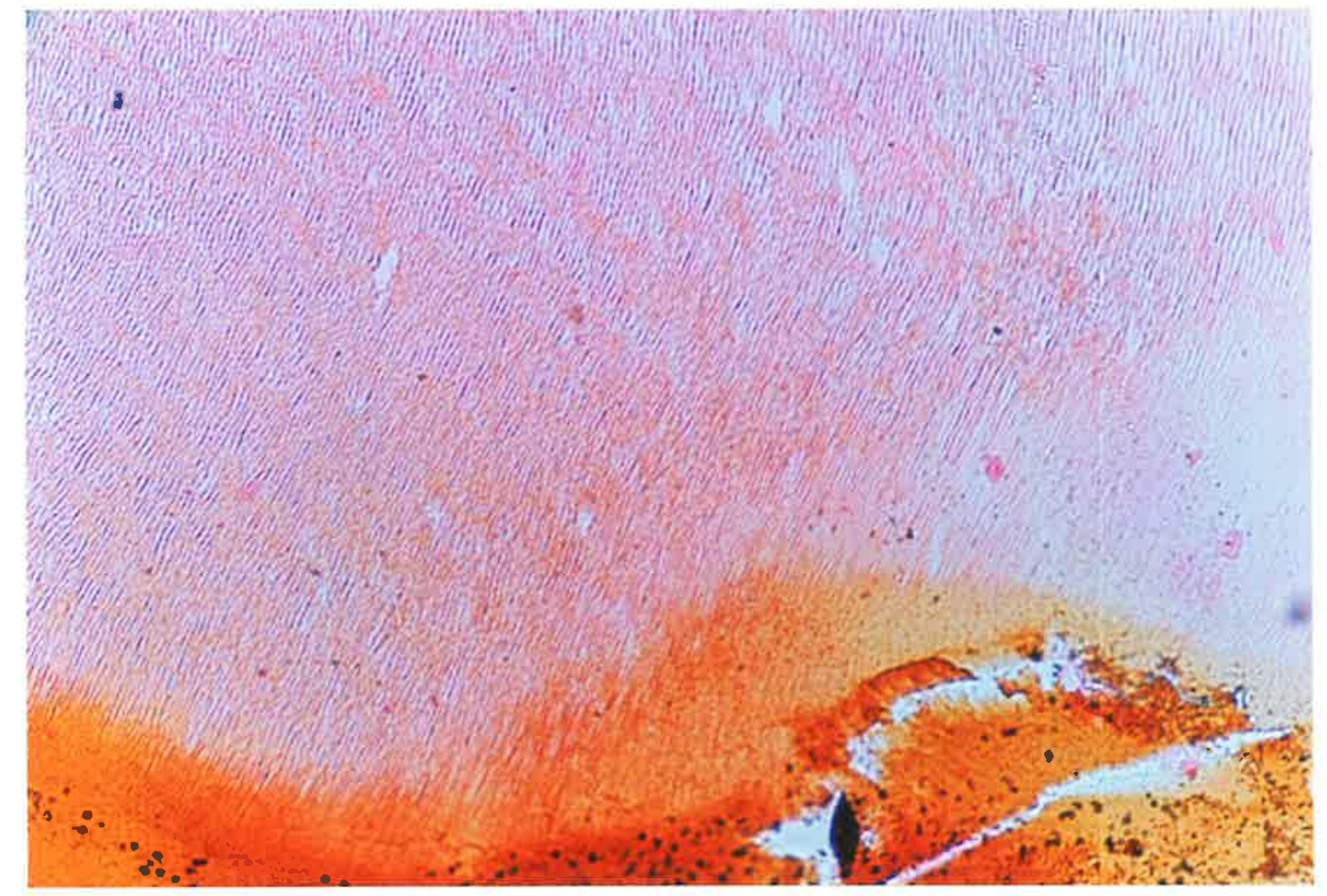


Figures 22:

Photomicrograph showing detail of the coronal dentine of Figure 20 and displaying the degree and distribution of a positive response to the benzidine histochemical test. Magnification $\times 93$. 


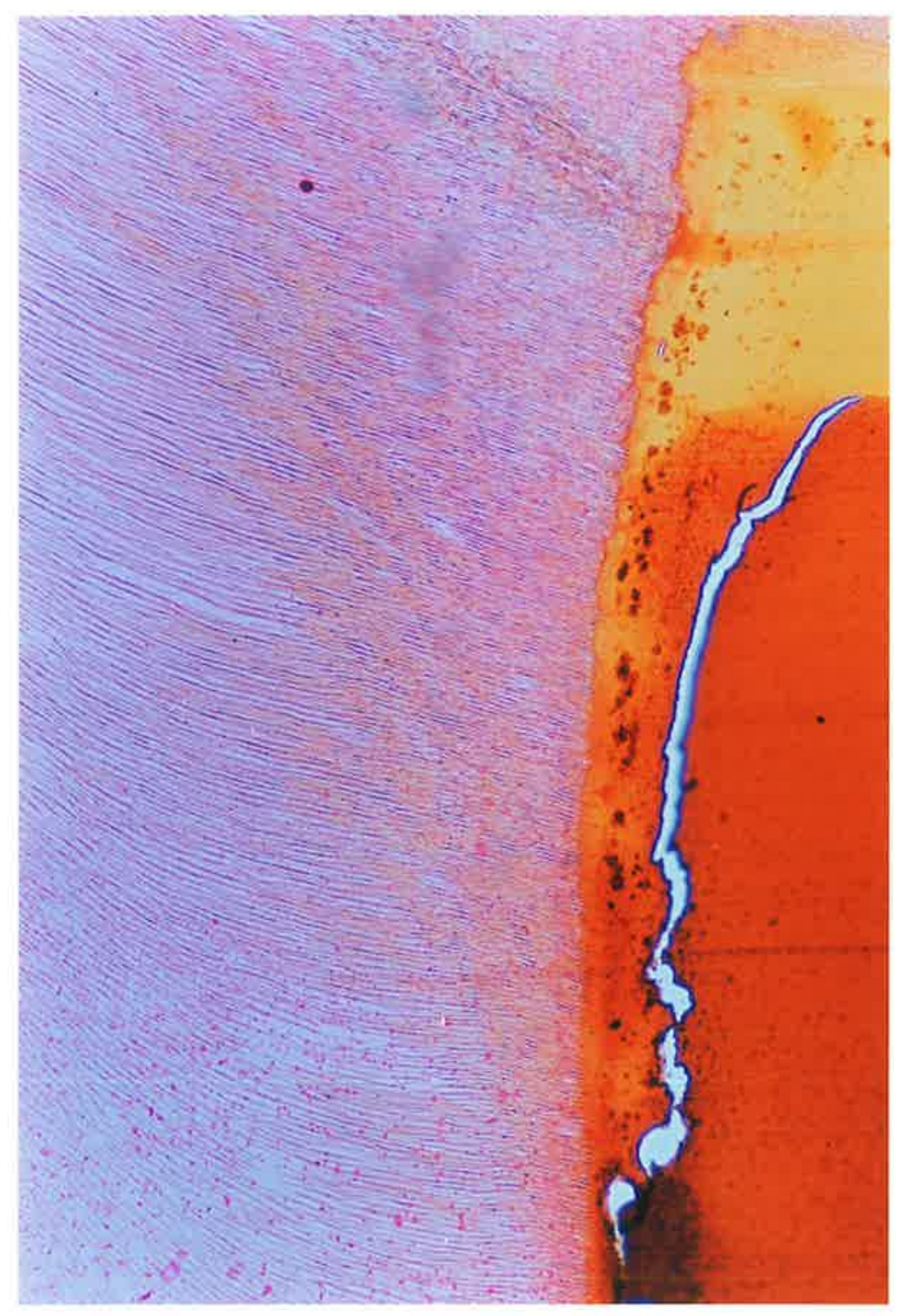


Figure 23:

Photomicrograph showing detail of Figure 22. Magnification x188. 


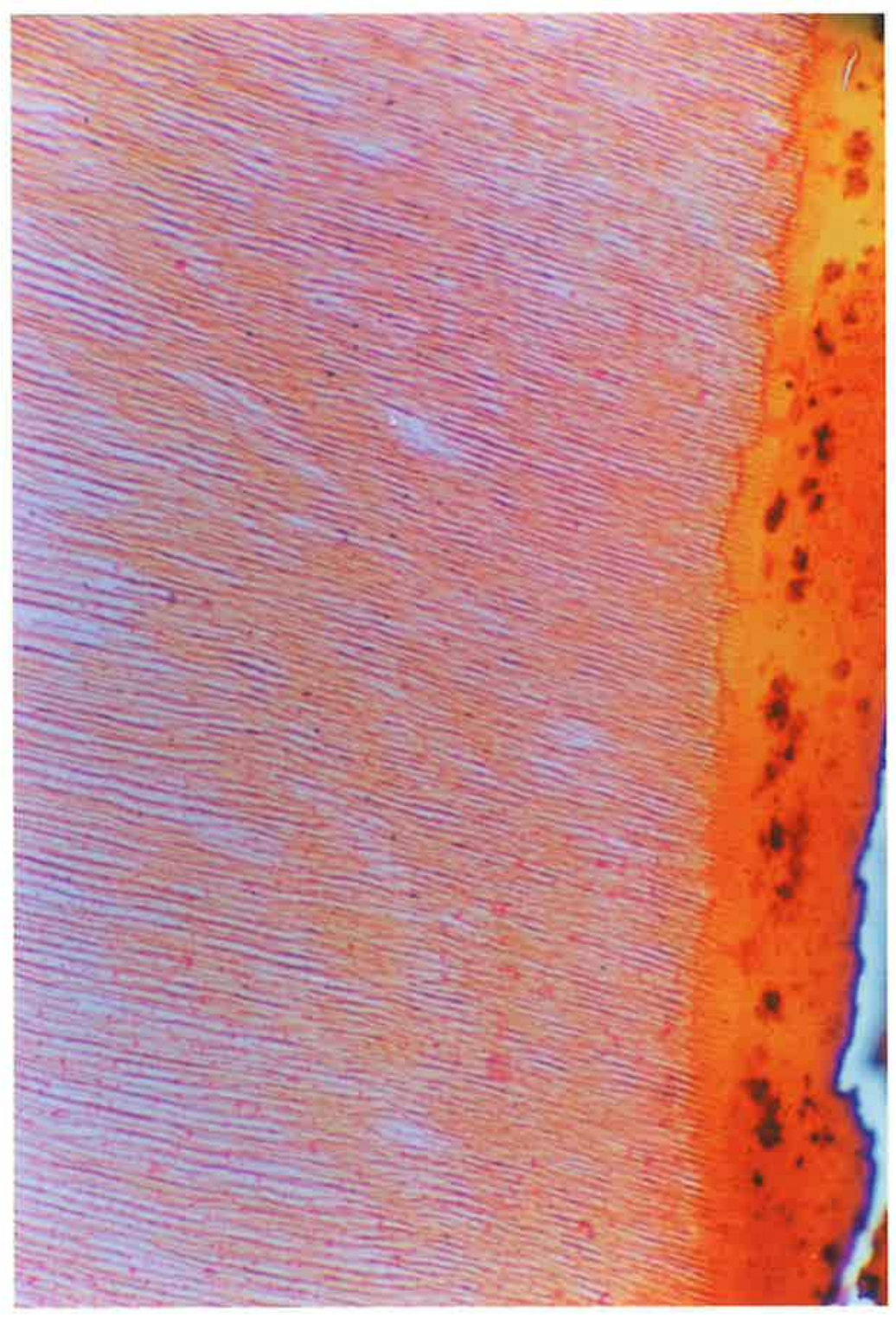


Figure 24:

Photomicrograph demonstrating a positive response to the benzidine histochemical test and showing detail of the structure and arrangement of the dentinal tubules packed with haematin compounds. Magnification $\times 375$. 


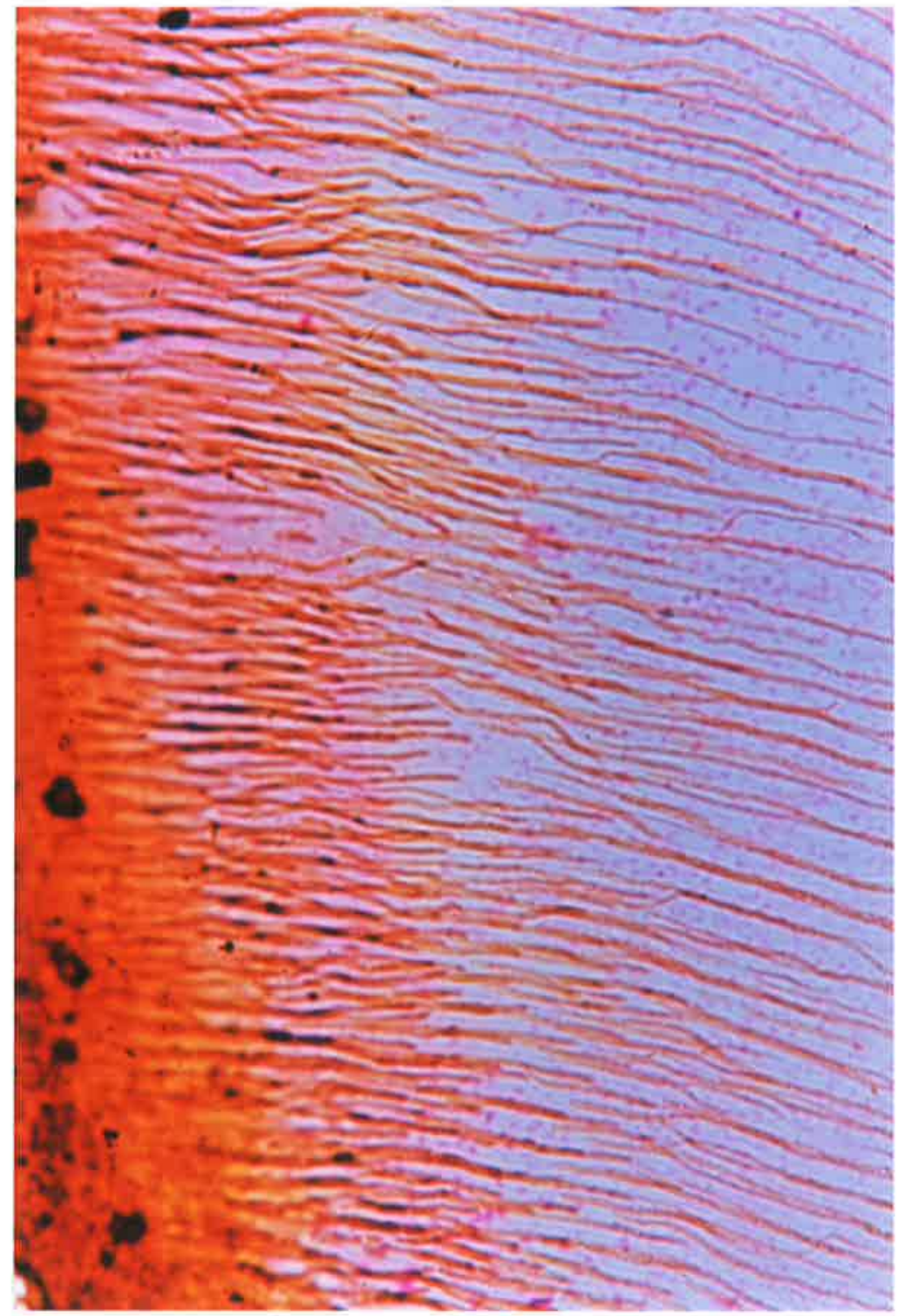


Figure 25:

Photomicrograph demonstrating a positive response to the benzidine histochemical test and showing detail of the varying arrangement of the dentinal tubules packed with haematin compounds. It can be seen that haematin is located within the tubules and not in the intertubular space. Magnification x 375 . 


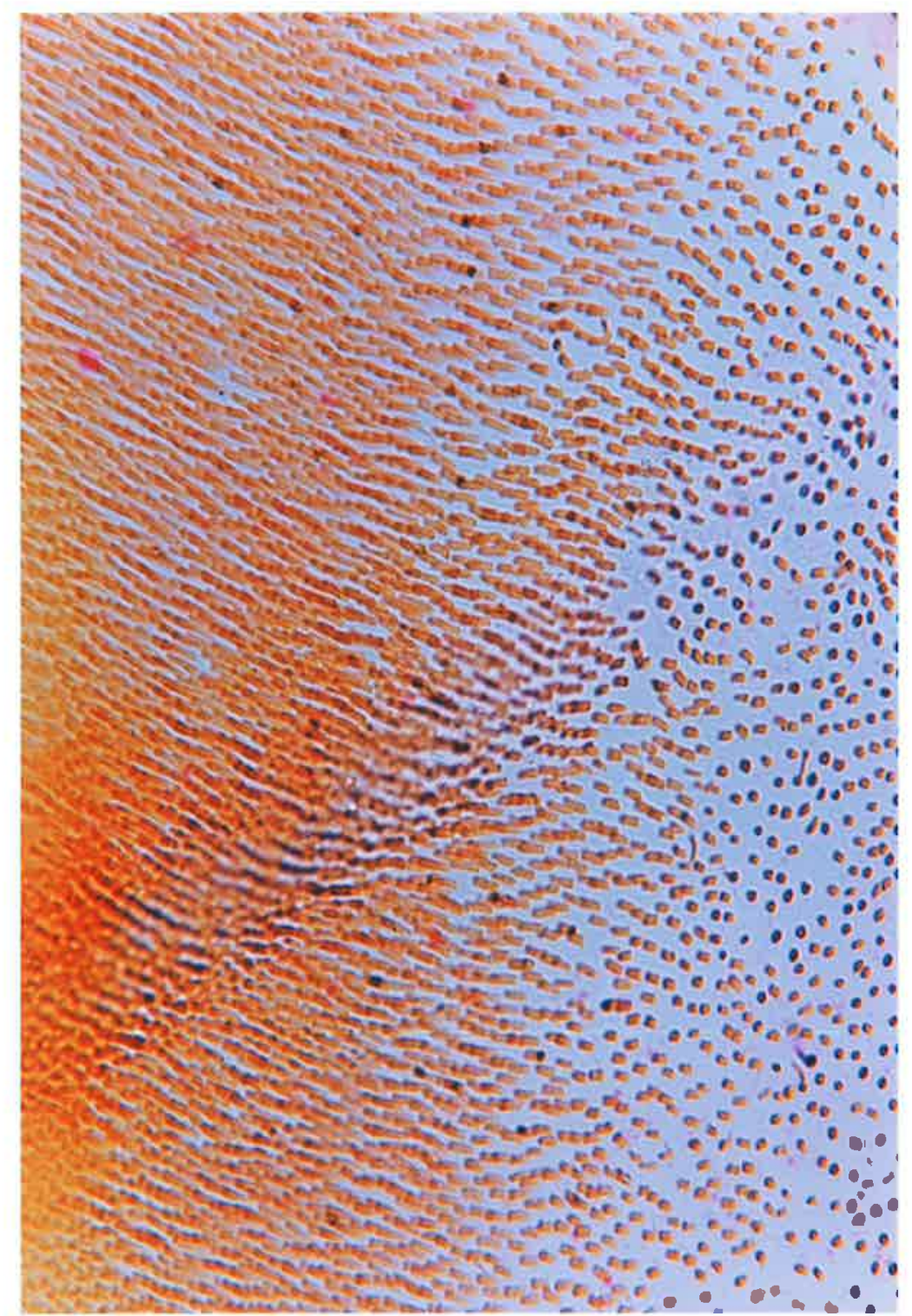


Figure 26:

A representative photomicrograph of a tooth stained with packed red blood cells and demonstrating a positive response to the zinc leuco histochemical test. Magnification x 20 . 


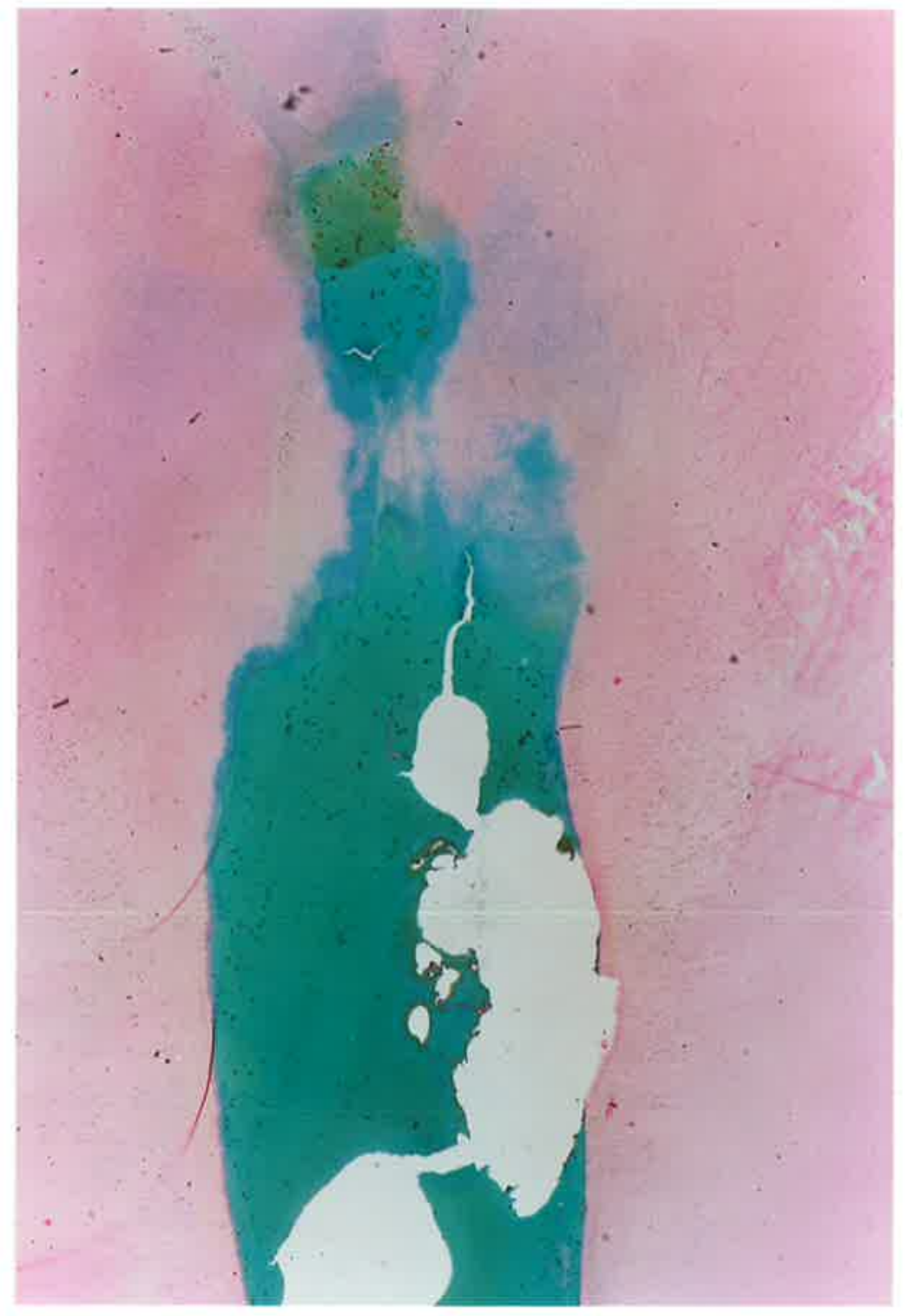


Figure 27:

Photomicrograph showing detail of Figure 26 and demonstrating the diffuse nature of the zinc leuco histochemical staining. Magnification $\times 38$ 


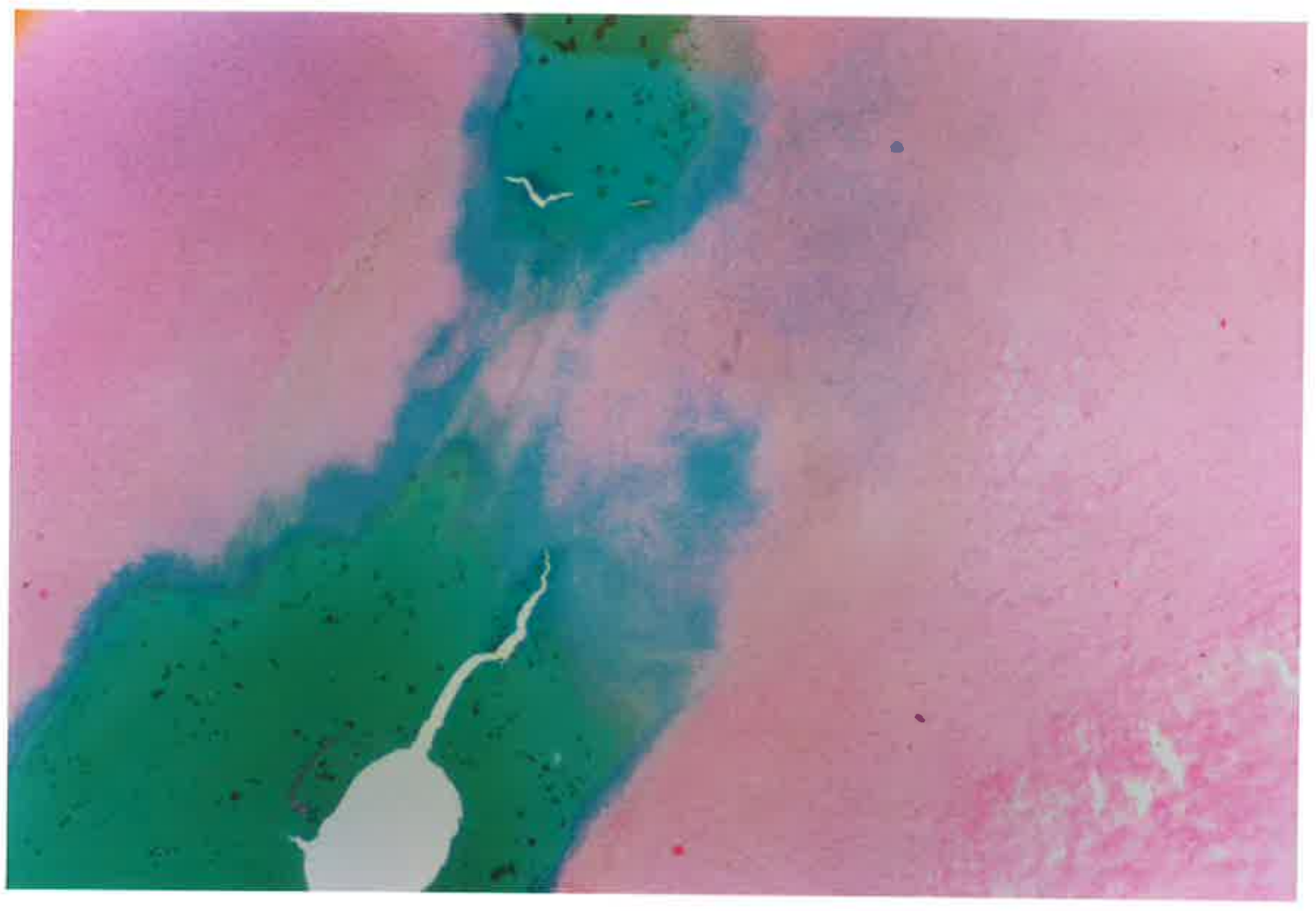


Figure 28:

Photomicrograph showing in detail the coronal dentine in Figure 27 and demonstrating the degree and distribution of the positive response to the zinc leuco histochemical test. Magnification $\times 93$. 


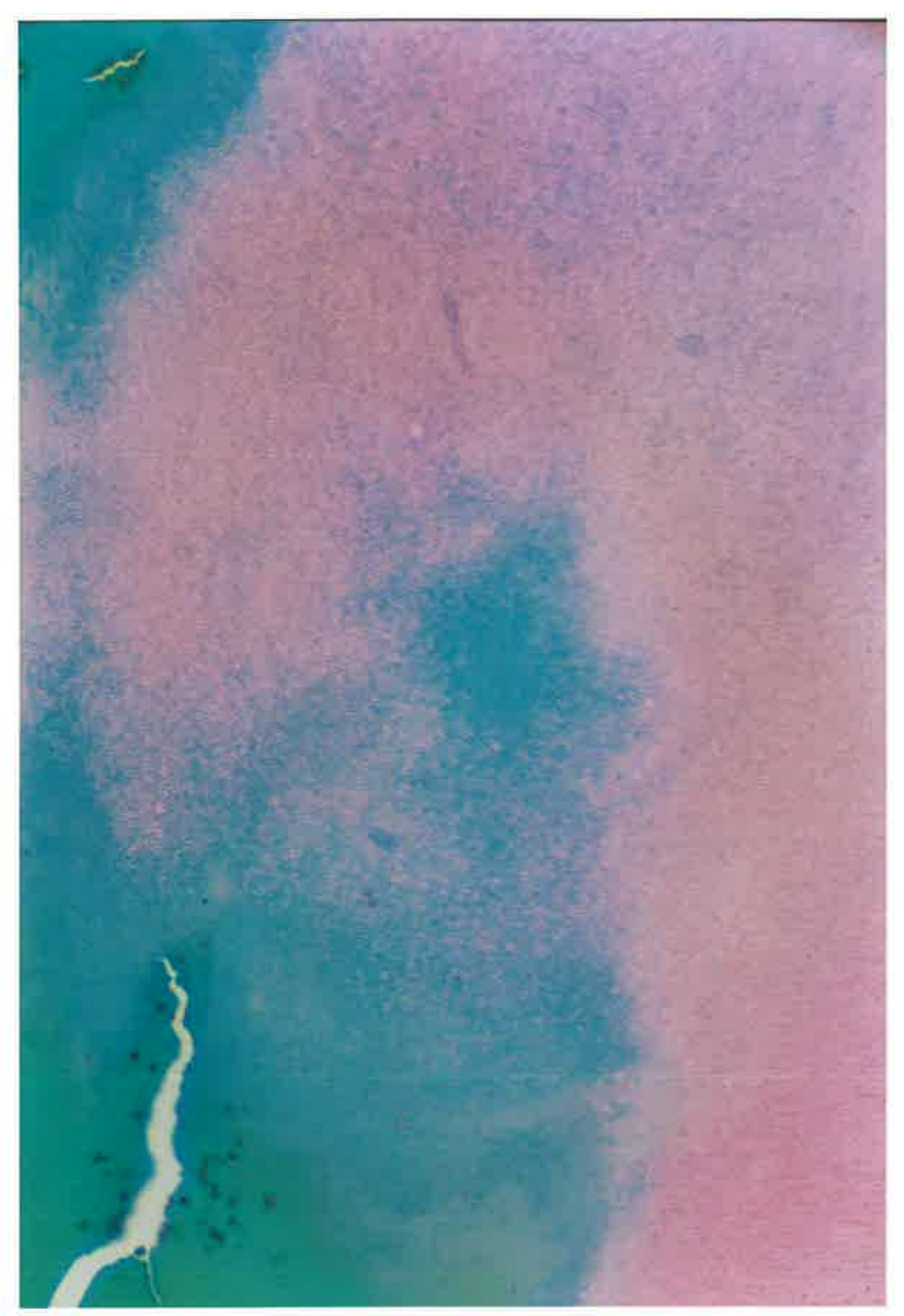


Figure 29:

Photomicrograph showing in detail another view of the coronal dentine in Figure 27 and demonstrating the degree and distribution of the positive response to the zinc leuco histochemical test. Magnification x 93 . 
Figure 30:

Photomicrograph from Figure 29 showing greater detail. Magnification $\times 188$. 


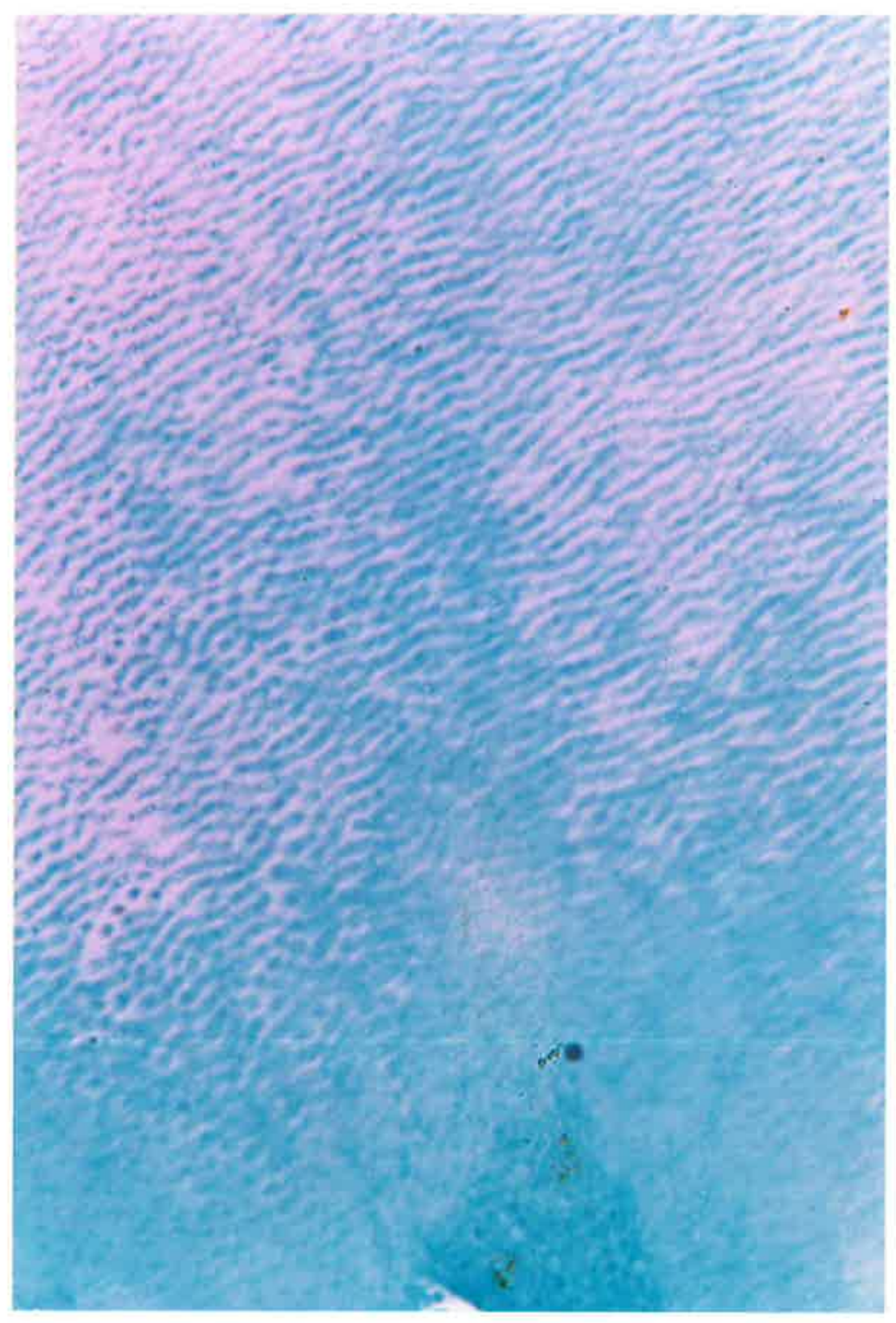


Figure 31:

Photomicrograph demonstrating in detail a positive response to the zinc leuco histochemical test and showing the structure and arrangement of the dentinal tubules packed with haemoglobin. Magnification $\times 188$. 


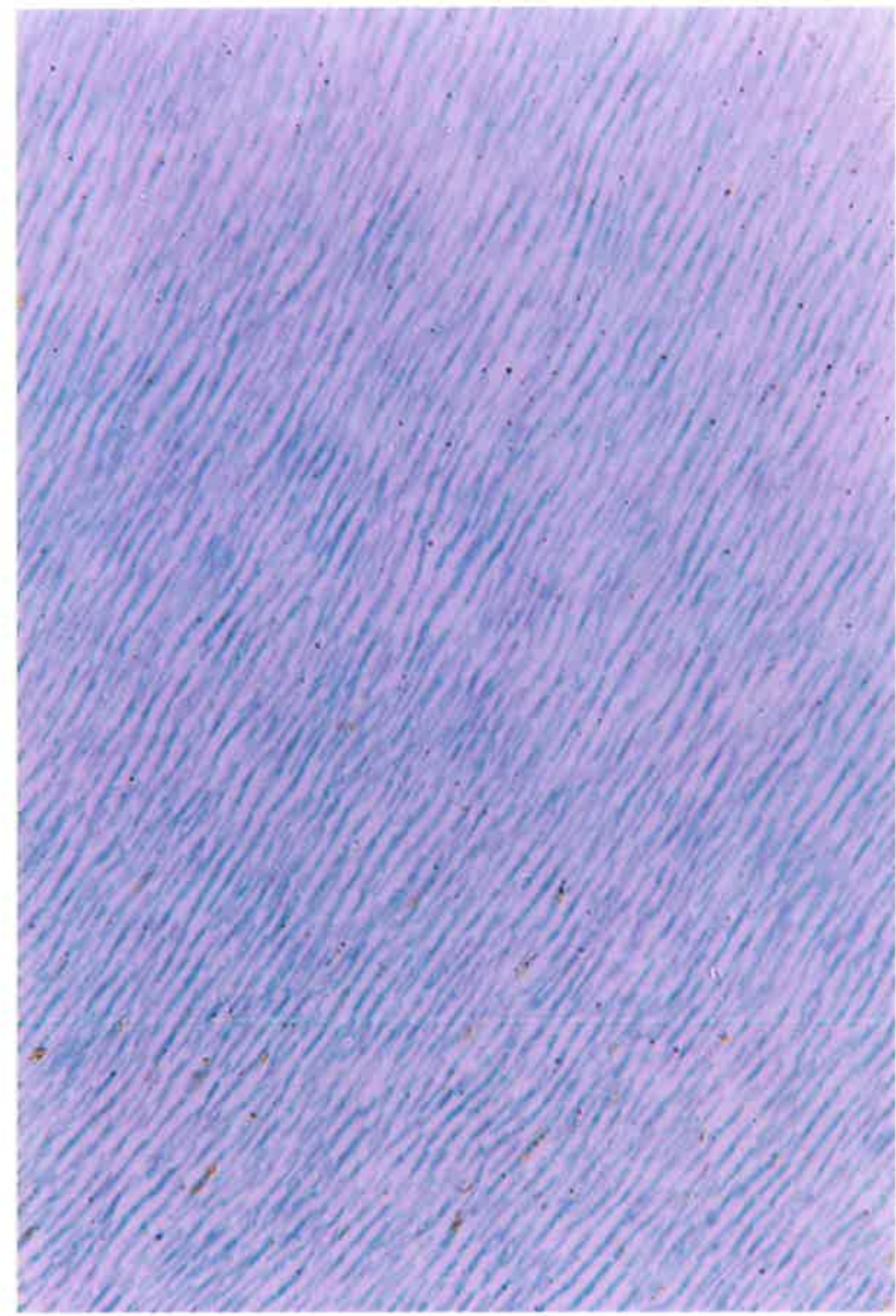


Figure 32:

Photomicrograph showing higher magnification of Figure 29. It demonstrates a positive response to the zinc leuco histochemical test and indicates that the haemoglobin is located within the dentinal tubules and not in the intertubular dentine. Magnificaton $\times 375$. 
Figure 33:

Photomicrograph of a representative tooth stained with packed red blood cells and demonstrating a negative response to the Perl's histochemical test. Magnification x 20 . 


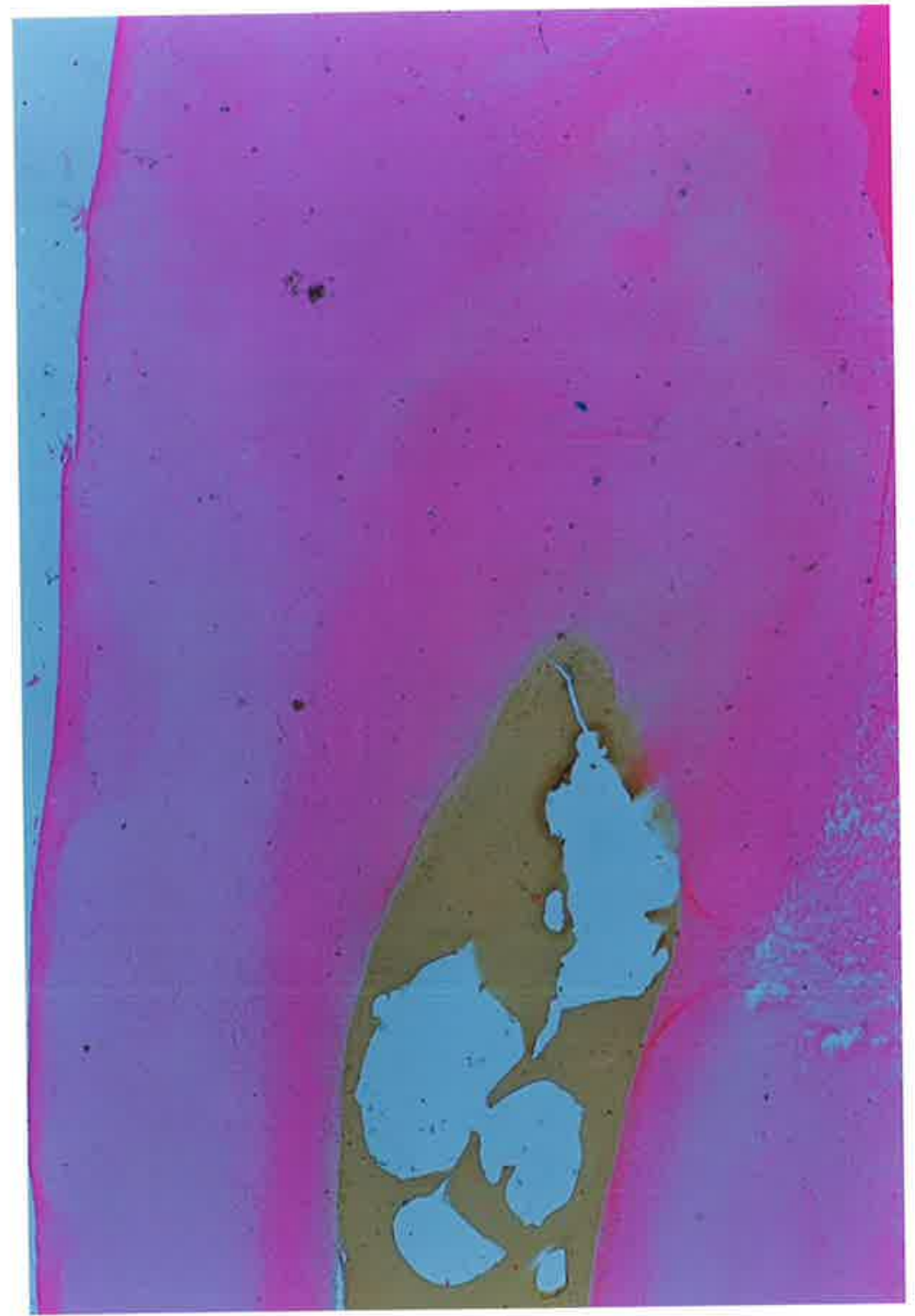


Figure 34:

Photomicrograph showing detail from Figure 33 and demonstrating a negative response to the Perl's histochemical test. Magnifiation $\times 93$. 


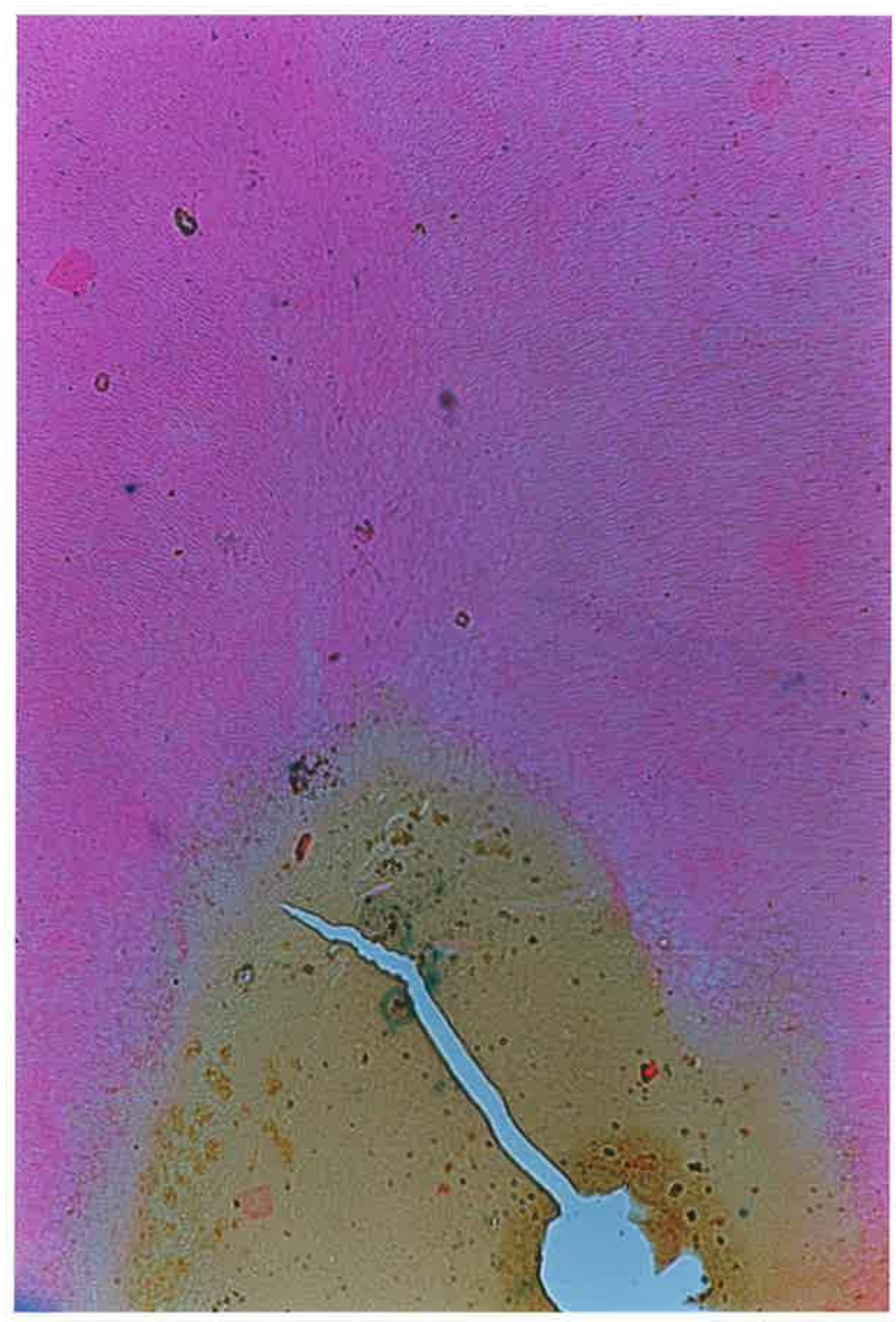


Figure 35:

Photomicrograph showing detail of another tooth stained with packed red blood cells and demonstrating a negative response to the Perl's histochemical test. Magnification $\times 188$. 
Figure 36:

Photomicrograph showing higher magnification of Figure 34 displaying blood products within the dentinal tubules and testing negative to the Perl's histochemical test. Magnification x 375 . 


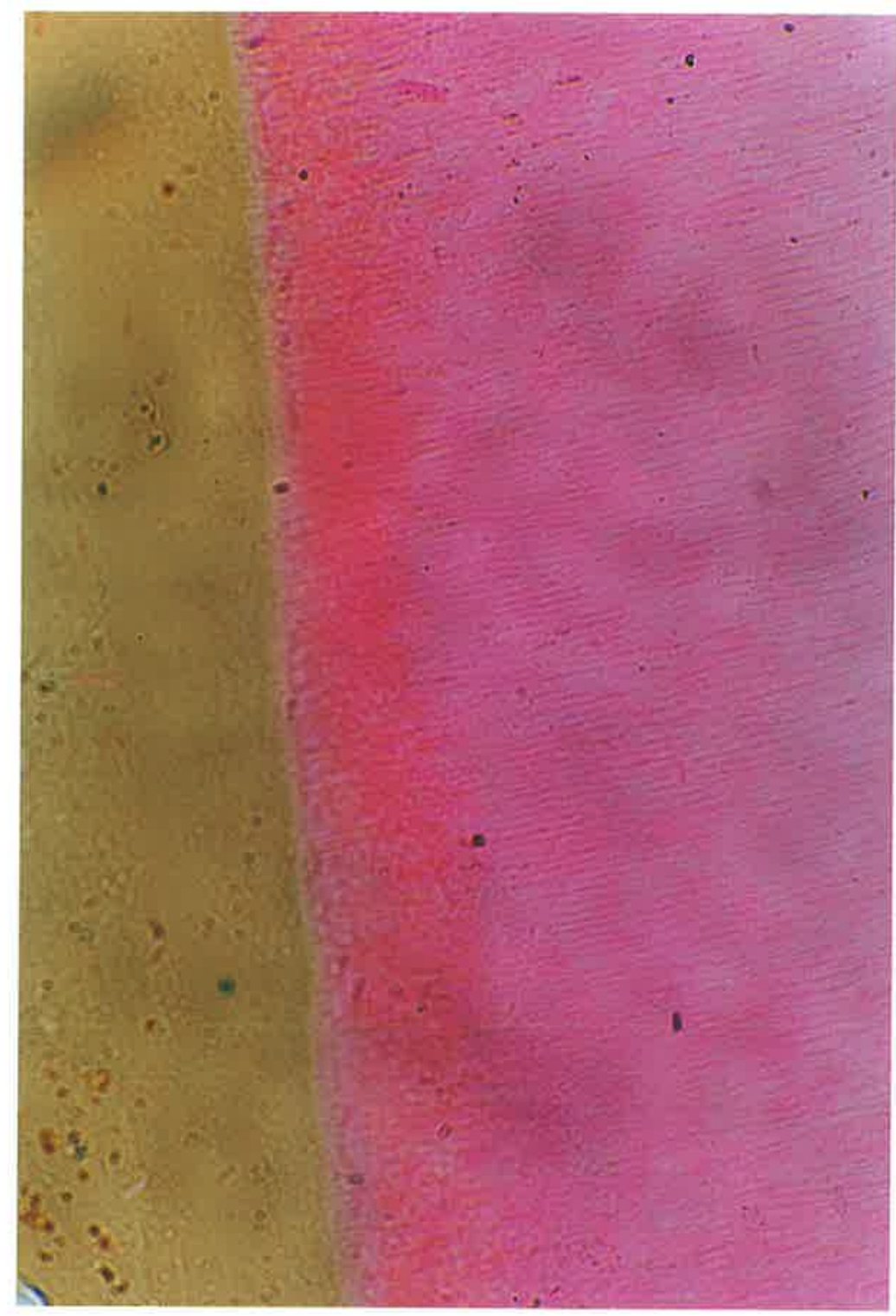


Figure 37:

Photomicrograph of a representative tooth stained with packed red blood cells and demonstrating a negative response to the Turnbull Blue histochemical test. Magnification x 20 . 


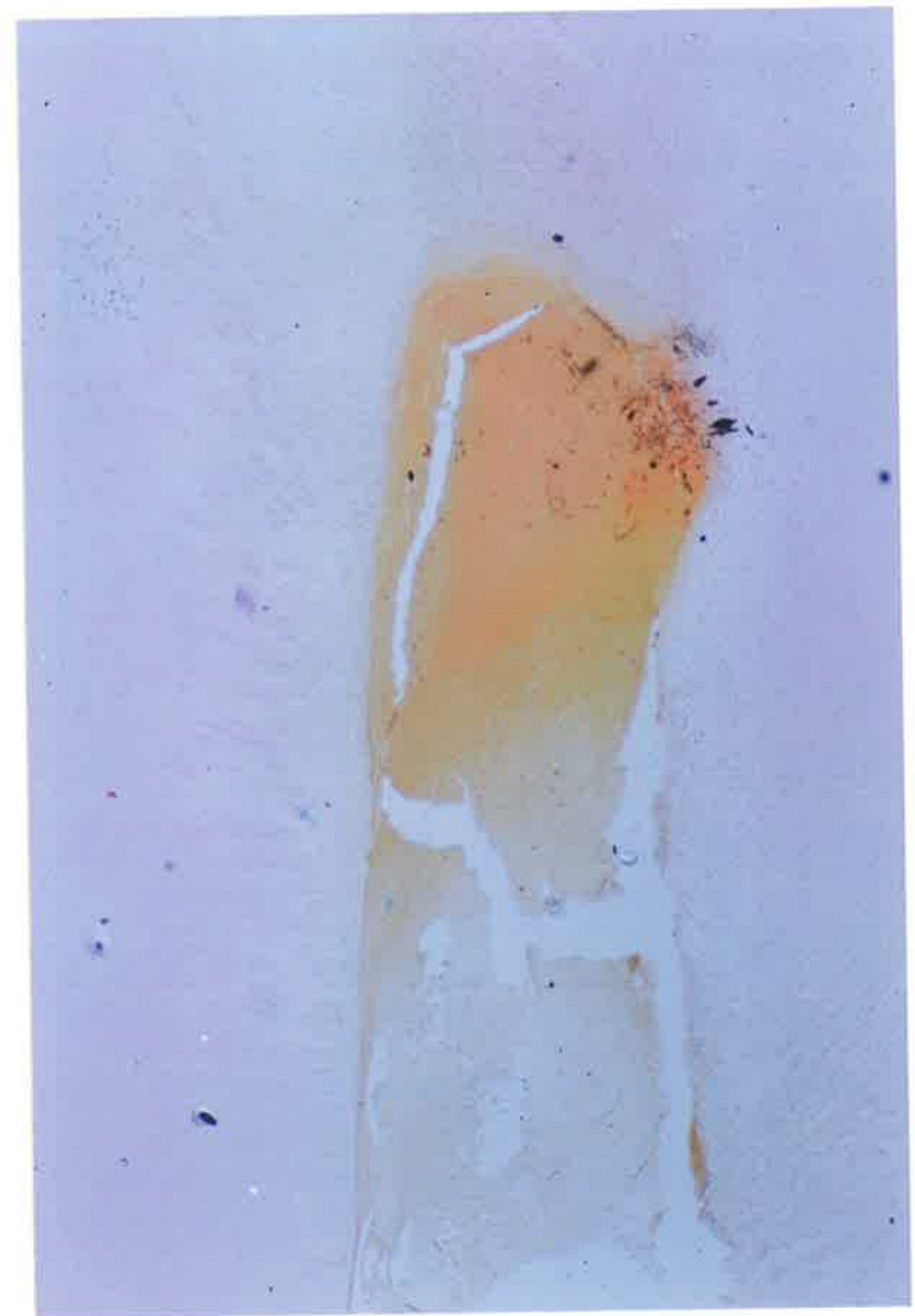


Figure 38:

Photomicrograph showing detail of Figure 37 and demonstrating a negative response to the Turnbull Blue histochemical test. Magnification x 93 . 


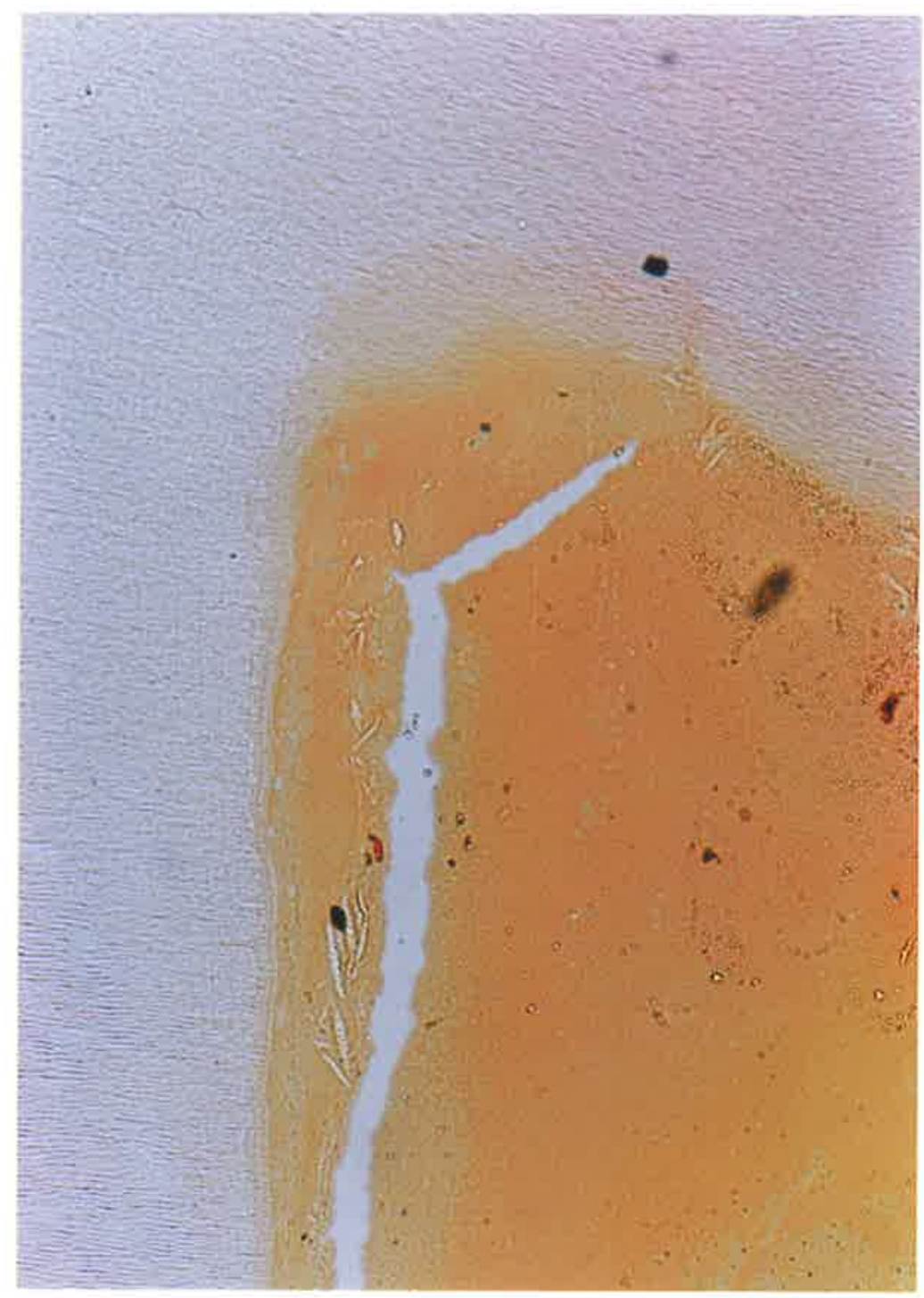


Figure 39:

Photomacrograph representing from left to right, the effect of adding (1) sterile saline (Group D), and (2) \& (3) packed red blood cells to the pulp chambers of teeth from Group F. They were prepared as outlined in section 4.5 and subjected to the benzidine test. Magnification $\times 4.5$. 


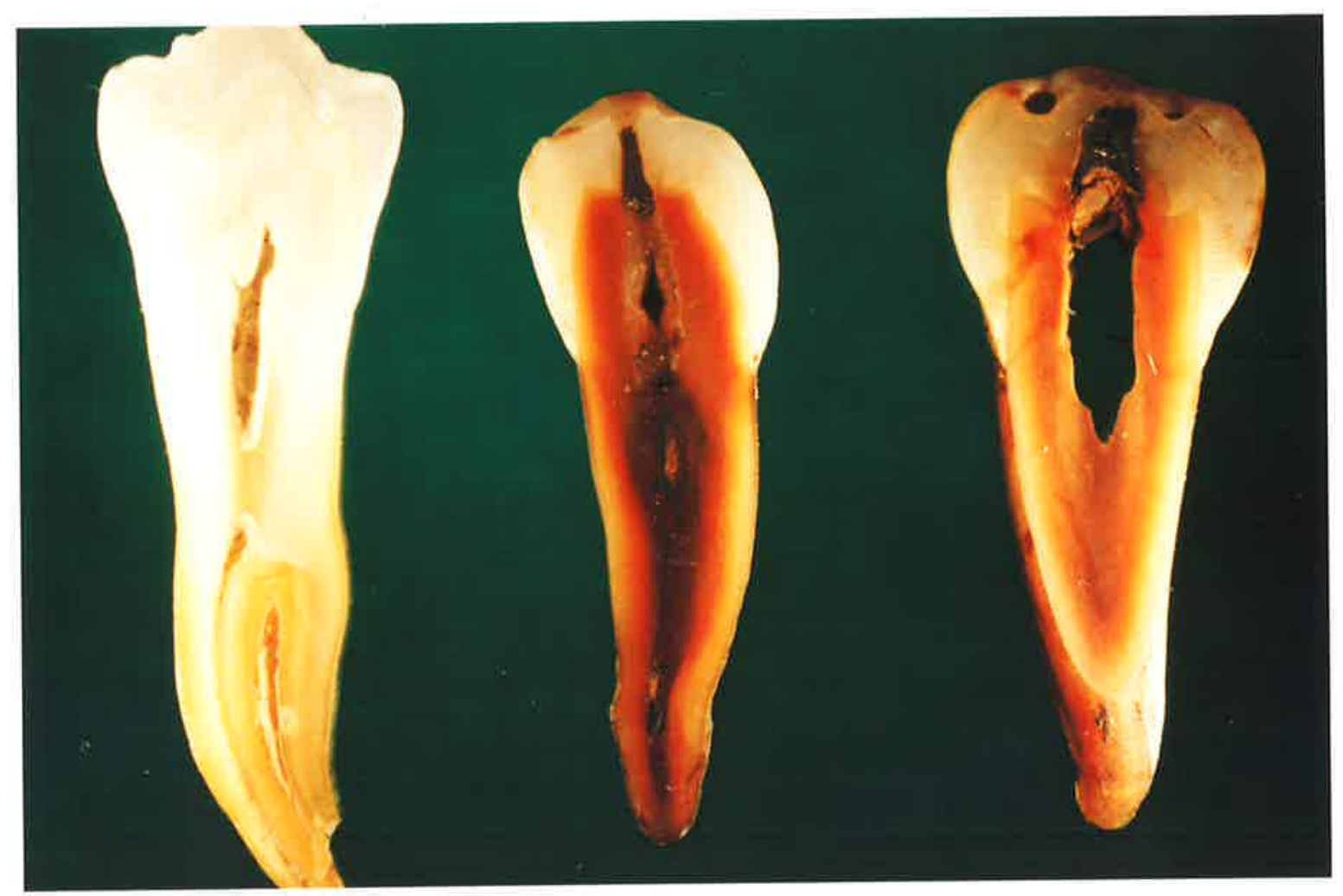


Figure 40:

Photomacrograph of a tooth from Group $F$ stained with packed red blood cells as outlined in section 4.5 , and then decalcified by acidEDTA. It was subjected to the benzidine test and demonstrated a negative response. Magnification x7.5. 


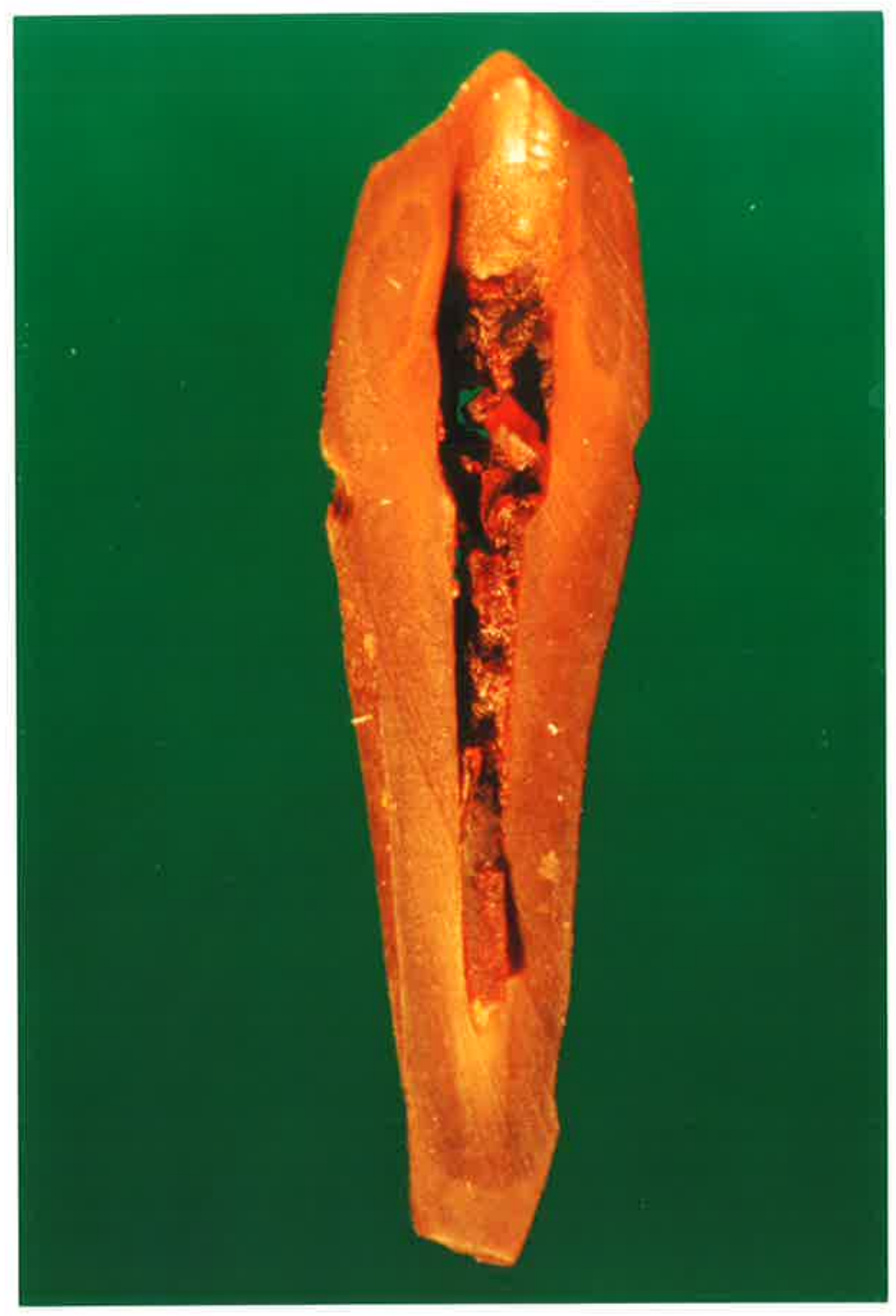


Figure 41:

Photomacrograph of a tooth from Group F stained with packed red blood cells and prepared as outlined in section 4.5. It was subjected to the zinc leuco test and demonstrated a positive response. Magnification $\times 7$. 
Figure 42:

Photomacrograph of a tooth from Group F cut longitudinally just beyond the pulp chamber and stained with packed red blood cells. It was prepared as outlined in section 4.5 , subjected to the zinc leuco test and demonstrated a positive response. Magnification $\times 9$. 


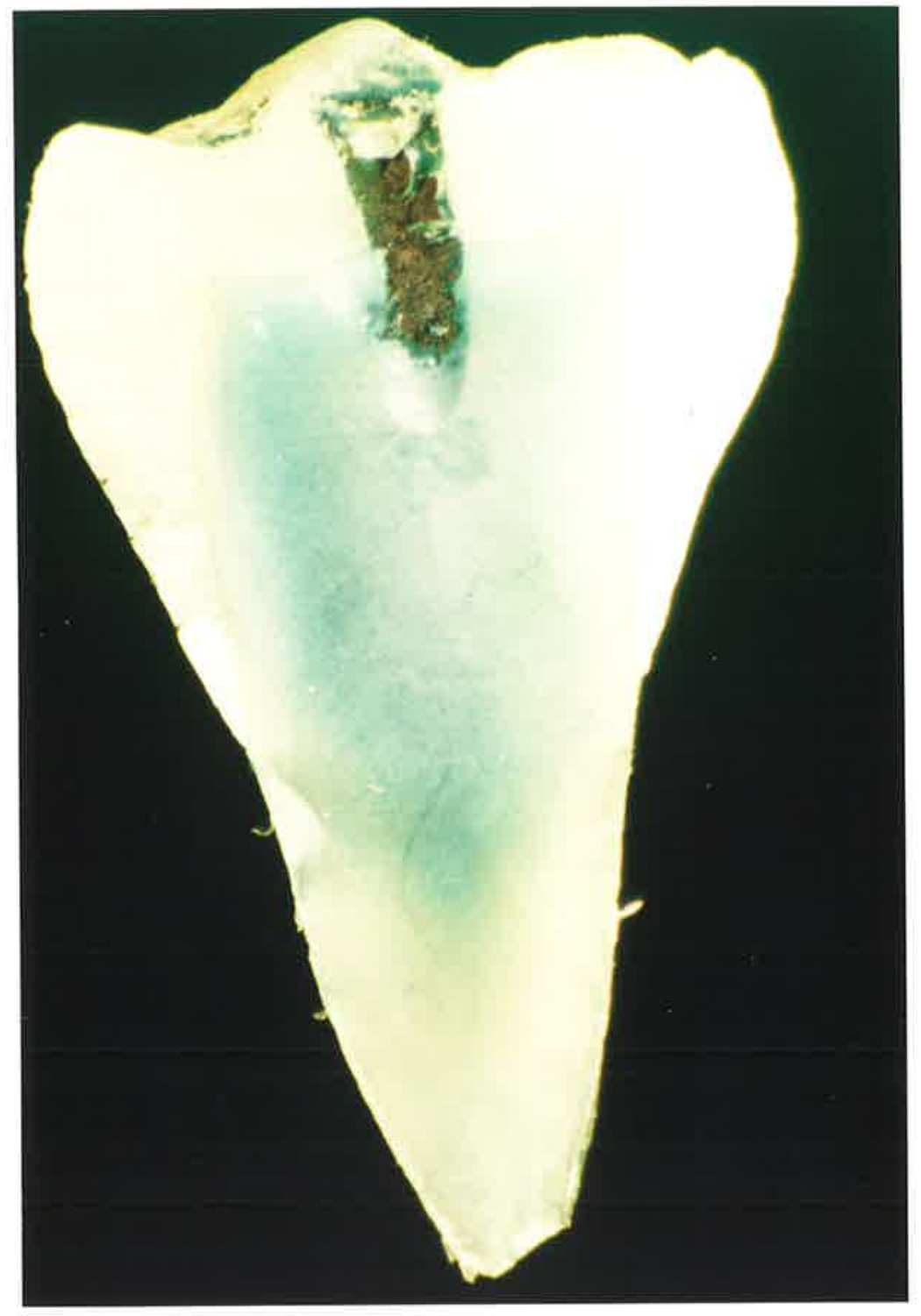


Figure 43:

Photomacrograph demonstrating the effect of adding sterile saline to the pulp chamber of a tooth from Group D. It was prepared as outlined in section 4.5, subjected to zinc leuco test and demonstrated a negative response. Magnification $\times 6$. 


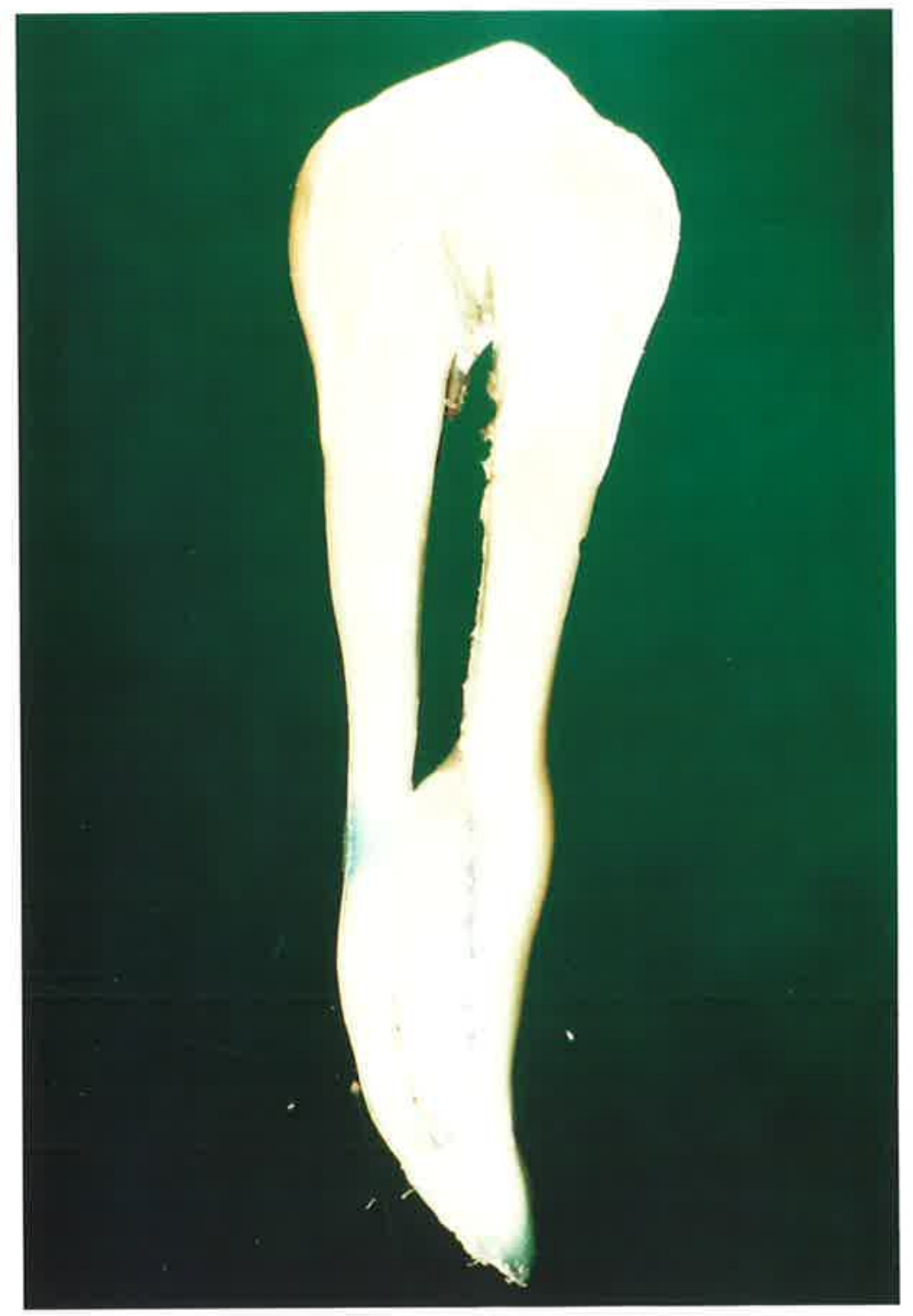


Figure 44 .

Photomacrograph of a tooth from Group $F$ stained with packed red blood cells and prepared as outlined in section 4.5. It was subjected to Perl's test and demonstrated a negative response. Magnification x 7.5. 


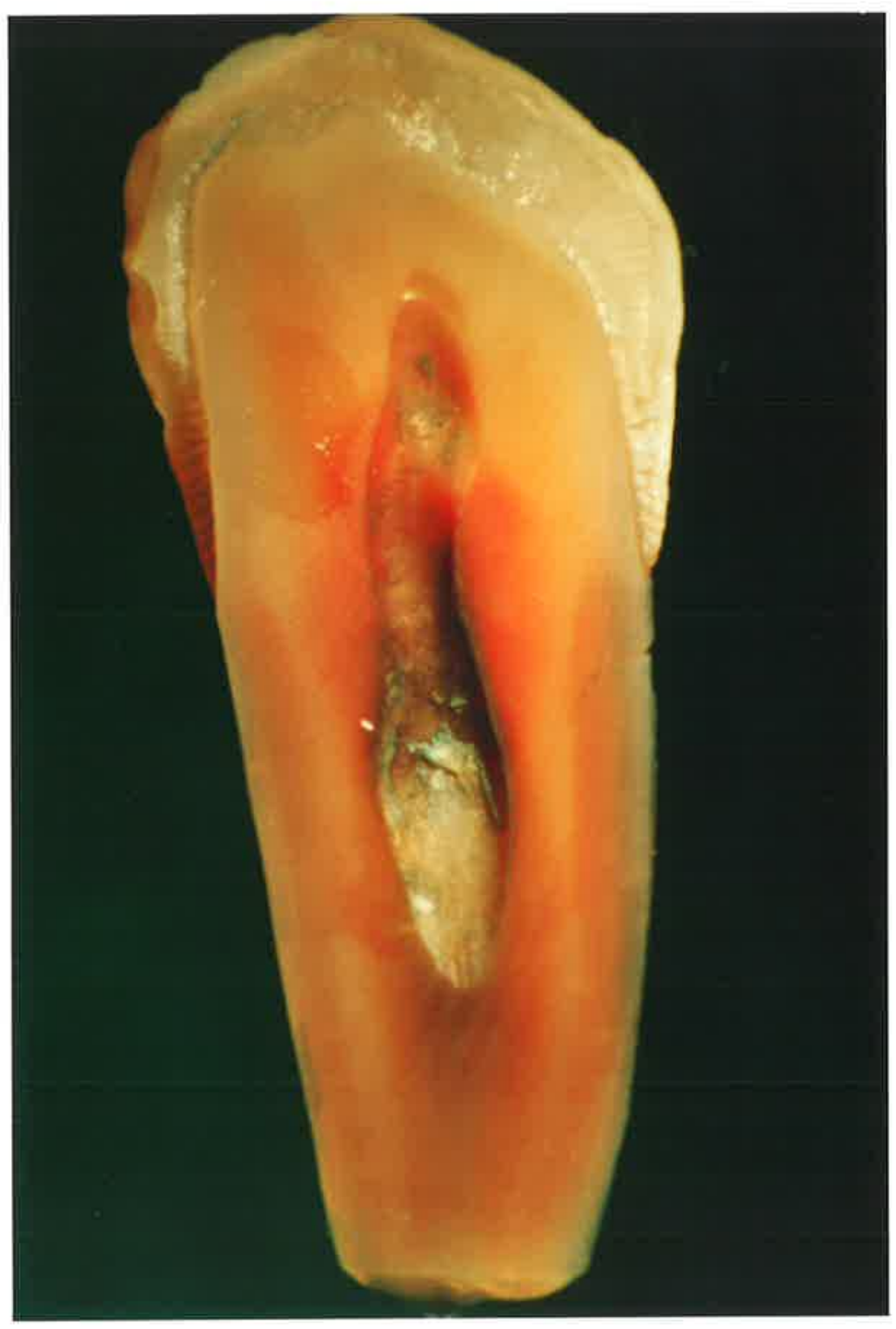


Figure 45:

Photomacrograph of a tooth from Group D after the addition of sterile saline to the pulp chamber and prepared as outlined in section 4.5. It was subjected to Perl's test and demonstrated a negative response. Magnification x 7.5. 


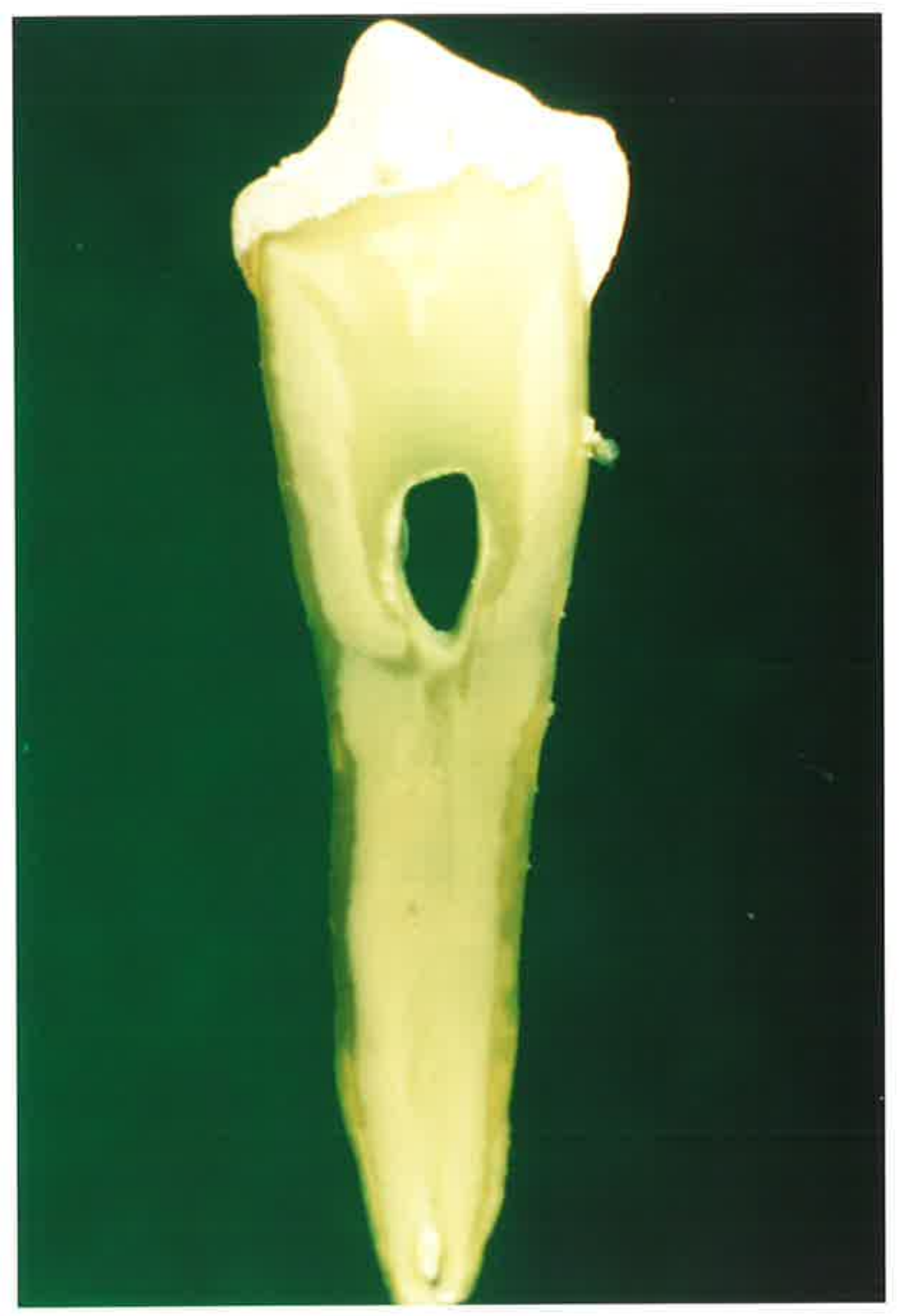


Figure 46:

A photomicrograph of the pulp from the discoloured upper right central incisor shown in Figure 3, demonstrating a positive response to the benzidine histochemical test. Magnification $\times 20$.

All histological specimens in Figures 46 to 51 were counterstained with nuclear fast red. 


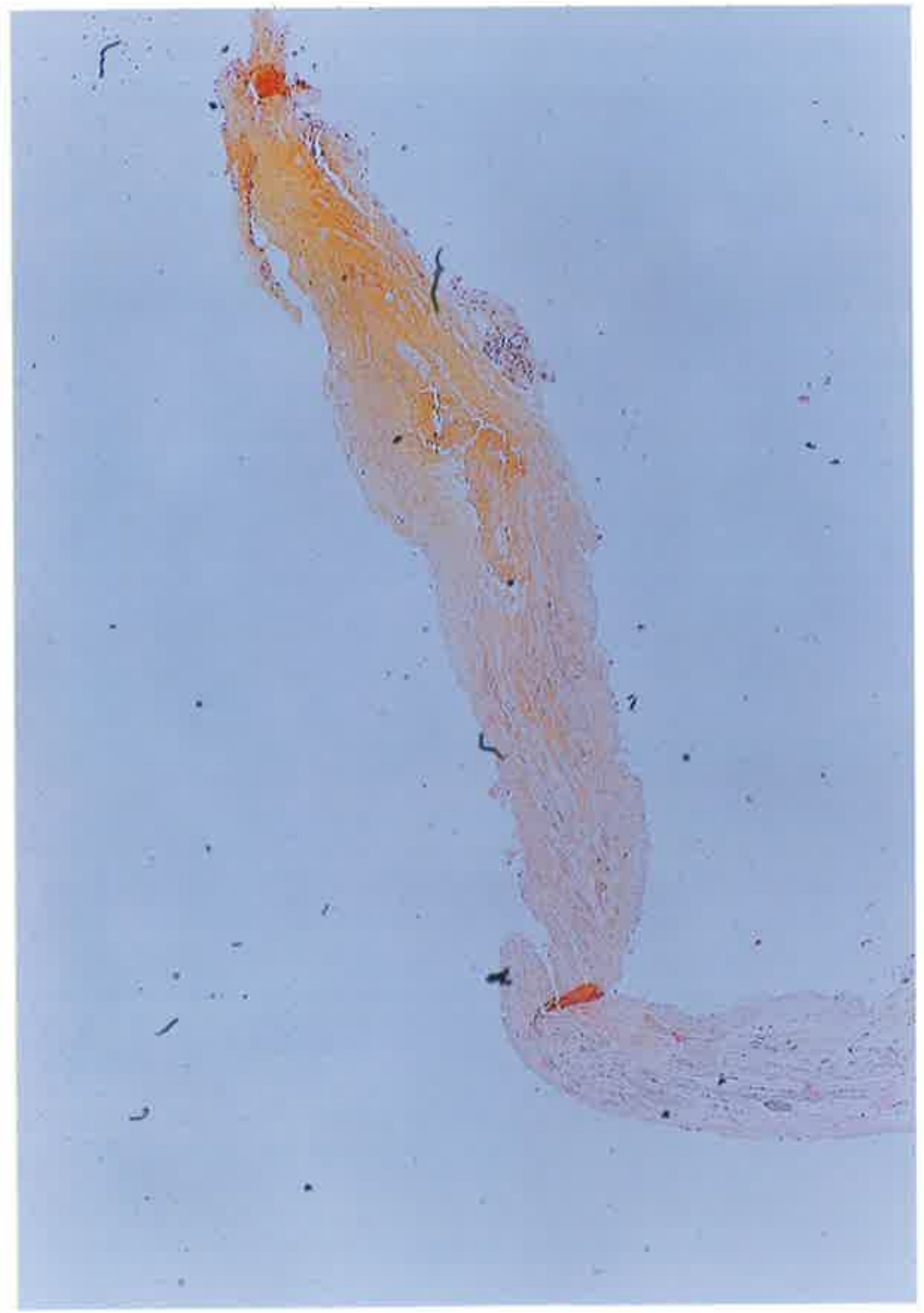


Figure 47:

A photomicrograph showing enlarged detail from Figure 46. Magnification $\times 38$. 


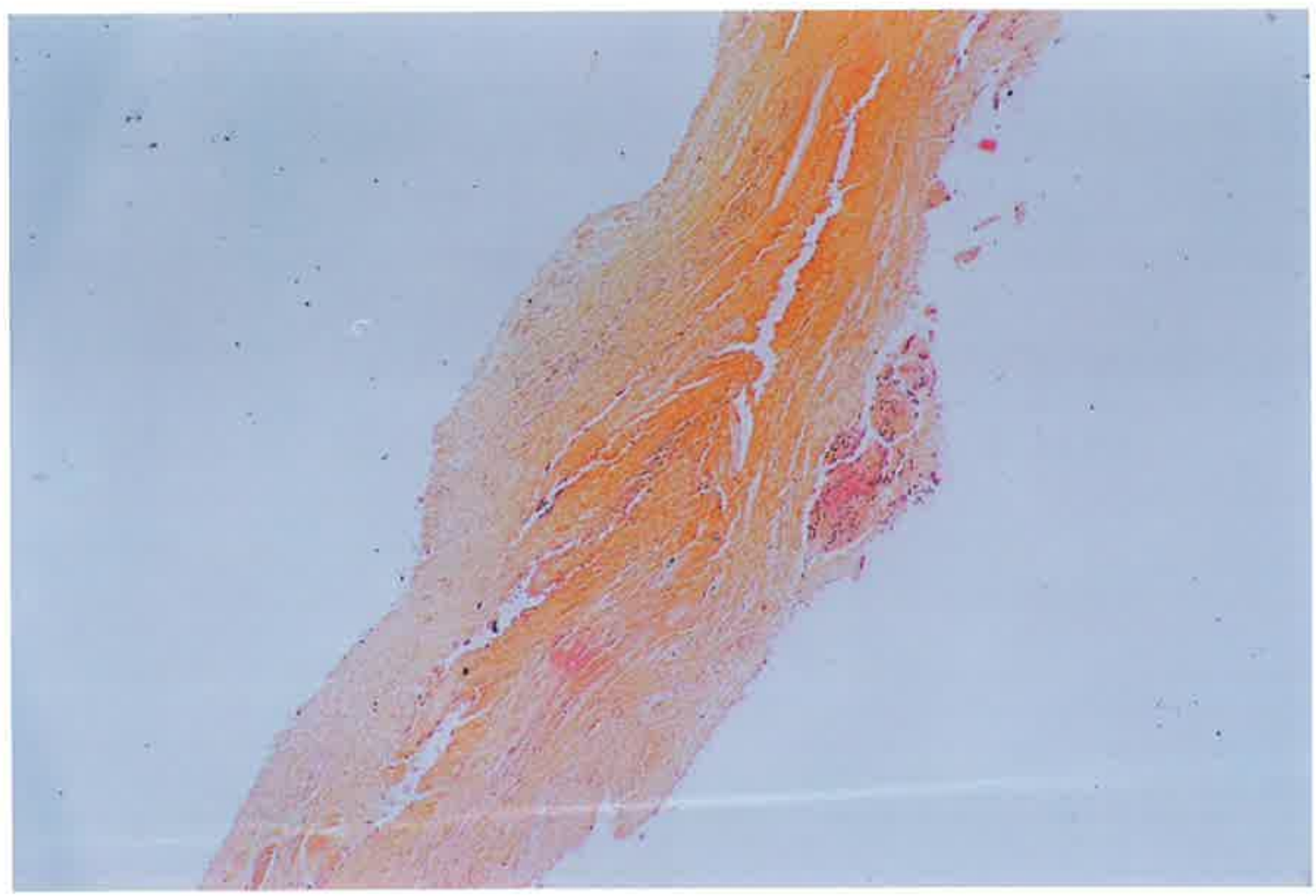


Figure 48:

A photomicrograph of the pulp form the discoloured upper right central incisor shown in Figure 3, demonstrating a positive response to the zinc leuco histochemical test. Magnification x 20 . 


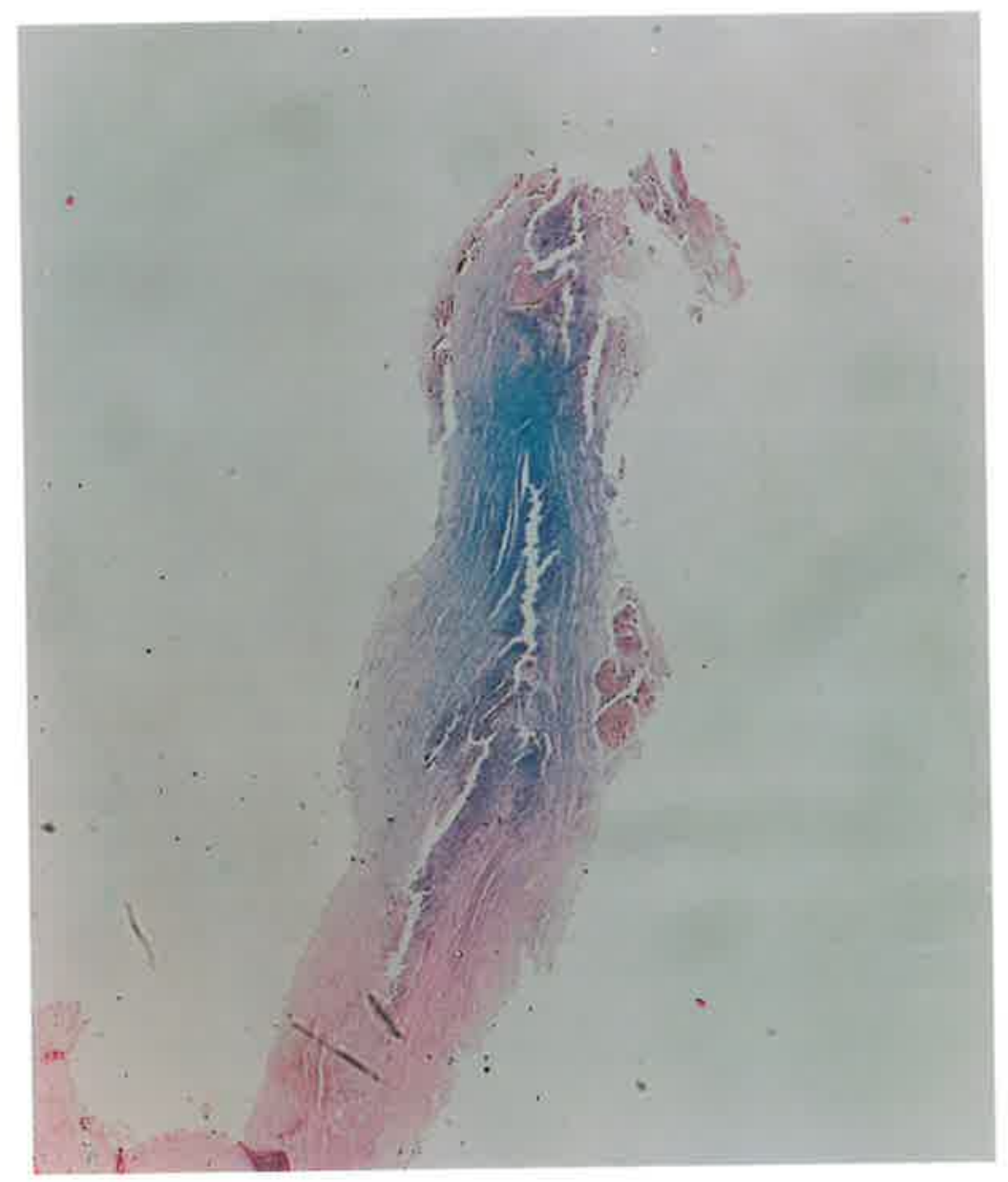


Figure 49:

A photomicrograph showing enlarged detail from Figure 48. Magnification $\times 38$. 


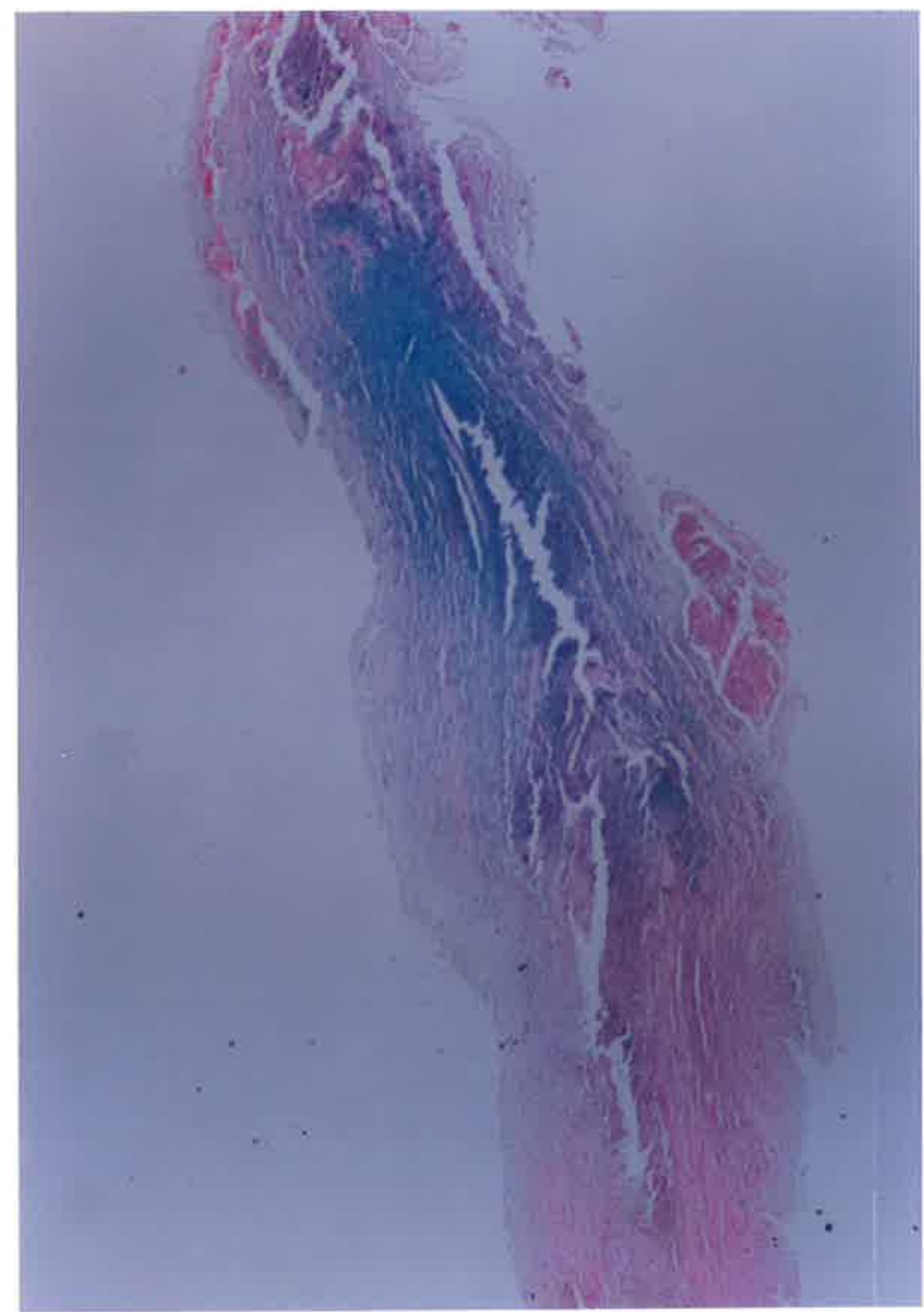


Figure 50:

A photomicrograph of the pulp from the discoloured upper central incisor shown in Figure 3, demonstrating a negative response to the Perl's histochemical test. Magnification x 20 . 


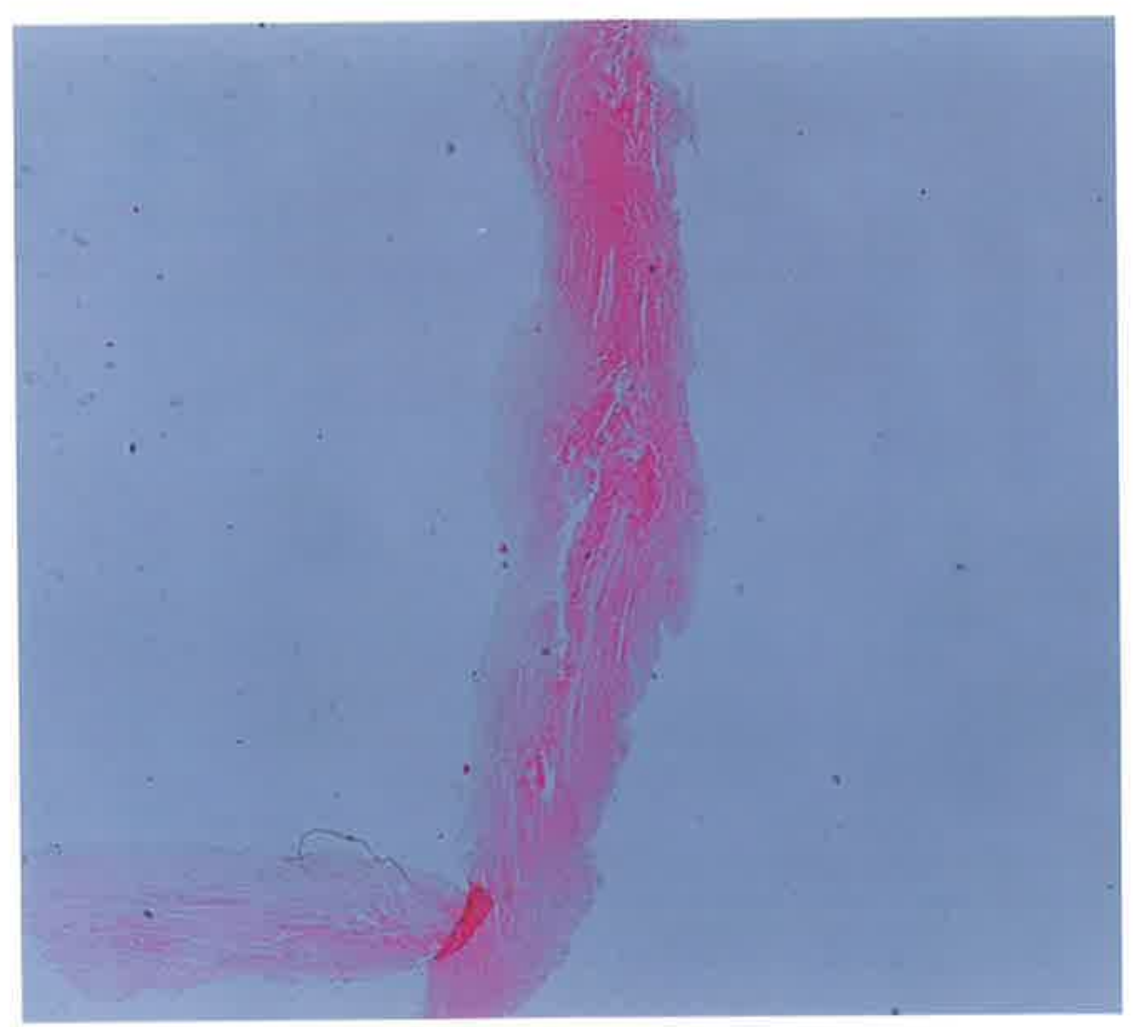


Figure 51:

A photomicrograph of the pulp from the discoloured upper central incisor shown in Figure 3, demonstrating a negative response to the Turnbull Blue histochemical test. Magnification $\times 20$. 


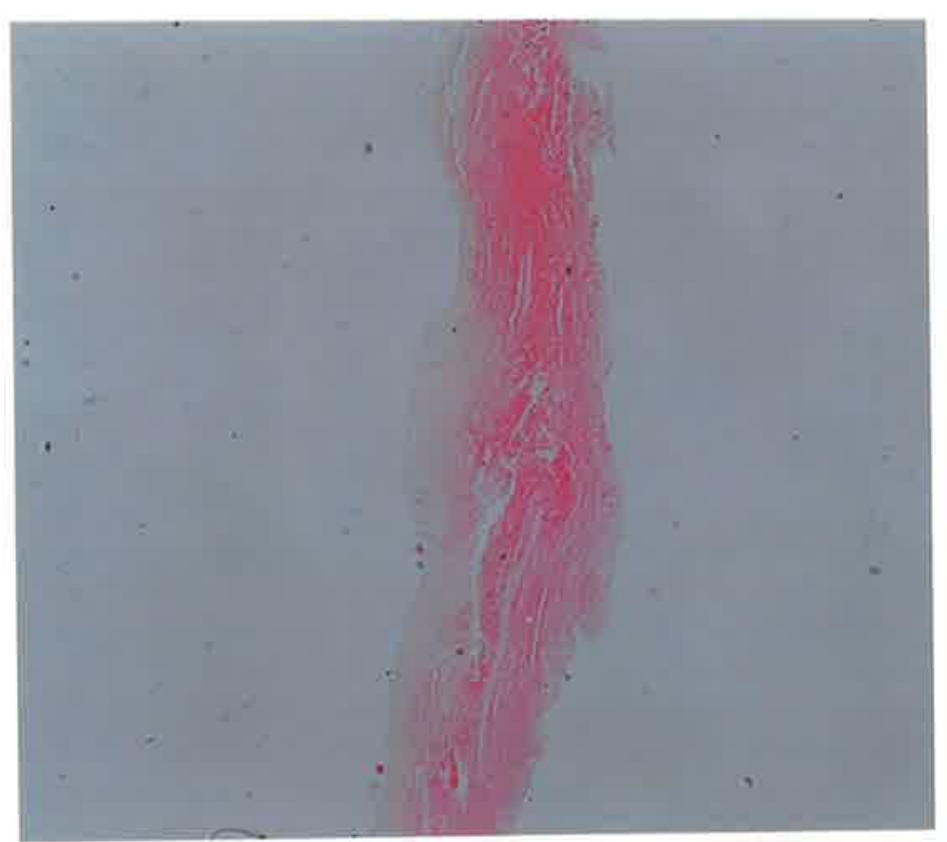




\subsection{TABLES}

Tables 3-14 represent the changes in reflectance density of five tooth samples over a period of one week when immersed in various bleaching solutions.

Table 3

REFLECTANCE DENSITY CHANGES OF STAINED TEETH DURING BLEACHING WITH HYDROGEN PEROXIDE

$\begin{array}{lllllll}\text { TIME (Days) } & \text { D1 } & \text { D2 } & \text { D3 } & \text { D4 } & \text { D5 } & \text { D7 }\end{array}$ HYDROGEN

PEROXIDE

SAMPLE 1

$\begin{array}{llllll}1.12 & 0.95 & 0.93 & 0.95 & 0.95 & 0.95\end{array}$

SAMPLE 2

$\begin{array}{llllll}1.03 & 0.91 & 0.87 & 0.86 & 0.86 & 0.88\end{array}$

SAMPLE 3

$\begin{array}{llllll}1.18 & 1.07 & 1.08 & 1.07 & 1.06 & 0.94\end{array}$

SAMPLE4

$\begin{array}{llllll}1.17 & 0.91 & 0.87 & 0.87 & 0.86 & 0.86\end{array}$

SAMPLE 5

$\begin{array}{llllll}1.13 & 1.03 & 0.97 & 0.98 & 0.98 & 0.97\end{array}$ 
Table 4

REFLECTANCE DENSITY CHANGES OF STAINED TEETH DURING BLEACHING WITH SODIUM PERBORATE

\begin{tabular}{|c|c|c|c|c|c|c|}
\hline TIME (Days) & D1 & $\mathrm{D} 2$ & D3 & D4 & D5 & D7 \\
\hline \multicolumn{7}{|l|}{ SODIUM } \\
\hline \multicolumn{7}{|l|}{ PERBORATE } \\
\hline SAMPLE 1 & 1.06 & 0.90 & 0.88 & 0.89 & 0.89 & 0.88 \\
\hline SAMPLE 2 & 1.08 & 1.05 & 1.03 & 0.99 & 0.99 & 0.99 \\
\hline SAMPLE 3 & 1.14 & 1.02 & 1.01 & 1.01 & 1.03 & 0.96 \\
\hline SAMPLE 4 & 1.13 & 1.07 & 1.03 & 1.02 & 0.99 & 0.99 \\
\hline SAMPLE 5 & 1.08 & 0.99 & 0.98 & 0.94 & 0.93 & 0.93 \\
\hline
\end{tabular}

Table 5

REFLECTANCE DENSITY CHANGES OF STAINED TEETH DURING BLEACHING WITH SATURATED OXALIC ACID

$\begin{array}{lllllll}\text { TIME (Days) } & \text { D1 } & \text { D2 } & \text { D3 } & \text { D4 } & \text { D5 } & \text { D7 }\end{array}$ OXALIC ACID (saturated)

SAMPLE 1

SAMPLE 2

SAMPLE 3

SAMPLE 4

SAMPLE 5 $\begin{array}{llllll}1.02 & 0.95 & 1.02 & 0.99 & 0.96 & 1.05\end{array}$

$\begin{array}{llllll}1.78 & 1.23 & 1.14 & 1.18 & 1.20 & 1,19\end{array}$

$\begin{array}{llllll}1.11 & 1.05 & 1.10 & 1.03 & 1.04 & 1.02\end{array}$

$\begin{array}{llllll}1.07 & 1.08 & 1.02 & 1.02 & 1.02 & 1.06\end{array}$

$\begin{array}{llllll}1.03 & 0.97 & 0.96 & 0.99 & 0.97 & 0.95\end{array}$ 
Table 6

REFLECTANCE DENSITY CHANGES OF STAINED TEETH DURING BLEACHING WITH "ENZYMATIC CLEANER"

$\begin{array}{lllllll}\text { TIME (Days) } & \text { D1 } & \text { D2 } & \text { D3 } & \text { D4 } & \text { D5 } & \text { D7 }\end{array}$ "ENZYMATIC

CLEANER"

SAMPLE 1

$\begin{array}{llllll}1.00 & 0.98 & 1.03 & 1.01 & 1.03 & 1.02\end{array}$

SAMPLE 2

$\begin{array}{llllll}1.03 & 1.00 & 1.04 & 1.02 & 0.97 & 0.98\end{array}$

SAMPLE 3

$\begin{array}{llllll}1.20 & 1.18 & 1.13 & 1.07 & 1.04 & 1.04\end{array}$

SAMPLE 4

$\begin{array}{llllll}1.07 & 1.03 & 1.01 & 1.03 & 0.99 & 0.99\end{array}$

SAMPLE 5

$\begin{array}{llllll}1.11 & 1.08 & 1.02 & 1.02 & 1.07 & 1.01\end{array}$

Table 7

REFLECTANCE DENSITY CHANGES OF STAINED TEETH DURING BLEACHING WITH 10\% HYDROCHLORIC ACID

$\begin{array}{llllll}\text { TME (Days) D1 } & \text { D2 } & \text { D3 } & \text { D4 } & \text { D5 } & \text { D7 }\end{array}$ 10\% HYDROCHLORIC ACID

SAMPLE 1

$\begin{array}{llllll}1.35 & 1.24 & 1.32 & 1.34 & 1.34 & 1.19\end{array}$

SAMPLE 2

$\begin{array}{llllll}1.31 & 1.37 & 1.36 & 1.35 & 1.34 & 1.20\end{array}$

SAMPLE 3

$\begin{array}{llllll}1.26 & 1.27 & 1.31 & 1.31 & 1.31 & 1.14\end{array}$

SAMPLE 4

$\begin{array}{llllll}1.45 & 1.40 & 1.42 & 1.42 & 1.42 & 1.20\end{array}$

SAMPLE 5

$\begin{array}{llllll}1.25 & 1.23 & 1.18 & 1.23 & 1.20 & 1.02\end{array}$ 
Table 8

REFLECTANCE DENSITY CHANGES OF STAINED TEETH DURING BLEACHING WITH 30\% HYDROCHLORIC ACID

$\begin{array}{lllllll}\text { TIME (Days) } & \text { D1 } & \text { D2 } & \text { D3 } & \text { D4 } & \text { D5 } & \text { D7 }\end{array}$ $30 \%$ HYDROCHLORIC

ACID

SAMPLE 1

1.33

SAMPLE 2

1.29

SAMPLE 3

1.28

SAMPLE 4

1.33

SAMPLE 5 1.36

Table 9

REFLECTANCE DENSITY OF STAINED TEETH DURING BLEACHING WITH $40 \%$ ORTHOPHOSPHORIC ACID

$\begin{array}{lllllll}\text { TIME (Days) } & \text { D1 } & \text { D2 } & \text { D3 } & \text { D4 } & \text { D5 } & \text { D7 }\end{array}$ ORTHOPHOSPHORIC ACID

SAMPLE 1

$\begin{array}{llll}1.32 & 1.14 & 0.95 & 1.08\end{array}$

SAMPLE 2

$\begin{array}{llll}1.37 & 1.14 & 1.20 & 1.02\end{array}$

SAMPLE 3

$\begin{array}{llll}1.38 & 1.14 & 0.99 & 0.97\end{array}$

SAMPLE 4

$\begin{array}{lllllllll}1.40 & 1.32 & 1.05 & 0.97 & - & -\end{array}$

SAMPLE 5

$\begin{array}{llllll}1.42 & 1.12 & 0.92 & 0.90 & - & -\end{array}$ 
Table 10

REFLECTANCE DENSITY CHANGES OF STAINED TEETH DURING BLEACHING WITH "HICLEAN"

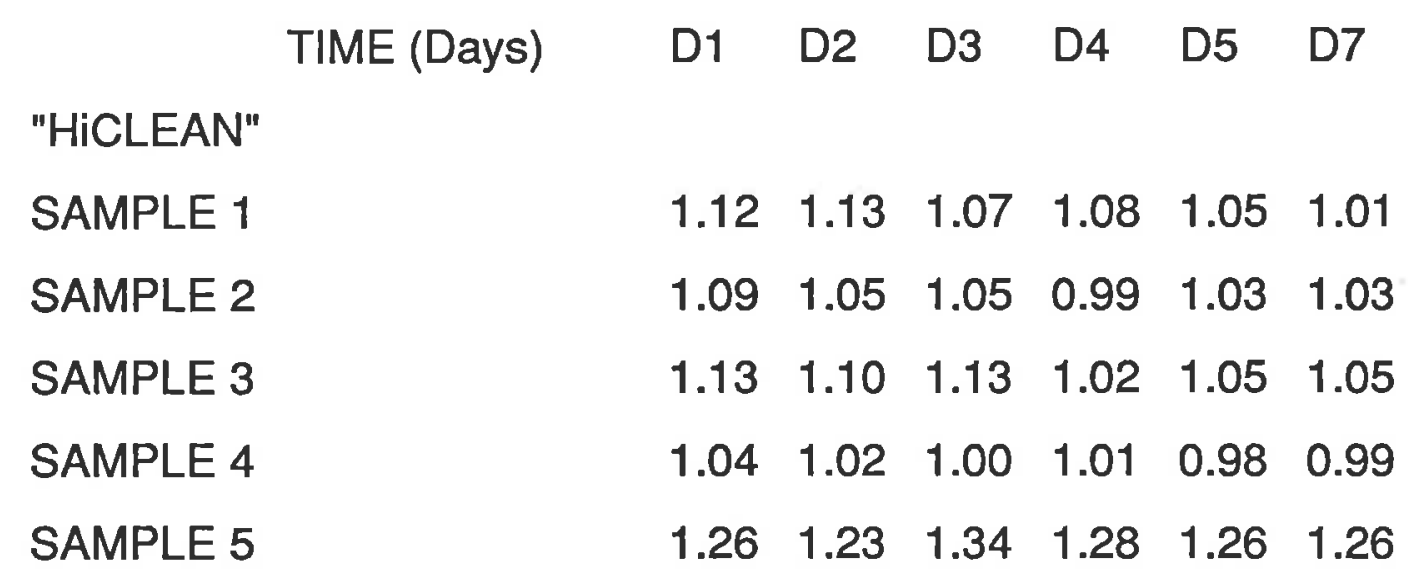

Table 11

REFLECTANCE DENSITY CHANGES OF STAINED TEETH DURING BLEACHING WITH "DESFERAL"

$\begin{array}{lllllll}\text { TIME (Days) } & \text { D1 } & \text { D2 } & \text { D3 } & \text { D4 } & \text { D5 } & \text { D7 }\end{array}$ "DESFERAL"

$\begin{array}{lllllll}\text { SAMPLE 1 } & 1.42 & 1.42 & 1.48 & 1.49 & 1.49 & 1.42 \\ \text { SAMPLE 2 } & 1.51 & 1.43 & 1.47 & 1.46 & 1.50 & 1.46 \\ \text { SAMPLE 3 } & 1.26 & 1.25 & 1.28 & 1.28 & 1.27 & 1.24 \\ \text { SAMPLE 4 } & 1.19 & 1.46 & 1.43 & 1.46 & 1.41 & 1.35 \\ \text { SAMPLE 5 } & 1.19 & 1.26 & 1.24 & 1.23 & 1.23 & 1.08\end{array}$


Table 12

REFLECTANCE DENSITY CHANGES OF STAINED TEETH DURING BLEACHING WITH 1M OXALIC ACID

$\begin{array}{lllllll}\text { TIME (Days) } & \text { D1 } & \text { D2 } & \text { D3 } & \text { D4 } & \text { D5 } & \text { D7 }\end{array}$

1M OXALIC ACID

SAMPLE 1

$\begin{array}{llllll}1.39 & 1.42 & 1.22 & 1.28 & 1.28 & 1.22\end{array}$

SAMPLE 2

$\begin{array}{llllll}1.17 & 1.20 & 1.17 & 1.19 & 1.19 & 1.20\end{array}$

SAMPLE 3

$\begin{array}{llllll}1.11 & 0.99 & 0.97 & 0.97 & 1.04 & 1.05\end{array}$

SAMPLE 4

$\begin{array}{llllll}1.08 & 1.03 & 0.98 & 1.00 & 0.97 & 1.03\end{array}$

SAMPLE 5

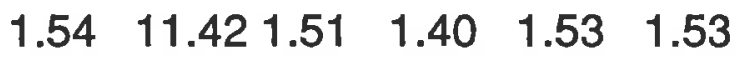

Table 13

REFLECTANCE DENSITY CHANGES OF STAINED TEETH DURING BLEACHING WITH "LIQUID IRON CHELATOR"

$\begin{array}{lllllll}\text { TIME (Days) } & \text { D1 } & \text { D2 } & \text { D3 } & \text { D4 } & \text { D5 } & \text { D7 }\end{array}$ "LIQUID IRON

CHELATOR"

SAMPLE 1

$\begin{array}{llllll}1.32 & 1.41 & 1.40 & 1.45 & 1.43 & 1.50\end{array}$

SAMPLE 2

$\begin{array}{llllll}1.91 & 1.22 & 1.16 & 1.22 & 1.21 & 1.17\end{array}$

SAMPLE 3

$\begin{array}{llllll}1.26 & 1.25 & 1.28 & 1.28 & 1.27 & 1.24\end{array}$

SAMPLE 4

$1.301 .44 *$ -

SAMPLE 5

$\begin{array}{llllll}1.28 & 1.32 & 1.27 & 1.45 & 1.47 & 1.46\end{array}$

"No further data available from sample 4 due to experimental mishap. 
Table 14

CHANGES IN REFLECTANCE DENSITY OF STAINED TEETH DURING "CONTROL" IMMERSION IN DDW

$\begin{array}{lllllll}\text { TIME (Days) } & \text { D1 } & \text { D2 } & \text { D3 } & \text { D4 } & \text { D5 } & \text { D7 }\end{array}$

DDW

SAMPLE 1

SAMPLE 2

SAMPLE 3

SAMPLE 4

SAMPLE 5

$\begin{array}{llllll}1.33 & 1.34 & 1.28 & 1.22 & 1.25 & 1.25 \\ 1.22 & 1.34 & 1.31 & 1.20 & 1.22 & 1.21 \\ 1.43 & 1.46 & 1.31 & 1.28 & 1.25 & 1.14 \\ 1.41 & 1.41 & 1.35 & 1.31 & 1.28 & 1.26 \\ 1.37 & 1.33 & 1.27 & 1.26 & 1.27 & 1.26\end{array}$

$\begin{array}{llllll}1.22 & 1.34 & 1.31 & 1.20 & 1.22 & 1.21\end{array}$

$\begin{array}{llllll}1.43 & 1.46 & 1.31 & 1.28 & 1.25 & 1.14\end{array}$

$\begin{array}{llllll}1.37 & 1.33 & 1.27 & 1.26 & 1.27 & 1.26\end{array}$ 
Table 15

\section{A COMPARISON OF THE VARIOUS BLEACHING SOLUTIONS}

The data for this table was assembled from the reflectance density changes presented in Tables 3-14 and prepared using the unbalanced repeated measures models with structures covariance matrices, BMDP5V, (BMDP Statistical Software, Inc). As a result of this analysis and selecting the average value D1 $=1.10$ for the initial reading in each treatment group, it was possible to illustrate the efficacy of the various solutions in the resultant model.

TIME (Days)

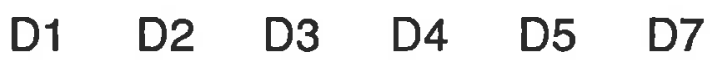

BLEACHING AGENT

$\begin{array}{lllllll}\text { HYDROGEN PEROXIDE } & 1.10 & 0.96 & 0.94 & 0.93 & 0.92 & 0.90 \\ \text { SODIUM PERBORATE } & 1.10 & 1.00 & 0.98 & 0.97 & 0.96 & 0.95 \\ \text { OXALIC ACID (saturated) } & 1.10 & 1.05 & 1.04 & 1.03 & 1.03 & 1.05 \\ \text { OXALIC ACID (1M) } & 1.10 & 1.08 & 1.07 & 1.06 & 1.06 & 1.06 \\ \text { "ENZYMATIC CLEANER" } & 1.10 & 1.06 & 1.05 & 1.04 & 1.03 & 1.02 \\ \text { 10\% HYDROCHLORIC ACID } & 1.10 & 1.15 & 1.19 & 1.19 & 1.16 & 1.00 \\ \text { "HICLEAN" } & 1.10 & 1.08 & 1.07 & 1.06 & 1.06 & 1.05 \\ \text { "DESFERAL" } & 1.10 & 1.20 & 1.23 & 1.23 & 1.22 & 1.15 \\ \text { "LIQUID IRON CHELATOR" } & 1.10 & 1.28 & 1.32 & 1.34 & 1.35 & 1.35 \\ \text { DDW } & 1.10 & 1.12 & 1.15 & 1.11 & 1.08 & 1.06\end{array}$


Table 16

MAXIMUM PERCENTAGE CHANGE AFTER BLEACHING AT D7.

$\begin{array}{ll}\text { HYDROGEN PEROXIDE } & =19.8 \% \\ \text { SODIUM PERBORATE } & =14.9 \% \\ \text { 10\% HYDROCHLORIC ACID } & =9.8 \% \\ \text { "ENZYMATIC CLEANER" } & =8.0 \% \\ \text { "HICLEAN" } & =5.0 \% \\ \text { OXALIC ACID (saturated) } & =4.7 \% \\ \text { OXALIC ACID (1M) } & =3.6 \% \\ \text { DDW } & =3.1 \% \\ \text { "DESFERAL" } & =-5.7 \% \\ \text { "LIQUID IRON CHELATOR" } & =-7.8 \%\end{array}$




\subsection{DISCUSSION}

\subsection{DISCUSSION OF MATERIALS, METHODS AND TECHNIQUES}

A modified version of the Freccia and Peters technique (1982) was utilized to reproduce the staining caused by haemorrhage into the pulp chamber following trauma and to allow the examination of the products of haemolysis of red blood cells and catabolism of haemoglobin. This method of staining teeth has been demonstrated by these authors to produce a larger degree of coronal and radicular dentine staining than would normally occur if centrifugation is not carried out. From the results obtained using such a method and on the basis of the overall pattern of discoloration, it was considered that this model accurately replicated the in vivo discoloration of a tooth following trauma and subsequent haemorrhage into the pulp chamber. This conclusion was further supported following histochemical examination of such teeth which demonstrated identical findings to those noted in a non-infected, necrotic pulp taken from a discoloured traumatized tooth.

In a study designed to evaluate the changes in permeability, with respect to time, of a small air bubble through dentine, Goodis et al. (1991) stored teeth in $70 \%$ ethanol, $10 \%$ formalin, distilled water with thymol or phosphate-buffered saline with thymol. In this study, teeth stored in phosphate buffered saline exhibited the greatest initial permeability at 4-8 days, followed by stabilization at 1-3 weeks. This latter observation was attributed to the formation of salt precipitates which may occur in phosphate buffered saline. This research project proceeded with the acceptance that there is an increase in dentine 
permeability with respect to time which may eventually stabilize and may after some time cease to occur (Outhwaite et al. 1976). On average, the teeth in this project were stored in phosphate buffered saline for ten weeks and no allowances were made for the possible changes in dentine permeability.

The primary objective of fixation is to halt post-mortem changes within the tissue preserving as close as possible the living state and to protect the tissue from subsequent treatments prior to the examination of the sections. When preservation of iron pigments is important, Lillie (1965a) suggested that neutral $10 \%$ formalin is the best fixative since less diffusion of these pigments occurs than with any other fixative. The same author showed that fixatives that contain acid and no formalin may completely remove haemosiderin or alter it in such a way that a positive reaction for iron is no longer obtainable. In view of these findings, a $10 \%$ solution of neutral buffered formalin (37-40\% formaldehyde, $\mathrm{pH} 7.0$, at room temperature) was used for 48 hours to fix the blood stained teeth in the present study. Formaldehyde acts with several parts of protein molecules forming methylene bridges which are largely responsible for the cross-linking of protein molecules that leads to fixation.

Samples of teeth from Group E freshly stained with packed red blood cells initially stained bright red in colour (Figure 10). After fixation in 10\% neutral buffered formalin, the bright red tooth stain darkened (Figure 11), and although there was a change in intensity of the discoloration, the arrangement and distribution of the teeth stained with packed red blood cells remained the same. This phenomenon is associated with the fixation process and it is due to the action of formaldehyde on blood rich 
tissues forming formaldehyde pigment which Lillie (1965b) stated is a dark brown microcrystalline substance which rotates the plane of polarized light. In addition, Lillie (1965b) reported that it withstands extraction by concentrated sulphuric, hydrochloric, phosphoric and acetic acids, and that fixation does not interfere with the Prussian blue or Turnbull's histochemical reactions. This is relevant to this project as it indicates that the decalcification process, using either acid-EDTA or EDTA-cacodylate, is unlikely to have any effect on the blood pigments, and equally important, formalin fixation is unlikely to interfere with any of the histochemical tests. However, from the outset of the study, it remained uncertain whether routine decalcifying solutions would interfere with or remove the previously incorporated blood pigments from the teeth being studied. The establishment of a method which allowed decalcification of blood stained teeth without removing the blood pigments was important to the final outcome of this research project.

Over the years, many different inorganic and organic acids have been used to achieve demineralization. It has been reported by Brain (1966a) that EDTA, nitric, hydrochloric, and acetic acids, and a combination of formic acid and sodium citrate are effective for light microscope studies. Lillie et al., (1963) demonstrated that $5 \mu \mathrm{m}$ sections show no detectable loss of iron in haemosiderin or other protein forms of iron, such as cytosiderin and enterosiderin, during 7 days exposure to EDTA at $\mathrm{pH}$ 7.5 , and that the loss is scarcely appreciable at $\mathrm{pH}$ 4.5. Lillie (1965a) proposed that protein and mucopolysaccharides (glycosaminoglycans) chelate the iron and protect it from leaching, at least in the $\mathrm{pH} 2.5-4.5$ range of acid treatment. It would appear that the higher the acid content of the decalcifying solution the more likely is the possibility of the 
removal of pigments from the blood stained teeth. Therefore, two decalcifying solutions of varying $\mathrm{pH}$ (acid EDTA, $\mathrm{pH} 1.0$ and EDTAcacodylate $\mathrm{pH}$ 7.3) were evaluated to determine which one is less likely to interfere with the experimentally induced discoloration of the teeth. Bjurholm et al. (1989) reported that demineralization of teeth using EDTA-cacodylate requires 6-8 weeks. It has been reported by Brain, (1966b) that altering the temperature of decalcifying solution affects the rate of decalcification, and that elevating the temperature of decalcifying fluids to $37^{\circ} \mathrm{C}$ significantly decreases the decalcification period. However, temperatures above $50^{\circ} \mathrm{C}$ should not be used because the rapid leaching of calcium salts produces swelling and hydrolysis of the collagen matrix with subsequent distortion of the tissues. Furthermore, a study examining the decalcification of rat femurs at different temperatures by Nikiforuk and Sreeby (1953) confirmed that EDTA is a more effective decalcification agent at higher temperatures. As a result of these findings, the temperature of the EDTA-cacodylate was elevated to $37^{\circ} \mathrm{C}$ to hastened the decalcification process. This had the desired affect in reducing the decalcification period of the blood stained teeth to four weeks. It was unnecessary to raise the temperature of the acidEDTA to accelerate the decalcification rate as the decalcification process occurs within 24-48 hours at normal room temperature.

Since the EDTA-cacodylate possessed one major disadvantage in that the decalcification process required 6-8 weeks, acid-EDTA, with a decalcification period of 24-48 hours, was selected as the solution of choice to decalcify the teeth prior to histological examination.

Histochemical tests were utilized to study the haemolysis of red blood cells and the breakdown of haemoglobin in the experimentally induced 
blood stained teeth. The histochemistry of the haemoglobins can be considered in two parts, that of the globins, and that of the haematins. Whether globin is present or not makes little difference in the tests for the haematin part of the molecule. The histochemical methods for staining the haem molecule depends on the peroxidase reaction, and these are equally effective with the native globins (reduced and oxyhaemoglobin, methaemoglobin, and sulphaemoglobin), denatured globins (haemochromogen and parahaematin), and with the globin free compounds (haematin, haem and haemin). The shared property of these compounds to exhibit weak peroxidase activity is utilized in the histochemical demonstration of haemoglobin in red blood cells. Peroxidases catalyse reactions of the type $\mathrm{AH}_{2}+\mathrm{H}_{2} \mathrm{O}_{2} \rightarrow 2 \mathrm{H}_{2} \mathrm{O}$, and the peroxide-peroxidase system thus causes the rapid oxidation of substances which peroxide alone would oxidize only slowly. The oxidizable substrate in the peroxidase reaction gives rise to products sufficiently coloured to be visible in tissue sections under light microscopy.

The histochemical demonstration of the peroxidase molecule is by the use of either benzidine or leuco dyes on specimens fixed with formalin (Pearse 1985a). It has been shown that the peroxidase reaction is negative with the porphyrins, haematoidin and haemosiderin (Pearse 1985a). The benzidine test is the most sensitive indicator of haemoglobin peroxidase activity (Pearse, 1985a) and that methods which detect primarily haemoglobin peroxidase activity correlate with the presence of red blood cells by virtue of their haemoglobin content. Allison and Whittaker (1990) have reported the usefulness of benzidine in forensic medicine to establish the presence of red blood cells dispersed in extra-cellular tissues. In such cases, a positive response to 
the benzidine test denotes the presence of the haemoglobin molecule or a haematin derivative. Similarly, in this research project, a positive response to benzidine would indicate that the blood products added to the pulp chamber remained within the tooth after centrifugation and not removed during the decalcifying process. More specifically, a positive benzidine reaction indicates the presence of either haemoglobin or haematin derivatives (native globins, denatured globins, or globin-free compounds) remaining in the teeth. In each of these species, the haem molecule is present as the protoporphyrin ring with an iron atom at its centre.

Haemoglobin is also demonstrated by its peroxidase action. Gomori (1951) considered the zinc leuco method to be superior to all others for the demonstration of haemoglobin, but noted that only intact haemoglobin is identified by the zinc leuco method, and that protein-free haematin derivatives, which may be demonstrated by benzidine, would not stain by this method. Enzymes of the peroxidase group act as catalysts reducing hydrogen peroxide and, in the presence of Patent blue, the haemoglobin is revealed by a characteristic blue appearance. Chemically, most if not all of the peroxidases appear to be haem proteins which are heat- and formalin-stable derivatives of haemoglobin. Lillie (1965b) categorized the existence of another type of peroxidase which is heat labile and appears during the process of tissue autolysis. The benzidine histochemical test gives a positive result with both types of tissue peroxidases (Pearse, 1985a). However, Lison (1953) stated that the zinc leuco blue method did not stain the type of peroxidase which appears during the process of tissue autolysis. Re-coloration of zinc leuco dyes by peroxide is a true enzymatic reaction requiring haemoglobin itself, whereas the benzidine reaction can be catalysed by 
non-protein haem compounds. In histochemistry, the most important application of the peroxidase reaction is the demonstration of haemoglobin and the zinc leuco test is used in this project because of its specificity in demonstrating the presence of haemoglobin.

Haemosiderin is a yellowish, or greenish-brown granular pigment which is normally intracellular. It is a water-insoluble, non-crystalline, proteiniron in the form of the hydroxide, $\mathrm{Fe}(\mathrm{OH})_{3}$, which is visible by light microscopy when stained by the Prussian-blue (Perl's) reaction. In this form, it is considered to resist the bleaching action of hydrogen peroxide (Pearse, 1985a). As a result of the sensitivity and specificity of the Prussian blue method, Perl's is the best method for the histochemical demonstration of $\mathrm{Fe}^{+++}$ions or any other protein bound forms of ferric ion (Pearse, 1985a).

In addition to the Perl's test for the presence of ferric ions, blood stained sections of teeth were subjected to the Turnbull Blue histochemical test. Luna (1969c) has reported that that the Turnbull Blue histochemical test is specific for the demonstration of haemosiderin.

Although the benzidine, zinc leuco, and Perl's tests were specifically devised for decalcified specimens of $6 \mu \mathrm{m}$ thickness, they were also tested on the macroscopic sections of blood stained teeth.

\subsection{DISCUSSION OF RESULTS}

Teeth left in PBS with azide over a period of twelve weeks showed no discoloration due to post-extraction degradation of the pulpal tissue. This confirmed the observations of Nutting and Poe (1963) that pulpal 
ischaemia and subsequent pulp death, without bacterial contamination, does not produce a marked degree of tooth discoloration. It was concluded that, in traumatized teeth severe changes in tooth colour occurs only when there has been haemorrhage into the pulp chamber. This is consistent with clinical observations in that it is difficult to diagnose an internally non-vital tooth merely on the basis of pulp degeneration. Unless there has been bacterial involvement or haemorrhage into the pulp chamber, an internally non-vital tooth does not discolour markedly.

It has been reported that traumatically devitalized teeth with an intact pulp chamber can remain free of bacterial contamination for a period of years (Bergenholtz, 1974; Sundquist, 1976; Andreasen, 1989). Sterile pulp necrosis following dental trauma is not an unusual occurrence and, in the event of haemorrhage into the pulp chamber, coincides with discoloration of the tooth. Bacterial contamination, which may occur later, provides an alternative metabolic pathway for the breakdown of the blood products. All the teeth examined in this research were stored in $0.05 \%$ sodium azide and were prepared using an aseptic technique. This minimized the likelihood of interference due to bacterial contamination.

In the process of experimentally producing blood-stained teeth by centrifugation and during the interim storage period at $370 \mathrm{C}$, there was a rapid increase in erythrocyte deterioration and haemolysis. These findings are in accordance with the observed deterioration of red blood cells when subjected to static conditions or an increase in temperature above 40 C (Gomperts 1967, Haradin et al. 1967, and Valeri et al. 1982). 
By comparing the different components added to the teeth, it was deduced that the coloured pigment which is responsible for the staining arises from haemoglobin found within the erythrocytes. This finding confirmed the observations of Pearse (1985a) who stated that the pigment in blood originates from the erythrocytes and is due to the haemoglobin component.

A colour gradient was observed in the teeth stained with the packed red blood cells with the staining greatest in the dentine layer closest to the pulp chamber and gradually decreasing in intensity as it extends towards the cementum. Although the teeth were immersed in packed red blood cells and both the apex and access cavity were open, the staining occurred from the inside of the tooth and extended through the dentine to the exterior surface of the tooth. The cementum layer appeared to act as a barrier to the passage of the blood pigments. Although the majority of blood staining was confined to the dentine, there was some discoloration of the enamel. The enamel staining was not as pronounced as that observed in the coronal and radicular dentine. It was concluded that in the model under review, enamel is not impervious to the uptake of the blood pigments. It might be argued that the degree of enamel staining may be more dependent upon the length of exposure to the blood pigment, and that, in this project, the staining period (three days) was too short to evaluate the long term degree of enamel discoloration or staining.

Spectrophotometric analysis of the acid-EDTA and EDTA-cacodylate decalcifying solutions before and after demineralization was unable to detect the removal of any of the blood pigments entrapped in the dentine. Spectrophotometric analysis of the acid-EDTA decalcifying 
solution "spiked" with a known volume of haemolysed packed red blood cells indicated that the spectrophotometer was able to detect the presence of haemolysed packed red blood cells below the limits of detection by eye. It was concluded that there was virtually no leaching of blood pigments during decalcification with either decalcifying solution. This finding was supported macroscopically when teeth were stained with packed red blood cells, and subsequently decalcified with acidEDTA (Figure 19). The degree and distribution of the staining was similar to that seen in non-decalcified, packed red blood cell stained teeth (Figure 11).

The irregular distribution of benzidine staining demonstrated in Figure 20 may be explained in relation to the experimental technique used. During the preparation of the teeth, the pulp chamber was filed to a size 40 Hedström file and irrigated with sterile saline. No steps were taken to remove the smear layer which may have obstructed the dentinal tubules and prevented penetration of blood products into some tubules during centrifugation.

The preparation of blood-stained teeth and subsequent decalcification and histochemical examination of such samples has not previously been reported. The histochemical tests indicated that following haemolysis of the red blood cells, haemoglobin was found intact or in the form of the early haematin derivatives such as parahaematin, haemochromagen or haemin. There was no evidence of any ferric ions or accumulation of iron stored as haemosiderin. This conclusion was supported by the macroscopic examination of the blood-stained teeth. Such findings contradict current opinions that there is further breakdown of the haemoglobin molecule within the pulp chamber to iron 
compounds and the release of ferrous/ferric ions (Rotstein, 1991). It is concluded that the major cause of discoloration in non-infected traumatized teeth is the accumulation of haemoglobin or other forms of haematin molecules. Unless there is bacterial contamination or partial revascularization of the root canal, allowing an inflammatory response to occur within the pulp chamber, it is unlikely that the protoporphyrin ring (haem tetra-pyrrole protein structure) could be opened, permitting the release of iron. Therefore, it is appropriate that any methods employed to remove the discoloration following trauma and haemorrhage into the pulp chamber should focus on the removal of the haematin molecule.

Histological examination of the teeth stained with packed red blood cells indicated that the blood pigments responsible for the discoloration are found within the dentinal tubules and not in the intertubular dentine. This has always been presumed but has not previously been demonstrated and documented.

The zinc leuco histochemical test displayed haemoglobin concentrated in the coronal dentine closest to the pulp and it does not penetrate through the dentinal tubules to the same extent as the benzidine stainable material. It was concluded that the haemoglobin molecule is degraded to haematin products and, because of its larger size, was unable to penetrate through the dentinal tubules to the same degree as the smaller haematin derivatives.

Different bleaching solutions were tested in an attempt to evaluate the efficacy of the currently accepted bleaching agents as well as nontraditional alternatives. It was demonstrated that the most effective 
agent for removing blood pigments from the teeth was hydrogen peroxide with sodium perborate being useful but less effective. This supported the work of Rotstein et al. (1991) who showed that both these agents are clinically useful bleaching agents. The greatest change in reflectance for hydrogen peroxide and sodium perborate solutions occurred after three days and thereafter, any further changes were minimal. It was concluded that the optimum interval between bleaching visits for these solutions can be effectively reduced to three days.

Although strong concentrations of acid have been used to remove tetracycline stains from enamel (Croll and Cavanaugh, 1986), 30\% hydrochloric acid and $40 \%$ orthophosphoric acid proved, in the model under review, to be unsuitable for bleaching the blood stained tooth samples.

The "Enzymatic Cleaner" contains a combination of three enzymes (amylase, lipase, trypsin) and disodium edetate. Although it was not effective as a bleaching agent it did have a modifying effect on the stains. Constraints of time prevented an extension to this part of the research. It is suggested that a further study to investigate other enzymes should be undertaken.

The manufacturer of "Desferal", Ciba-Geigy Pharmaceuticals, states that it does not remove iron from the haemoglobin or from other haemincontaining substances in the body, such as myoglobin and ironcontaining enzymes (cytochrome, catalase, and peroxidases). Therefore, it is not surprising that "Desferal" is ineffective in removing blood stains in the model under review, since it had been shown that no free ferric ions or haemosiderin were present in the stained sections. It 
was concluded that "Desferal" is unsuitable for bleaching root filled teeth. The "Liquid Iron Chelator" was also associated with an increase in staining of the tooth sections and failed to demonstrate any ability to remove the blood stains.

Erythrocytes do not contain self-digesting autolytic enzymes but require a normal hyperaemic inflammatory response for the breakdown of the haemoglobin and recycling of the constituent amino acids and iron. The haemolysis and catabolism of erythrocytes in the pulp chamber is different from other parts of the body because the pulp chamber is surrounded by dentine and cementum isolating it from any inflammatory or healing response. If revascularization does not occur, the haematin material from the erythrocytes remains within the pulp chamber and the tooth appears with a pinkish hue. On the other hand, if revascularization does occur, then the tooth can revert to its normal colour within twothree months (Andreasen, 1986). This suggests that an enzyme may be present in blood which is capable of degrading the components of haemolysed red blood cells and restoring normal tooth colour. Further research is needed to test this hypothesis. 


\subsection{CONCLUSIONS}

The principal findings of this study can be summarized as follows:

1. In the in vitro model under review, replicating traumatized teeth, severe changes in tooth colour occurs only after blood products have been introduced into the pulp chamber.

2. The method of preparation of blood stained teeth in this project duplicated the in vivo discoloration of a sterile, necrotic tooth following trauma. This was further supported by the histological examination of a pulpectomized, necrotic pulp from a discoloured traumatized tooth.

3. The component of blood responsible for the staining of the teeth was found in the packed red blood cells (erythrocytes) and is most likely due to the haemoglobin component.

4. The histochemical tests indicated that following haemolysis of the red blood cells, haemoglobin was found intact or in the form of one of the haematin molecules. There was no detectable evidence of any ferric ions or the accumulation of iron stored as haemosiderin.

5. The most effective agent tested to remove blood pigments from the teeth was hydrogen peroxide followed by sodium perborate. Although the "Enzymatic Cleaner" was not effective as a bleaching agent it did have a modifying effect on the stains. It is suggested that a further study be conducted to investigate other enzymes of both commercial and biological types to evaluate their efficacy in removing staining in teeth due to blood pigments. 


\section{APPENDIX I}

\section{FRECCIA AND PETERS (1982) METHOD OF STAINING TEETH}

1 Anterior teeth are scaled with an ultrasonic scaler, polished with a rubber cup and pumice to remove all extrinsic debris.

2 Lingual access cavities are prepared in the teeth, pulps extirpated, and the root canals instrumented with size 10-20 files.

3 The teeth are placed in $5.25 \%$ sodium hypochlorite solution for 24 hours to open the dentinal tubules.

$4 \mathrm{Immersion}$ of the teeth in test tubes containing samples of whole blood (minus the serum).

5 The samples are centrifuged at $10,000 \mathrm{rpm}$ for ten minutes at $37^{0} \mathrm{C}$ twice daily for three consecutive days.

6 The teeth are removed and distilled water is then added to the blood samples (without teeth) and centrifuged to further haemolyze the red blood cells. This results in two layers present in the test tube; a precipitate containing the cell membranes, and a haemolysate containing the haemoglobin protein. The precipitate is separated from the haemolysate and placed back in the test tube with the teeth, and centrifuged for an additional three days as previously outlined.

7 The teeth are then rinsed with running water for two minutes to remove the excess blood pigment. 


\section{APPENDIX II}

\section{MANUFACTURERS INFORMATION}

"AH26" is an epoxy resin based root canal sealer. De Trey, Zurich, Switzerland.

"Amosan" mouthwash powder, 68.6\% Sodium peroxyborate monohydrate $\left(\mathrm{NaBO}_{3} \cdot \mathrm{H}_{2} \mathrm{O}\right)$ buffered with Sodium bitartrate. Oral B Laboratories Pty. Ltd. Sydney, Australia.

Benzidine free base, $\left(\mathrm{C}_{12} \mathrm{H}_{12} \mathrm{~N}_{2}\right)$; $p$-Diaminodiphenyl, or 4-4'-diphenylene diamine. Sigma Chemical Company. St Louis, Missouri 63178. USA.

BHG Roto-Uni. Centrifuge, West Germany.

"Cavit" is a temporary endodontic coronal sealing agent comprising of calcium sulphate / zinc oxide - zinc sulphate. ESPE Gmbh, Seefeld, Oberbay, Germany.

"Desferal" ( $\mathrm{C}_{26} \mathrm{H}_{52} \mathrm{~N}_{6} \mathrm{O}_{11} \mathrm{~S}$; mol wt 560.71, Desferrioxamine mesylate) Ciba-Geigy Pharmaceuticals Australia Limited, 140 Bungaree Rd, Pendle Hill, N.S.W. It is an iron chelator and is capable of taking up iron from transferrin, ferritin and haemosiderin, thereby forming the iron complex, ferrioxamine. Ferrioxamine is water soluble and is rapidly and completely excreted. However, "Desferal" does not remove iron from the haemoglobin or from other haemin-containing substances in the body, such as myoglobin and iron-containing enzymes (cytochrome, catalase, and peroxidases). 
Distilled De-ionized Water (DDW); Ultra-pure water prepared using an ELGASTAT ${ }^{\circledR} U$ HQ Water Purifier (Quality, $0.5 \mu \mathrm{S} / \mathrm{cm}$. Measured using an Elgameter Water Purity Indicator), ELGA Limited. Lane End, High Wycombe Bucks, England HP 143JH.

"Enzymatic Cleaner" effervescent tablets contain the enzymes, amylase, trypsin and lipase in the total enzyme content of 98.55 $\mathrm{mg} / \mathrm{tablet}$ and an unspecified amount of disodium edetate. The manufacturer claims that the effervescent tablets are capable of removing organic substances deposited on contact lens and the disodium edetate is capable of removing inorganic deposits such as calcium or iron salts. Manufacturer: Dr. Thilo \& Co. GmbH, D-8029 Sauerlach, Germany. Distributor: OPSM Pty Ltd., 5-21 Mary St., Surrey Hills 2010.

"HiClean" ia a commercial stain remover with an unknown, "secret" formula. The manufacturer's claims include that it is capable of removing even "dried blood" by soaking. Howe Chemical Inc. Nashville, TN 37210.

Hydrogen peroxide $30 \% \mathrm{w} / \mathrm{v}$ (100 volumes). BDH AnalaR Chemicals, Australia LImited., Kilsynth, Victoria.

Lambda 5 UVNIS Spectrophotometer, Perkin-Elmer Inc., Norwalk, CT, USA. 
"Liquid Iron Chelator", 5\%w/v ethylene diamine tetra-acetic acid. Used for the prevention and correction of iron deficiency in plants. Bass Laboratories, Bastin Seabourne Pty. Ltd. Brunswick, Victoria.

Lovibond Quartz UV Cuvettes, Type W260. Tintometer Limited. Wiltshire SP12JY, England. Distributor: Adelab Scientific. 23 Wright St, Adelaide.

Patent Blue V $\left(\mathrm{C}_{27} \mathrm{H}_{31} \mathrm{~N}_{2} \mathrm{O}_{7} \mathrm{~S}_{2} \mathrm{Ca}_{1 / 2}\right.$; mol. wt. 579.725; C. I. 42051). Sigma Chemical Company. St Louis, Missouri 63178. USA.

"Savlon" is a disinfectant comprising of $15 \% \mathrm{w} / \mathrm{v}$ cetrimide and $1.5 \%$ chlorhexidine gluconate. ICI Australia Operations Pty. Ltd., Christina Road, Villawood, New South Wales. 2163

Shandon Citadel Tissue Processor. Distributor: Stansens Scientific Division, Norwood. South Australia.

Speedmaster R-75CP Reflection Densitometer. Electronic Systems Engineering. Cushing, Oklahoma. 74023.

Van Moppes Diamond cutting discs, IDP Pty. Ltd., Tuffey Cres, Gloucester, UK. 


\section{APPENDIX III}

\section{PHOSPHATE BUFFERED SALINE (PBS)}

This solution has been shown to be the optimal storage solution for studies involving dentine permeability (Goodis et al., 1991).

Formula: $10 \mathrm{mM}$ sodium phosphate $(\mathrm{pH} 7.5)$ in $0.9 \%$ sodium chloride.

Preparation: Dissolve $27.6 \mathrm{~g}$ of mono basic sodium phosphate in 1 litre of $0.9 \%$ sodium chloride (solution A). Mix $28.39 \mathrm{~g}$ of dibasic sodium phosphate in 1 litre of $0.9 \%$ sodium chloride (solution B). Add $16 \mathrm{ml}$ of solution $\mathrm{A}$ to $84 \mathrm{ml}$ of solution $\mathrm{B}$ and dilute to $200 \mathrm{ml}$ for a final $\mathrm{pH}$ of 7.5 .

A concentration of $0.02 \%$ of sodium azide was added to the PBS. Special precautions were taken when handling the azide. It was weighed in a fume cupboard with the operator wearing gloves, safety glasses and a mask. 


\section{APPENDIX IV}

\section{BLOOD SAMPLES, AUSTRALIAN RED CROSS, ADELAIDE.}

The blood products were made available by courtesy of the Australian Red Cross, Adelaide (APPENDIX IV) and, in accordance with their recommendations, were stored at $4^{\circ} \mathrm{C}$ to prevent deterioration and to prolong normal biochemical function for as long as twelve weeks.

Packed red blood cells, Type $A B, R h$ negative. The packed red blood cells contain erythrocytes concentrated in a fluid of $10-15 \%$ protein serum.

Platelet concentrate, Type O, Rh positive.

Whole blood, Type Ab, Rh negative.

All blood samples provided tested negative for HIV antibody and Hepatitis B surface antigen. Sodium citrate $(0.2 \mathrm{gm} / 100 \mathrm{ml})$ had been added to the whole blood to act as an anticoagulant. 


\section{APPENDIX V}

\section{HISTOLOGICAL TECHNIQUES FOR OPTICAL MICROSCOPY}

\section{Tissue Fixation}

Specimens for light microscopy were fixed in $10 \%$ solution of neutral buffered formalin $\mathrm{pH} 7.0$ at room temperature for two days.

Formula: Formalin

$37-40 \%$ formaldehyde solution $500 \mathrm{ml}$

Tap water $4500 \mathrm{ml}$

Acid sodium phosphate monohydrate $20 \mathrm{~g}$ Anhydrous disodium phosphate $32 \mathrm{~g}$

\section{Decalcifying Solutions}

(i) Acid-EDTA (Formula courtesy of the Department of Oral Pathology, The University of Adelaide.)

9.5\% hydrochloric acid technical grade $1.0 \%$ solution of sodium acetate Added to a saturated solution of EDTA-di-sodium salt. pH 1.0.

(i) EDTA-cacodylate (Bjurholm et al. 1989)

EDTA-di-sodium salt

Sodium cacodylate
$40.0 \mathrm{~g}$

$24.2 \mathrm{~g}$ 
Sodium hydroxide

$3.0 \mathrm{~g}$

Dissolved in $1000 \mathrm{ml}$ distilled water and adjusted to $\mathrm{pH} 7.3$ using $1 \mathrm{M}$ hydrochloric acid.

\section{Tissue Processing}

All specimens were processed in the following reagents:
(1) $70 \%$ Alcohol
$0.5 \mathrm{hr}$
(2) $80 \%$ Alcohol
$1 \mathrm{hr}$
(3) $90 \%$ Alcohol
$1 \mathrm{hr}$
(4) $100 \%$ Alcohol
$1 \mathrm{hr}$
(5) $100 \%$ Alcohol
$1 \mathrm{hr}$
(6) $100 \%$ Alcohol
$1 \mathrm{hr}$
(7) Histoclear
$1 \mathrm{hr}$
(8) Histoclear
$1 \mathrm{hr}$
(9) Histoclear
$1 \mathrm{hr}$
(10) Wax
1hr
(11) Wax \& Vacuum
4hrs

\section{VACUUM}

All specimens were placed in a vacuum for 10-25 min for the evacuation of air bubbles.

\section{EMBEDDING}

The specimens were embedded in "Surgipath" wax, orientated in specially constructed trays, and placed on a cold tray of a Reichert-Jung 
Tissue Embedding Centre. The trays permitted the correct mounting to the microtome.

\section{SECTIONING}

An Elite Rotary Microtome (Ernst Leitz Wetzlar GMBH, Germany) was used to section the blocks which were iced to avoid expansion and aid cutting. The sections were cut at a thickness of $6 \mu \mathrm{m}$ and floated onto clean specially prepared glass slides (see 6 . below) and dried on a slide warming tray.

\section{PREPARATION OF GLASS SLIDES}

Method for coating slides.

Pre-rinse slides in two washes of xylol.

Rinse for 10 seconds in a $2 \%$ solution of 3-aminopropyl-triethoxy-silane in acetone.

Rinse in xylol.

Rinse in DDW.

Air dry. 


\section{APPENDIX VI}

\section{HISTOCHEMICAL TECHNIQUES}

\section{BENZIDINE TEST FOR HAEMATINS (Luna 1968a)}

Benzidine is extremely toxic, being a recognized mutagen and carcinogen which is readily absorbed through the skin, causing damage to the liver and kidneys. Other symptoms from exposure to benzidine can include nausea, vomiting, and painful and irregular urination. Therefore, special precautions were employed during its manipulation and usage. Protective clothing, gloves, face mask, and glasses were used and all procedures with benzidine were carried out in a fumecupboard.

Fixation: $10 \%$ formalin buffered to $\mathrm{pH} 7.0$.

Technique: Embedded in paraffin and sectioned to 6 microns.

Benzidine solution:

Benzidine $1.0 \mathrm{gm}$

Methanol $99.0 \mathrm{ml}$

Peroxide solution:

Hydrogen peroxide, $30 \% \mathrm{v} / \mathrm{v}$ $25.0 \mathrm{ml}$ Alcohol, $70 \%$ v/v $75.0 \mathrm{ml}$

\section{Staining procedure:}

De-paraffinize and hydrate to distilled water. 
Flood slide with benzidine solution for 1 minute.

Drain off and flood with the peroxide solution for 2 minutes.

Rinse in DDW for 15 seconds.

Nuclear fast red for 5 minutes.

Rinse in DDW.

Dehydrate in $95 \%$ alcohol, absolute alcohol, and clear in xylol, two changes each.

Soak in Histoclear for 10 minutes.

Mount Depex.

\section{NUCLEAR FAST RED (KERNECHTROT) SOLUTION}

Dissolve $0.1 \mathrm{gm}$ nuclear fast red in $100 \mathrm{ml}$ of $5 \%$ solution of aluminium sulphate with aid of heat. Cool filter, add grain of thymol as a preservative

Results:

Haemoglobin dark brown

Decalcified dentine pink

2. ZINC LEUCO-PATENT BLUE FOR HAEMOGLOBIN (Pearse 1985b)

Fixation: $10 \%$ formalin buffered to $\mathrm{pH} 7.0$.

Technique: Embedded in paraffin and sectioned to 6 microns.

Patent Blue solution (stock):

Patent Blue V (C.I. No. 42051)

$1 \mathrm{gm}$

DDW

$100.0 \mathrm{ml}$ 
Powdered zinc

$10.0 \mathrm{gm}$

Glacial acetic acid

$2.0 \mathrm{ml}$

Boil until colourless

Cool and filter

Patent Blue solution (working):

Patent Blue solution

$100.0 \mathrm{ml}$

Glacial acetic acid

$20.0 \mathrm{ml}$

$33 \%$ hydrogen peroxide

$10.0 \mathrm{ml}$

\section{Staining procedure:}

De-paraffinize and hydrate to $70 \%$ alcohol.

Working Patent Blue solution for 3 minutes.

Rinse in DDW.

Counterstain in nuclear fast red for 3-5 minutes

Rinse in distilled water.

Dehydrate in $95 \%$ alcohol, absolute alcohol, and clear in xylol, two changes each.

Soak in histoclear.

Mount with Depex.

Results:

Haemoglobin

dark blue to green

Decalcified dentine

light pink

3. PERL'S METHOD FOR IRON (Luna 1968b) 
Fixation: $10 \%$ formalin buffered to $\mathrm{pH} 7.0$.

Technique: Embedded in paraffin and sectioned to 6 microns.

10\% Potassium ferrocyanide solution (stock):

Potassium ferrocyanide

$10.0 \mathrm{gm}$

DDW

$100.0 \mathrm{ml}$

$10 \% \mathrm{v} / \mathrm{v}$ Hydrochloric acid solution (stock):

Hydrochloric acid, concentrated

$10.0 \mathrm{ml}$

DDW

$90.0 \mathrm{ml}$

Potassium ferrocyanide-hydrochloric acid solution (working).

Potassium ferrocyanide solution (stock)

$70.0 \mathrm{ml}$

Hydrochloric acid solution (stock)

$30.0 \mathrm{ml}$

Mix just before use.

Staining procedure:

Deparaffinize and hydrate to distilled water.

Stock potassium ferrocyanide solution for 5 minutes.

Working potassium ferrocyanide-hydrochloric acid for 20 minutes.

Rinse well in distilled water.

Counterstain in nuclear fast red solution for 5 minutes.

Wash well in running water. 
Dehydrate in $95 \%$ alcohol, absolute alcohol, and clear in xylol, two changes each.

Mount with Depex.

Results:

Ferric iron bright blue

Decalcified dentine light pink

\section{TURNBULL BLUE METHOD FOR HAEMOSIDERIN (Luna 1968c)}

Fixation: $10 \%$ formalin buffered to $\mathrm{pH} 7.0$.

Technique: Embedded in paraffin and sectioned to 6 microns.

Ammonium sulphide $10 \%$ solution

1\% HYDROCHLORIC ACID (STOCK)

Hydrochloric acid, concentrated $\quad 1.0 \mathrm{ml}$

DDW

$99.0 \mathrm{ml}$

20\% POTASSIUM FERRICYANIDE SOLUTION (STOCK)

Potassium ferricyanide

20.0gm

DDW $100.0 \mathrm{ml}$

HYDROCHLORIC ACID-POTASSIUM FERRICYANIDE SOLUTION (WORKING) 
Hydrochloric acid (stock)

$50.0 \mathrm{ml}$

Potassium ferricyanide (stock)

$50.0 \mathrm{ml}$

Mix just before use.

Staining procedure:

De-paraffinize and hydrate to distilled water.

Ammonium sulphide for 4 hours.

Rinse thoroughly in DDW.

Hydrochloric acid-potassium ferricyanide solution for 20 minutes.

Rinse thoroughly in distilled water.

Counterstain in nuclear fast red for 5 minutes.

Rinse in DDW.

Dehydrate in $95 \%$ alcohol, absolute alcohol, and clear in xylol, two changes each.

Mount with Depex.

Results:

Haemosiderin

blue

Decalcified dentine

light pink 


\section{APPENDIX VII}

\section{PHOTOGRAPHIC EQUIPMENT}

Specimens for Figures 3-8, 15, and 35-41 were photographed using a Wild Photomakrosk M400 stereomicroscope and a Wild Photoautomat fully automatic exposure unit. The information was recorded on Fujicolor Reala Daylight ISO 100/210 film.

Histological specimens Figures 16-34 and 46-51 were photographed using an Olympic BH-2 stereomicroscope and an Olympic automatic exposure unit. The information was recorded on Fujicolor Daylight ISO $100 / 21^{0}$ film. 


\section{BIBLIOGRAPHY}

Abbot C.H. (1918) Bleaching discoloured teeth by means of 30 percent perhydrol and electric light rays. Journal of Allied Dental Societies 13:259-262.

Allison R.T., Whittaker D.K. (1990) Use of benzidine for histological demonstration of haemoglobin in human bite marks. Journal of Clinical Pathology 43:600-603.

Allison A.C., Rees W. (1957) The binding of hemoglobin by plasma proteins. British Medical Journal 2:1137-1143.

Andreasen F.M. (1986) Transient apical breakdown and its relation to color and sensibility changes after luxation injuries to teeth. Endodontics \& Dental Traumatology 2:9-19.

Andreasen F.M. (1989) Pulpal healing after luxation injuries and root fracture in permanent dentition. Endodontics \& Dental Traumatology 5:111-131.

Andreasen J.O. (1981) Traumatic injuries of the teeth. Second Edition. Munksgaard; Copenhagen, p39.

Arvill T., Henschen B., Sundwall-Hagland I. (1967) The pulpal reaction in traumatized permanent incisors in children aged 9-18. Odontologisk Tidskrift 75:130-147. 
Beeley J.A., Harvey W. (1973) Pink teeth appearing as a post mortem phenomenon. Journal of the Forensic Science Society 13:297-305.

Bergenholtz G.R. (1974) Micro-organisms from necrotic pulp of traumatized teeth. Odontogisk Revy 25:347-358.

Bjurholm A., Kreicbergs A., Schultzberg M. (1989) Fixation and demineralization of bone tissue for immunohistochemical staining of neuropeptides. Calcified Tissue International 45:227-231.

Block R.M., Lewis R.D., Sheaths J.B., Fawley J. (1977) Cell mediated immune response to dog pulp tissue altered by formocresol within the root canal. Journal of Endodontics 3:424-430.

Block R.M., Lewis R.D., Sheaths J.B., Burke S.G. (1978) Antibody formation to dog pulp tissue altered by formocresol within the root canal. Oral Surgery, Oral Medicine and Oral Pathology 45:282-292.

Boksman L., Jordan R.E., Skinner D.H. (1983) Non-vital bleachinginternal and external. Australian Dental Journal 28:149-152.

Brain E.B. (1966a) Preparation of decalcified sections. Charles C. Thomas; Illinois, p 89.

Brain E.B. (1966b) Preparation of decalcified sections. Charles C. Thomas; Illinois, p 107.

Bunn H.F., Jandl J.H. (1972) Haemoglobin and erythrocyte catabolism in rat liver. Blood: The Journal of Hematology 40:812-822. 
Casey L.J., Schinder W.G., Murata S. (1989) The use of dentinal etching with bleaching procedures. Journal of Endodontics 15:535-538.

Chapple J.A. (1877) Restoring discoloured teeth to normal. Dental Cosmos 19:499.

Chivian N. (1987) Root resorption. In: Cohen S., \& Burns R.C. (ed). Pathways of the pulp. Fourth Edition. C.V. Mosby; St. Louis, pp 534538.

Coburn R.F., Williams W.J., White P, Kahn S.B. (1967) The production of carbon monoxide from hemoglobin in vivo. Journal of Clinical Investigation 46:346-356.

Costas F.L., Wong M. (1991) Intracoronal isolating barriers: Effect of location on root leakage and effectiveness of bleaching agents. Journal of Endodontics 17:365-368.

Croll T.P., Cavanaugh R.R. (1986) Enamel color modification by controlled hydrochloric acid-pumice abrasion. I. Techniques and examples. Quintessence International 17:81-87.

Cvek M., Lindvall A-M. (1985) External root resorption following bleaching of pulpless teeth with oxygen peroxide. Endodontics \& Dental Traumatology 1:56-60.

Erslev A.J., Gabuzda T.G. (1975) Pathophysiology of blood. W. B. Saunders Company; Philadelphia, pp 16-17. 
Fairbanks V.F.. Beutler V. (1990) In: Williams W.J., Beutler E., Erslev A.J., Lichtman M.A. (ed) Haematology. Fourth Edition. MaGraw-Hill Book Company; New York, pp 498-499.

Frank A. (1980) Bleaching of vital and non vital teeth. In: Cohen S., Burns R. (ed) Pathways of the pulp. Second Edition. CV Mosby; St. Louis, pp 568-569.

Freccia W.F., Peters D.D. (1982) A technique for staining extracted teeth: a research and teaching aid for bleaching. Journal of Endodontics 8:67-69.

Friedman S., Rotstein I., Libfeld H., Stabholz A., Heling I. (1988) Incidence of external root resorption and esthetic results in 58 bleached pulpless teeth. Endodontics \& Dental Traumatology 4:23-26.

Garretson JE. (1895) A system of oral surgery. Sixth Edition. JB Lippincott and Co; Philadelphia, p 231.

Goldstein RE. (1987) Bleaching teeth: new materials - new role. American Dental Journal-December Esthetics E. p 44-52.

Goldstein R.E., Feinman R.A. (1987) Bleaching of vital and non vital teeth. In Cohen S, Burns RC. (ed). Pathway of the pulp. Fourth Edition. C.V. Mosby; St. Louis, pp 636-637.

Gomori G. (1951) Microscopic Histochemistry. Principals and practice. The University of Chicago Press; Chicago, p164. 
Gomperts B.D. (1967) Metabolic changes in human red cells during incubation of whole blood in vitro. Biochemical Journal 102:782-790.

Goodis H.E., Marshall G.W., White J.M. (1991) The effects of storage after extraction of teeth on human dentine permeability in vitro. Archives of Oral Biology 36:561-566.

Goon W.W.Y., Cohen S., Borer R.F. (1986) External cervical root resorption following bleaching. Journal of Endodontics 12:414-418.

Grossman L. (1943) Root Canal Therapy. Second Edition. Lea \& Febiger; Philadelphia, p 327.

Grossman L., Oliet S., Del Rio C.E. (1988) Endodontic Practice. Eleventh Edition. Lea \& Febiger; Philadelphia, p 247.

Haradin A.R., Weed R.J., Reed C.F. (1967) Changes in physical properties of stored erythrocytes: Relation to in vivo survival. Blood: The Journal of Hematology 30:876-877.

Harrington G.W., Natkin E. (1979) External resorption associated with bleaching of pulpless teeth. Journal of Endodontics 5:344-348.

Harlan A.W. (1884) The removal of stains caused by administration of medicinal agents and the bleaching of pulpless teeth. American Journal of Science 18:521.

Hershko C. (1975) The fate of circulating haemoglobin. British Journal of Haematology 29:199-204. 
Ho S., Goerig A.C. (1989) An in vitro comparison of different bleaching agents in the discolored tooth. Journal of Endodontics 15:106-111.

Hoffbrand A.V., Lewis S.M. (1989) Postgraduate Haematology. Third Edition. Heinemann Medical Books; Oxford, p16-33.

Holmstrup G., Palm A.M., Lambjerg-Hansen H. (1988) Bleaching of discoloured root filled teeth. Endodontics \& Dental Traumatology 4:197201.

Howell R.A. (1980) Bleaching discoloured root-filled teeth. British Dental Journal 148:159-162.

Hume W.R. (1984) An analysis of the release and the diffusion through dentine of Eugenol from Zinc Oxide-Eugenol mixtures. Journal of Dental Research 63:881-884.

Ingle J.I. (1974) Endodontics. Lea \&Febiger; Philadelphia, p 607.

Ingle J.I. Taintor J.F. (1985) Endodontics. Third Edition. Lea \& Febiger; Philadelphia, p771.

Jacobsen I. (1980) Criteria for diagnosis of pulp necrosis in traumatized incisors. Scandinavian Journal of Dental Research. 88:306-312.

Lado E.A., Stanley H.R., Weisman M.I. (1983) Cervical resorption in bleached teeth. Journal of Oral Surgery 55:78-80. 
Latcham N.L. (1986) Postbleaching cervical resorption. Journal of Endodontics 12:262-264.

Lillie R.D., Geer J.C., Gutierreza A. (1963) The removal of histochemically demonstrable iron from tissue sections by the brief exposure to sodium dithionite solution. Journal of Histochemistry and Cytochemistry 11:662-664.

Lillie R.D. (1965a) Histopathological Technic and Practical Histochemistry. Third Edition. McGraw-Hill Book Company; New York, p 626.

Lillie R.D. (1965b) Histopathological Technic and Practical Histochemistry. Third Edition. McGraw-Hill Book Company; New York, p 365.

Lillie R.D. (1965c) Histopathological Technic and Practical Histochemistry. Third Edition. McGraw-Hill Book Company; New York, p 391.

Linman J.W. (1975) Haematology. Physiologic, Pathophysiologic, and Clinical Principles. MacMillan Publishing Company; New York, p 115.

Lison L. (1953) Histochemie et Cytochimie Animales. Second Edition: Gauthier-Villars; Paris, p425.

Luna L.G. (1968a) Manual of Histological Staining Methods of Armed Forces Institute of Pathology. Third Edition. McGraw-Hill Book Company; New York, p 125. 
Luna L.G. (1968b) Manual of Histological Staining Methods of Armed Forces Institute of Pathology. Third Edition. McGraw-Hill Book Company; New York, p184.

Luna L.G. (1968c) Manual of Histological Staining Methods of Armed Forces Institute of Pathology. Third Edition. McGraw-Hill Book Company; New York, p178.

Luzzatto L. (1989) In: Hoffman A.V., Lewis S.M. (ed) Postgraduate Haematology. Third Edition. Heineman Medical Books; Oxford, pp155156.

Madison S., Walton R. (1990) Cervical root resorption following bleaching of endodontically treated teeth. Journal of Endodontics 16:570-574.

Magnusson B.O., Holm A-K. (1969) Traumatized permanent teeth in children-a follow up. 1. Pulpal complications and root resorption. Svensk Tandlakare Tidskrif 62:61-70.

Magnusson B.O. (1978) Therapeutic pulpotomies in primary molars with the formocresol technique: a clinical and histological follow up. Acta Odontologica Scandinavica 36:157-165.

Möller Å.J.R., Fabricius L., Dahlen G., Öhman A., Heyden G. (1981) Influence on periapical tissues of indigenous oral bacteria and necrotic pulp tissue in monkeys. Scandinavian Journal of Dental Research 89:475-484. 
Montgomery S. (1984) External cervical resorption after bleaching a pulpless tooth. Journal of Oral Surgery 57:203-6.

Myers D.R., Pashley D.H., Whiteford G.M. (1983) Tissue changes induced by absorption of formocresol from pulpotomy sites in dogs. Journal of Pediatric Dentistry 5:6-8.

Neumann E. (1888) Virchows Arch 111:25. Cited in, Pearse A.G.E. (1985) Histochemistry Theoretical and Applied. Volume II: Analytical Technology. Fourth Edition. Churchill Livinsgstone; London, p 1068.

Nikiforuk G., Sreebny L. (1953) Demineralization of hard tissues by organic chelating agents at neutral $\mathrm{pH}$. Journal of Dental Research 32;859-867.

Noyes W.D., Garby L. (1967) The rate of haptoglobin synthesis in normal man. Scandinavian Journal of Clinical and Laboratory Investigation 20:33-38.

Nutting E.C., Poe G.S. (1963) A new combination of bleaching teeth. Journal of Southern California Dental Association 31:289-291.

Outhwaite W.C., Livingstone M.J., Pashley D.H. (1976) Effects of changes in surface area, thickness, temperature and post-extraction time on human dentin permeability. Archives of Oral Biology 21: 599-603. 
Pearse A.G.E. (1985a) Histochemistry Theoretical and Applied. Volume II: Analytical Technology. Fourth Edition. Churchill Livinsgstone; London, pp 888-889.

Pearse A.G.E. (1985b) Histochemistry Theoretical and Applied. Volume II: Analytical Technology. Fourth Edition. Churchill Livinsgstone; London, p 1135.

Pearson H.H. (1958) Bleaching of the discolored pulpless tooth. Journal of the American Dental Association 56:64-68.

Perutz M.F. (1978) Haemoglobin structure and respiratory transport. Science 239:92-125.

Pippard M.J., Hoffbrand A.V. (1989) In: Hoffman A.V., Lewis S.M. (ed) Postgraduate Haematology. Third Edition. Heineman Medical Books; Oxford, p 26-33.

Prinz H. (1924) Recent improvements in tooth bleaching. Dental Cosmos 66:558-559.

Pruhs R.J., Olen G.A., Sharma P.S. (1977) Relationship between formocresol pulpotomies on primary teeth and enamel defects on their permanent successors. Journal of the American Dental Association 94:698-700.

Rich A.R. (1924) Bull. Johns Hospk. 35:414. Cited in, Pearse A.G.E. (1985) Histochemistry Theoretical and Applied. Volume II: Analytical Technology. Fourth Edition. Churchill Livinsgstone; London, p1068. 
Robinson S.H. (1990) In: Williams W.J., Beutler E., Erslev A.J., Lichtman M.A. (ed) Haematology. Fourth Edition. McGraw-Hill Book Company; New York, pp 409-410.

Rolling I., Hasselgren E., Tronstad L. (1976) Morphological and enzyme histochemical observations on the pulp of human primary molars, three to five years after formocresol treatment. Journal of Oral Surgery 42:518-528.

Rotstein I., Zalkind M., Mor C., Tarabeah A., Freidman S. (1991) In vitro efficacy of sodium perborate preparations used for intracoronal bleaching of discolored non-vital teeth. Endodontics \& Dental Traumatology 7:177-180.

Seltzer S., Bender I.B., Kaufman I.J. (1961) Histologic changes in dental pulps of dogs and monkeys following application of pressure, drugs, and microorganisms on prepared cavities. Oral Surgery, Oral Medicine, and Oral Pathology 14:327-346.

Smales R.J., Gerke D.C., White I.L. (1990) Clinical evaluation of occlusal glass ionomer, resin, and amalgam restorations. Journal of Dentistry 18:243-249.

Spasser H.F. (1961) A simple bleaching technique using sodium perborate. NewYork State Dental Journal 27:332-334.

Stanley H.R., Weisman M.I., Michanowicz A.E., Bellizzi R. (1978) Ischemic infarction of the pulp: Sequential degenerative changes of the pulp after traumatic injury. Journal of Endodontics 4:325-235. 
Stewart G.G. (1965) Bleaching discoloured pulpless teeth. Journal of American Dental Association 70:325-328.

Stryer L. (1988) Biochemistry. Third Edition. W. H. Freeman and Company; New York, p 144.

Sundqvist G. (1976) Bacteriologic studies of necrotic dental pulps. Thesis, University of Ümea, Sweden, p 23.

Taft J (1878) Bleaching teeth. American Journal of Dental Science 12:364-366.

Tenhunen R.S., Marver H.S., Schmid R. (1969) Microsomal heme oxygenase. Characterization of the enzyme. Journal of Biological Chemistry 244:6388-6394.

Thomas A.E. (1959) Bleaching of teeth. Journal of Dental Education 23:187-191.

Tronstad L. (1991) Clinical Endodontics. Thieme Medical Publishers; New York, p 215.

Valeri C.R., Valeri D.A., Gray A., Melaragno A., Dennis R.C., Emerson C.P. (1982) Viability and function of red blood cell aninbral stored at $40^{\circ} \mathrm{C}$ for 35 days in CPDA-1, CPDA-2, CPDA-3. Transfusion: The Journal of the American Association of Blood Banks 22:210-216.

van der Burgt T.P. (1986) Staining patterns in teeth discolored by endodontic sealers. Journal of Endodontics 12:187-191. 
Van Wyk C.W. (1987) Pink teeth of the dead: 1. A clinical and histological description. Journal of Forensic Odonto-Stomatology 15: 41-50.

Virchow R. (1847) Virchows Arch 1:379. Cited in, Pearse A.G.E. (1985) Histochemistry Theoretical and Applied. Volume II: Analytical Technology. Fourth Edition. Churchill Livinsgstone; London, p1068.

Walter J.B., Israel M.S. (1987) General Pathology. Sixth Edition. Churchill Livingstone; Edinburgh, p 419.

Walton R.E., O'Dell N.L., Myers D.L., Lake F.T., Shrimp R.G. (1982) External bleaching of tetracycline stained teeth in dogs. Journal of Endodontics 8:535-542.

Warren M.A., Wong M., Ingram T.A. (1990) An in vitro comparison of bleaching agents on the crowns and roots of discoloured teeth. Journal of Endodontics 16:463-467.

Wilson A.D., McLean J.W. (1988) Glass-ionomer cement. Quintessence Publishing Co; Chicago, p 30.

Wintrobe M.M., Lee G.R., Boggs D.R., Bithell T.C., Athens J.W., Foerster J. (1981) Clinical Haematology. Eighth Edition. Lea \& Febiger; Philadelphia, pp159-160. 